\title{
The Disappearing IPO Puzzle: New Insights from Proprietary U.S. Census Data on Private Firms
}

by

\author{
Thomas Chemmanur \\ Boston College
}

Jie (Jack) He

University of Georgia

Xiao (Shaun) Ren

University of Georgia

Tao Shu

Chinese University of Hong Kong, Shenzhen

CES 20-20 June, 2020

The research program of the Center for Economic Studies (CES) produces a wide range of economic analyses to improve the statistical programs of the U.S. Census Bureau. Many of these analyses take the form of CES research papers. The papers have not undergone the review accorded Census Bureau publications and no endorsement should be inferred. Any opinions and conclusions expressed herein are those of the author(s) and do not necessarily represent the views of the U.S. Census Bureau. All results have been reviewed to ensure that no confidential information is disclosed. Republication in whole or part must be cleared with the authors.

To obtain information about the series, see www.census.gov/ces or contact Christopher Goetz, Editor, Discussion Papers, U.S. Census Bureau, Center for Economic Studies 5K038E, 4600 Silver Hill Road, Washington, DC 20233, CES.Working.Papers@census.gov. To subscribe to the series, please click here. 


\begin{abstract}
The U.S. equity markets have experienced a remarkable decline in IPOs since 2000, both in terms of smaller IPO volume and entrepreneurial firms' greater tendency to exit through acquisitions rather than IPOs. Using proprietary U.S. Census data on private firms, we conduct a comprehensive analysis of the above two notable trends and provide several new insights. First, we find that the dramatic reduction in U.S. IPOs is not due to a weaker economy that is unable to produce enough "exit-eligible" private firms: in fact, the average total factor productivity (TFP) of private firms is slightly higher post-2000 compared to pre-2000. Second, we do not find evidence supporting the conventional wisdom that the disappearing IPO puzzle is mainly driven by the decline in IPO propensity among small private firms. Third, we do not find a significant change in the characteristics of private firms exiting through acquisitions from pre- to post-2000. Fourth, the decline in IPO propensity persists even after we account for the changing characteristics of private firms over time. Fifth, we show that the difference in TFP between IPO firms and acquired firms (and between IPO firms and firms remaining private) went up considerably post-2000 compared to pre-2000. Finally, venture-capital-backed (VC-backed) IPO firms have significantly lower postexit long-term TFP than matched VC-backed private firms in the post-2000 era relative to the pre- 2000 era, while this pattern is absent among IPO and matched private firms without VC backing. Overall, our results strongly support the explanations based on standalone public firms' greater sensitivity to product market competition and entrepreneurial firms' access to more abundant private equity financing in the post-2000 era. We find mixed evidence regarding the explanations based on the smaller net financial benefits of being standalone public firms or the increased need for confidentiality after 2000.
\end{abstract}

Keyword: IPOs, Exit Choices, Disappearing IPOs, Private Equity, Weak Economy, Product Market Competition

JEL Classification: G32, G34, G24

\footnotetext{
* Any opinions and conclusions expressed herein are those of the authors and do not necessarily represent the views of the U.S. Census Bureau. This research was performed at a Federal Statistical Research Data Center under FSRDC Project Number 1091. All results have been reviewed to ensure that no confidential information is disclosed. CBDRBFY20-147. We thank Jingxuan Zhang for research assistance. Any errors and omissions are the responsibility of the authors.
} 


\section{INTRODUCTION}

It is now well known that the volume of private firms going public in the U.S. equity market has declined significantly after the year 2000 (see, e.g., Gao, Ritter, and Zhu (2013)). A related phenomenon is that, among the private firms that do choose to "exit" (i.e., to change ownership structures to allow early equity investors such as entrepreneurs and venture capitalists to cash out), a much larger proportion choose to be acquired by another firm rather than have an IPO to become a standalone public firm. ${ }^{1}$ This paper aims to provide new insights into the causes of the above salient trends by empirically analyzing two related research questions using a comprehensive dataset on private firms from the U.S. Census Bureau. First, what explains the tremendous decline in IPOs in the U.S. after the year 2000? Second, what drives the dramatic shift toward acquisitions rather than IPOs in the case of exiting private firms after the year 2000 ?

A number of hypotheses have been advanced and empirically analyzed to explain the above two phenomena. For example, Gao, Ritter, and Zhu (2013), who proposed an "economy of scope" hypothesis, argue that the ongoing changes in the U.S. competition environment reduce the profitability of small companies, whether public or private. As a result, many small firms can create greater operating profits by selling out in trade sales (acquisitions) rather than going public to become standalone firms. ${ }^{2,3}$ Further, Gao, Ritter, and Zhu (2013) suggest that the decline in IPOs is unlikely due to the higher costs to public firms imposed by the Sarbanes-Oxley Act of 2002 and the Global Settlement of 2003. On the other hand, Doidge, Karolyi, and Stulz (2013) document a decline in the propensity of U.S. firms to be listed after 1996 and attribute this tendency to a decrease in the net benefits of listing for U.S. firms, especially for smaller firms. They conjecture that this decline in net benefits may arise from the increasing costs of being listed together with the non-increasing benefits of being listed (such as the ability to raise large amounts

\footnotetext{
${ }^{1}$ See, for example, Chemmanur, He, He, and Nandy (2018), who empirically analyze private firms' choices between going public, getting acquired, and remaining private. The literature that focuses on the exit choices of private firms between IPOs and acquisitions includes Aggarwal and Hsu (2014), Bayar and Chemmanur (2012), Poulsen and Stegemoller (2008), and Brau, Francis, and Kohers (2003). A closely related literature, e.g., Cumming (2008) or Ball, Chiu, and Smith (2011), focuses exclusively on the exit choices of venture-backed private firms.

${ }^{2}$ Bayar and Chemmanur (2011) developed such a hypothesis using a theoretical model of a firm's choice between IPOs and acquisitions. In their setting, where entrepreneurs have private information about a firm's future viability, only firms with the strongest business models choose to go public, while weaker firms choose to be acquired in order to benefit from the acquirers' help in product market competition.

${ }^{3}$ In a companion study, Ritter, Signori, and Vismara (2013) argue that the "economy of scope" also explains the disappearing IPOs in Europe.
} 
of capital in the public equity markets). ${ }^{4}$

More recently, Ewens and Farre-Mensa (2020) argue that the deregulation in securities laws in the 1990s, especially the National Securities Markets Improvement Act (NSMIA) of 1996, facilitated the process of raising capital privately and thus allowed private firms to grow larger without accessing the public equity markets until later in their life cycle. Thus, in their view, the decline in IPOs is a result of private firm founders taking advantage of the greater abundance and the lower cost of private equity financing by choosing to remain private for a longer period. Finally, Doidge, Kahle, Karolyi, and Stulz (2018) link the decline in listed firms in the U.S. (and by implication, the decline in IPOs) to the growing importance of intangible investments such as intellectual property and human capital in the U.S. economy. They conjecture that raising capital in public markets causes confidentiality concerns for young and R\&D-intensive firms so that such firms choose to remain private for a longer period of time.

While the above analyses provide useful insights, most of them have been conducted from the point of view of firms that have already gone public. As a result, many interesting questions regarding the disappearing IPO puzzle and the growing trend in exiting through acquisitions are left unanswered. For example, is the decline in IPOs driven by a dearth of "exit-eligible" private firms (i.e., with large enough productivity and size) in the U.S. economy? Is it possible that the changes in characteristics of an average U.S. private firm post the year 2000 lead to the observed change in exit choices even if the economic and product market conditions remain the same? Further, in recent years, do private firms that choose to delay their IPOs with the possible help of private equity financing perform better relative to their peers that choose to go public? To fully answer such questions, it is essential to conduct a comprehensive analysis of private firms' exit decisions over time.

Differing from previous studies, our paper examines the implications of various existing and new hypotheses from the point of view of private firms that contemplate exiting through IPOs or acquisitions. To that end, we make use of the restricted-access version of the Longitudinal Business Database (LBD) of the U.S. Census Bureau, which contains establishment-level data for virtually the entire universe of U.S. firms, both public and private. We further use the combined data from the Census of Manufacturing Firms (CMF) and the Annual Survey of Manufacturers

\footnotetext{
${ }^{4}$ Consistent with Gao, Ritter, and Zhu (2013), Doidge, Karolyi, and Stulz $(2013,2017)$ find little evidence that the lower propensity to be listed is caused by regulatory changes in early 2000 s.
} 
(ASM), which cover a comprehensive set of public and private firms in the manufacturing sector and contain rich operational and financial information such as sales, capital intensity, and the ingredients for calculating a firm's total factor productivity (TFP), thus allowing us to examine various hypotheses at greater depth than previous studies. ${ }^{5}$ Our unique data and the focus on private firms allow us to provide a more complete picture of the two salient phenomena in entrepreneurial finance, namely, the reduction in IPO volume and the greater likelihood of exiting through acquisitions in lieu of IPOs. ${ }^{6}$

Our empirical analyses test five different hypotheses that are not mutually exclusive:

1) Hypothesis 1 "Weaker economy": The number of private firms that are "eligible" to exit successfully (either through an IPO or an acquisition) went down significantly after the year 2000 relative to pre-2000 levels. ${ }^{7}$

2) Hypothesis 2 "Greater sensitivity to product market competition": A standalone public firm is more prone to product market competition in the post-2000 period than in the pre2000 period, so that a greater fraction of exiting private firms would choose to be acquired rather than going public. These firms are not strong enough to sustain the increased product market rivalry post-2000 as standalone public firms, but can survive by selling out to other companies, who can help the exiting firms on the product markets (Bayar and Chemmanur (2011)). ${ }^{8}$ This hypothesis is closely related to the "economy of scope" hypothesis of Gao, Ritter, and Zhu (2013) but the latter focuses on firm size and predicts that the disappearing IPO puzzle is mainly caused by the increasingly tougher competition facing smaller firms in the economy.

\footnotetext{
5 The CMF and ASM datasets together were previously known as the Longitudinal Research Database (LRD).

${ }^{6}$ Some recent papers analyze hypotheses more distantly related to our paper. For example, Bowen, Fresard, and Hoberg (2019) argue that private firms with disruptive innovations are more likely to exit through an IPO. They show, using new measures of innovation based on textual analysis, that there has been a steady decline in the number of firms with disruptive innovations between 1930 and 2010, which explains a significant fraction of the disappearing IPOs. Further, Lattanzio, Megginson, and Sanati (2019) argue that the listing gap identified by Doidge, Karolyi, and Stulz (2017) was caused by an unprecedented merger wave occurring between 1997 and 2001. Focusing on deregulated industries between 1973 and 2017, Loveland, Mulherin, and Okoeguale (2018) find that not only mergers, but also new listings and delistings of firms cluster in deregulated industries, with new listings preceding delistings.

7 As pointed out by Doidge, Karolyi, and Stulz (2017), the reduced listing volume could result from either the smaller number of eligible candidates (lower base) or the reduced propensity to go public. However, their analysis uses only the public version of LBD, which measures eligibility solely by firm size proxied by the number of employees but not quality (e.g., TFP or sales growth), and contains only aggregate data for firms across size bins rather than individual firm-level data.

8 This hypothesis does not have immediate implications for the total number of private firms exiting in the U.S. (either through IPOs or acquisitions) since Bayar and Chemmanur (2011) postulate that even firms with weaker business models are likely able to sustain the greater product market competition post-2000 with the help of acquiring firms.
} 
3) Hypothesis 3 "More abundant private equity financing": The greater supply of private equity financing in the post-2000 period led to the decline in IPOs. This hypothesis is motivated by the argument of Ewens and Farre-Mensa (2020) that the deregulation in securities laws in late 1990s made private equity financing more abundant to late-stage entrepreneurial firms in the post-2000 period. However, instead of focusing on the implications of securities regulations for the private equity industry, we directly examine the changing relationship between private firms' exit decisions and the corresponding private-equity-financing metrics from pre-2000 to post-2000.

4) Hypothesis 4 "Smaller net financial benefits from being a standalone public firm": On the one hand, the financial benefit of going public (arising from the lower information asymmetry and therefore greater stock liquidity) may have declined (or at least remained the same) after early 2000s. In fact, some have argued that the financial benefits declined partly due to a decrease in the number of sell-side analysts after 2002 (see, e.g., Gao, Ritter, and Zhu (2013)). On the other hand, the additional regulatory requirements imposed on public firms in the early 2000s (namely, Regulation Fair Disclosure (Reg FD) in the year 2000; the Sarbanes-Oxley Act (SOX) in the year 2002; and the Global Settlement in the year 2003) may have led to higher financial costs of becoming a stand-alone listed firm in the post-2000 period. These regulatory changes have been widely blamed as the cause of declining IPOs (see, e.g., Zweig (2010), Weild (2011)).

5) Hypothesis 5 "Increased need for confidentiality": The importance of intangible assets has gone up significantly starting in the early 2000s, which, coupled with the unavoidable release of confidential information at the time of and subsequent to IPO, implies that a greater fraction of U.S. private firms, especially those concerned with leaking valuable information to competitors, will choose to remain private or delay going public to the extent possible. ${ }^{9}$ We do not expect a similar effect on private firms' exiting through acquisitions. Our empirical analysis starts by confirming the phenomenon of disappearing IPOs in our sample, which includes all U.S. firms in the LBD data from 1990-2014. Consistent with the

\footnotetext{
9 Doidge, Kahle, Karolyi, and Stulz (2018) show that the R\&D expenditures exceeded capital expenditures for the average U.S. firm from 2002. Consistent with the negative impact of disclosure concerns on IPO decisions, Dambra, Field, and Gustafson (2015) document that the JOBS Act, which was enacted in April 2012 aiming to alleviate IPOs' disclosure requirements, led to a $25 \%$ increase in the number of IPOs after its passage. The findings of the latter paper, however, contrasts with those of Chaplinsky, Hanley, and Moon (2017), who find evidence that, while the JOBS Act increased IPO underpricing within the first three years of its passage, it has not reduced the direct costs of going public.
} 
existing literature, we observe a significant decrease in IPO propensity after the year 2000 . The proportion of private firms that go public drops dramatically from $0.005 \%$ in 1999 to $0.001 \%$ in 2001, and remains at a low level afterwards. This is in sharp contrast to the acquisition propensity of private firms, which is not lower in the post-2000 period relative to the pre-2000 period. ${ }^{10}$ While the decline in IPO propensity is pervasive across industries, states, and firm size groups, two notable patterns stand out. First, California and Massachusetts experienced the largest declines in IPO propensity, possibly due to the increasing abundance of private equity supply in these two states. This finding is consistent with the more abundant private equity financing hypothesis. Second, using the number of employees as a proxy for firm size, we find little evidence that small firms experience a greater decline in IPO propensity than large firms. Thus, our evidence based on micro-level data of private firms contradicts the conventional wisdom that the puzzle of disappearing IPOs is mainly driven by the decline in IPO propensity among small firms (see, e.g., Gao, Ritter, and Zhu (2017); Doidge, Karolyi, and Stulz (2017)).

Next, we test the weaker economy hypothesis by examining whether the population of private firms in the U.S. economy indeed becomes weaker post 2000 so that fewer private firms are eligible of going public. Using the LBD data of all U.S. private firms, we document an increase in the total number of private firms from 1990 to 2007. The number drops from 2008 (possibly due to the financial crisis) but quickly bounces back after 2011. More importantly, the proportion of large private firms (with 200 or more employees) among all private firms increases throughout our sample period of 1990-2014. We further use private manufacturing firms in the U.S. (i.e., the sample from the ASM/CMF database) for which we have available information on their sales and total factor productivity (TFP). We find that the average TFP and sales for these private firms, as well as the proportion of high-sales or high-TFP private firms in the manufacturing sector, increases from pre-2000 to post-2000. These results, taken together, are against the weaker economy hypothesis.

The greater sensitivity to product market competition hypothesis and the more abundant private equity financing hypothesis both predict that the quality threshold of going public becomes higher in the post-2000 period than in the pre-2000 period, because only higher-quality firms can fend off the greater product market threat or need additional public financing in the presence of

${ }^{10}$ In untabulated analysis, we find that these patterns hold if we only examine the manufacturing sector using the ASM/CMF database. 
more abundant private equity supply after 2000. In contrast, neither hypotheses clearly predicts the quality threshold of being acquired to be higher in the post-2000 period. We therefore use the rich data of private firms in the manufacturing sector (ASM/CMF database) and find that, consistent with these two hypotheses, the differences in TFP and sales between IPO firms and acquired firms and those between IPO firms and private firms have both increased after the year 2000. In contrast, the differences in TFP and sales between acquired and private firms remain unchanged. These results suggest that the quality threshold has been raised for IPOs but not acquisitions.

While our univariate analyses above provide useful insights, they do not explicitly consider the possible changes in firm characteristics over time. For example, the lower IPO propensity post the year 2000 may be caused by changes in some firm characteristics that are related to exit decisions. Hence, we turn to multivariate analyses using the rich financial information on manufacturing firms from the ASM/CMF database. Specifically, we build a multinomial logit model of private firms' exit decisions on going public, getting acquired, or remaining private. The independent variables include various firm-, industry-, and state-level characteristics. We then use the characteristics of firms in the pre-2000 sample period to calculate two sets of fitted IPO probabilities, one using the estimated coefficients from our pre-2000 regressions and the other using the estimated coefficients from the post-2000 regressions. Since this approach virtually fixes the pool of private firms, the difference between the two sets of IPO probabilities is likely driven by the changing environment rather than changing firm characteristics. We find that the fitted IPO probabilities in the post-2000 period are significantly lower than those in the pre-2000 period. In contrast, there is little change in these firms' fitted acquisition probabilities from the pre-2000 period to the post-2000 period.

To test whether the disappearing IPO phenomenon is caused by the series of regulations (e.g., Reg FD, SOX, and the Global Settlement) during 2001-2003, we conduct similar analyses for the exit decisions during a narrow window around the adoptions of these regulations in early2000s, but find no significant drop (in fact, even a slight increase) in the fitted IPO probabilities, which is inconsistent with the smaller net financial benefits hypothesis.

Next, we use the multinomial logit model to analyze the determinants of exit choices. Specifically, we interact the firm-, industry-, and state-level characteristics with a post2000 dummy variable which equals one for the year of 2001 and onwards, and zero otherwise. We find 
that firms with higher TFP are more likely to go public after year 2000 relative to the pre-2000 period, but they are not more likely to get acquired, which is consistent with the greater sensitivity to product market competition hypothesis and the more abundant private equity financing hypothesis. ${ }^{11}$ Additionally, firms in industries with more venture-capital investments are less likely to go public after year 2000, which provides further evidence supporting the more abundant private equity financing hypothesis. Consistent with the greater sensitivity to product market competition hypothesis, we find that firms in more competitive industries and those operating in fewer business segments (i.e., having lower economy of scope) are less likely to go public after year 2000. Further, firms in industries with lower analyst coverage (i.e., more information asymmetry and lower stock liquidity) are less likely to go public after year 2000, which supports the smaller net financial benefits hypothesis. In stark contrast to our IPO results, none of these interactions are statistically significant in our acquisition regressions.

To more closely examine how various metrics of economic environment (e.g., product market competition or the supply of private equity financing) impact exit choices differently over time, we conduct difference-in-differences (DiD) analyses based on our multinomial logit models. Specifically, we divide firms along two different dimensions based both on time periods (pre- vs. post-2000) and on a particular metric of the economic environment (e.g., high- vs. low-venture capital activities in an industry/state), and run multinomial logit regressions on these four sets of firms' exit decisions. Then we calculate IPO probabilities using the fixed firm characteristics of a pre-2000 baseline sample and the four sets of estimated coefficients to calculate fitted IPO probabilities. The results of DiD analyses show that firms in states or industries with higher VC investments and those in high-tech industries experienced a larger decline in IPO propensity than their peers, which supports the more abundant private equity financing and the increase need for confidentiality hypotheses. Additionally, firms in more competitive industries and those operating exclusively in one business segment experienced a larger decline in IPO propensity compared to their peers, which supports the greater sensitivity to product market competition hypothesis. Firms in industries with lower analyst coverage experienced a larger decline in IPO propensity compared to firms in industries with higher analyst coverage, which supports the smaller net financial

\footnotetext{
${ }^{11}$ We also conduct multivariate analysis around the regulatory changes, A similar multinomial logit analysis using data from 2001-2006 reveals that firms with higher TFP are NOT more likely to go public during 2004-2006 relative to 2001-2003, which is again inconsistent with the smaller net financial benefits hypothesis.
} 
benefits hypothesis. ${ }^{12}$

Last but not least, we examine IPO firms' post-exit long-term TFP relative to matched remaining-private firms. Among VC-backed firms, IPO firms have significantly higher post-exit long-term TFP than matched private firms in the pre-2000 era but this pattern disappears in the post-2000 era. In contrast, among non-VC-backed firms, the difference in post-exit long-term TFP between IPO and matched private firms is statistically insignificant in both eras. These findings suggest that staying private with the help of $\mathrm{VC}$ financing, relative to raising public equity via IPOs, is more beneficial (in terms of spurring long-term productivity) in the post-2000 era, which supports the more abundant private equity financing hypothesis.

In summary, using proprietary datasets from the U.S. Census Bureau on private firms, our results show that, in contrast to some common conjectures, the dramatic reduction in U.S. IPOs is not due to the economy being unable to produce enough private firms that are eligible (strong enough) to go public by pre-2000 standards. In fact, the average TFP of private firms is slightly higher post-2000 compared to pre-2000. Likewise, we do not find evidence supporting the conventional wisdom that the disappearing IPO puzzle is mainly driven by the decline in IPO propensity among small private firms. Nor do we find a significant change in the characteristics of private firms exiting through acquisitions from pre- to post-2000. Further, the decline in IPO propensity persists even if we account for the changing characteristics of private firms over time, and the difference in TFP between IPO firms and acquired firms (and between IPO firms and firms remaining private) is considerably higher post-2000 compared to pre-2000. Finally, IPO firms backed by venture capital have significantly lower post-exit long-term TFP than matched private firms that are also VC-backed in the post-2000 era relative to the pre-2000 era, while this pattern is absent among IPO and matched private firms without VC backing. Overall, our results strongly support the greater sensitivity to product market competition hypothesis and the more abundant private equity financing hypothesis, and only provide mixed evidence regarding the smaller net financial benefits hypothesis and the increased need for confidentiality hypothesis.

\section{THEORY AND HYPOTHESIS DEVELOPMENT}

In this section, we outline the underlying theories and develop testable hypotheses for our

${ }^{12}$ In further multivariate analyses, we find that IPO firms have significantly larger TFP in the post-2000 era, but acquired firms do not, which confirms our univariate results. 
empirical analyses. We describe each hypothesis and its implications for the proportion and quality of private firms undertaking IPOs, being acquired, or remaining private.

\subsection{The Weaker Economy Hypothesis}

The weaker economy hypothesis argues that, after the year 2000, the number of private firms eligible to exit successfully through IPOs or acquisitions has gone down significantly compared to the pre-2000 years. Since the proprietary Census data allow us to observe the number of private firms that are able to meet various thresholds for going public or being acquired (measured in terms of TFP, sales, employment, and etc.), we are able to directly test this hypothesis.

In particular, we test the following predictions of the weaker economy hypothesis:

Hla: The number of private firms that are "eligible" to undertake IPOs or acquisitions, based on the levels of TFP, sales, and employment, is lower post-2000 than pre-2000.

H1b: The average TFP, sales, and employment of private firms in the U.S. economy are lower post-2000 than pre-2000.

\subsection{Greater Sensitivity to Product Market Competition Hypothesis}

This hypothesis posits that, post-2000, the nature of product market competition may have dramatically changed, threatening the viability of standalone public firms to a greater extent. Consequently, only a smaller fraction of private firms would choose to exit by going public, while a large fraction choose to exit by being acquired by a larger firm. In their theoretical analysis of the exit choices of private firms, Bayar and Chemmanur (2011) argue that only private firms with stronger business models (more viable against product market competition) choose to go public, while weaker firms choose to be acquired, since they can benefit from the help of their acquirers in product market competition.

Under this hypothesis, only stronger firms would be able to meet the higher threshold for being stand-alone public firms post-IPO. We therefore test the following prediction:

H2a: The TFP, sales, and employment of IPO firms at the time of going public are higher post-2000 than pre-2000.

On the other hand, we would not expect a significant change in the average TFP, sales, and size of private firms being acquired because even weaker private firms that exit through acquisitions can survive greater product market threat with the help of their acquiring firms. We 
therefore test the following prediction:

$H 2 b$ : The TFP, sales, and employment of acquired private firms do not significantly change from pre-2000 to post-2000.

The greater sensitivity to product market competition hypothesis also predicts that private firms faced with greater competition tend to experience a larger decline in IPO propensity from pre-2000 to post-2000. To examine this prediction, we employ two proxies of the intensity of product market competition facing a firm: the industry concentration ratio (i.e., the sales-based Herfindahl-Hirschman Index) and a firm's business diversification (i.e., the number of business segments that the firm operates in) because lower industry concentration or a more focused business model indicates greater product market competition to the firm.

H2c: Private firms in less concentrated industries or those operating in fewer business segments experience a larger decline in IPO propensity relative to their peers from pre-2000 to post 2000 .

\subsection{More Abundant Private Equity Financing Hypothesis}

It has been argued that the deregulation of securities laws in the 1990s, and in particular, the passage of the National Securities Markets Improvement Act (NSMIA) in 1996, allowed many private firms abundant access to private equity financing, especially after the year 2000 (see, e.g., Ewens and Farre-Mensa (2020) and de Fontenay (2017)). ${ }^{13}$ As Ewens and Farre-Mensa (2020) show, the passage of the NSMIA made it easier for unregistered funds such as venture capital (VC) and private equity funds to raise capital, by exempting these funds from the blue-sky laws in various states and increasing the maximum number of investors that these funds may have without unregistering under the Investment Company Act. Ewens and Farre-Mensa (2020) argue that these regulatory changes were particularly effective in increasing the supply of VC financing for latestage startups, since VC funds investing in such firms tend to be larger and have more investors, which in turn, allowed many firms to remain private longer.

The more abundant private equity financing hypothesis thus leads to the following prediction.

13 Other regulatory changes that affected firms' access to private financing in the 1990s are the SEC's adoption of Rule 144A in 1990 and several subsequent amendments to Rule 144A, allowing unfettered resale of private shares after a short period (de Fontenay, 2017) and thus potentially reducing the cost of capital of private firms. 
H3a: Private firms in states or industries with greater venture capital investments experience a larger decline in IPO propensity relative to their peers from pre-2000 to post-2000.

Additionally, the increased VC or other private financing can also affect the quality threshold of private firms exiting through IPOs. Since private firms can now raise more capital from private equity post-2000, only the most productive ones among them will further turn to public markets for additional funding when their efficient production scale exceeds the existing amount of capital they own (see theory papers such as Clementi (2002) and Chemmanur and He (2011) for the relationship between firms' productivity and their going public decision). Therefore, the more abundant private equity financing hypothesis yields the following prediction.

H3b: The TFP of IPO firms at the time of their going public is higher post-2000 than pre2000 .

If the more abundant private equity flowed only to the highest-quality firms that would have otherwise gone public (but not chosen to be acquired), the TFP of private firms that are acquired would be unaffected. However, if the more abundant VC and other private equity financing applied to all exit-eligible private firms across the board (i.e., those firms that may have gone public or been acquired in the absence of such financing), then we would expect the TFP of

private firms going public as well as those being acquired post-2000 to be greater than those exiting pre-2000. Thus, the more abundant private equity financing hypothesis is agnostic about the change in TFP for private firms choosing to be acquired from pre-2000 to post-2000.

H3c: The TFP of acquired private firms either becomes higher or remains the same from pre-2000 to post-2000.

Finally, the more abundant private equity financing will make the marginal benefit (in terms of future growth and productivity) of going public (and raising capital from the public market) relative to staying private (and raising capital from PE financing) lower in the post-2000 era, which leads to the following prediction.

H3d: Among firms with actual private equity financing (e.g., those that are VC-backed), the gap in the post-exit long-term TFP between an IPO firm and its remaining-private peer firm is significantly lower in the post-2000 era than in the pre-2000 era. In contrast, this pattern does not exist among non-VC-backed firms.

\subsection{Smaller Net Financial Benefits from Becoming a Standalone Public Firm Hypothesis}


Several papers have hypothesized that the changes in the public equity market in the early 2000s, namely, the Regulation Fair Disclosure (Reg FD) in the year 2000, the Sarbanes-Oxley Act (SOX) in the year 2002, and the Global Settlement in the year 2003, may have increased the financial costs of being a standalone public firm (see, e.g., Gao, Ritter, and Zhu (2013) and Doidge, Karolyi, and Stulz (2013)). At the same time, some have conjectured that the closure of many boutique brokerage firms in the early 2000s reduced analyst coverage and therefore the benefits of being a standalone firm in terms of increased analyst coverage and stock liquidity. In the following, we define the "net benefits" of being a standalone public firm as the liquidity and other financial benefits arising from lower information asymmetry (due to, e.g., lower analyst coverage) associated with being a public firm net of the regulatory costs of being a standalone public firm.

In our context, we hypothesize that the net benefits of being a standalone public firm relative to being acquired by another firm or remaining private declined after the year 2003 (i.e., after the series of regulatory changes took full effect). This hypothesis yields two testable predictions.

H4a: Everything else equal, the propensity for a private firm to go public is significantly lower after 2003, while that for a private firm to get acquired does not significantly change around 2003.

H4b: The difference in the TFP, sales, or employment between private firms going public and those being acquired or remaining private is greater after 2003, while that between private firms that are acquired and those remaining private does not significantly change around 2003.

Finally, if the decreased analyst coverage (stock liquidity) of being a standalone public firm post 2000 is an important driving force for the disappearing IPO puzzle post 2000, then we would observe a larger drop in IPO propensity for firms suffering more from information asymmetry because these firms value analyst coverage the most. This leads to the following prediction.

H4c: Private firms in industries with more information asymmetry (i.e., lower analyst coverage) experience a greater decline in IPO propensity post 2000.

\subsection{Increased Need for Confidentiality Hypothesis}

After the dramatic growth in the use of the internet for business purposes in the 1990s, the number of private firms with intangible assets (e.g., internet, software, or other high-tech firms) 
went up dramatically. Given that many of these firms have relatively few fixed assets, a large portion of their value is likely to have come from intellectual property, which, in turn, likely led to a greater need for confidentiality in firms exiting after 2000. Several authors have argued theoretically that there is a considerable release of private (confidential) information by firms during the IPO process (see, e.g., Bhattacharya and Ritter (1983) and Maksimovic and Pichler (2001)). This means that firms having a need for confidentiality (e.g., high-tech firms) are less likely to go public post-2000 than to be acquired or to remain private. Hence, we have the following prediction.

H5: Private firms in the technology sector experience a larger decline in IPO propensity relative to their non-tech peers from pre-2000 to post-2000.

\section{DATA, SAMPLE CONSTRUCTION, AND VARIABLE DEFINITIONS}

\subsection{Data and Sample Construction}

Our empirical analyses use two samples from 1990-2014, which is the data period approved for our Census project. The first sample is the Longitudinal Business Database (LBD) maintained by the Center of Economic Studies at the U.S. Census Bureau. The LBD database tracks the births and deaths of all business establishments in the U.S. and provides basic information about each establishment including industry, age, payroll (salaries), and employment (number of employees) on an annual basis. We further obtain name and location (state, city, zip code, and street address) for each establishment by matching LBD to the Standard Statistical Establishment List (SSEL). The latter is the Business Register or the "master" data set of the U.S. Census Bureau which contains names and locations of establishments. ${ }^{14}$ We use LBD's firm identifier, "FIRMID", to aggregate the attributes of all establishments that belong to the same firm.

Our second sample is the combination of the Census of Manufacturers (CMF) and the Annual Survey of Manufacturers (ASM) databases, which cover establishments in the manufacturing sector. This database is formerly referred to as the Longitudinal Research Database (LRD). Compared to LBD, the second sample contains richer establishment-level information for a comprehensive sample of both private and public firms in the manufacturing sector. The variables include the total value of shipments (sales), payroll to different types of workers (e.g., blue-collar vs. white-collar), and capital expenditures. The CMF covers the entire universe of U.S.

${ }^{14}$ A comprehensive description of the SSEL can be found in Jarmin and Miranda (2002). 
manufacturing establishments in the census years (e.g., 1992, 1997, 2002, 2007, and 2012), and the ASM surveys a large sample of manufacturing establishments in every non-census year, including all establishments with more than 250 employees as well as smaller establishments that are randomly selected every fifth year to complete a rotating five year panel. ${ }^{15}$

Following Chemmanur, He, He, and Nandy (2018), we obtain the data of U.S. IPOs and acquisitions during our sample period from the Securities Data Company (SDC) database. For the sample of IPOs, we remove all IPOs related to equity carve-outs, American depositary receipts, American depositary shares, global deposit receipts, global deposit shares, units, trust receipts, and trust units. We also require that the IPO firm is present on Compustat for the fiscal year of the IPO. For the sample of private firms getting acquired, we remove all deals that are reverse takeovers, spin-offs, recapitalizations, self-tenders, exchange offers, repurchases, minority stake purchases, acquisitions of remaining interest, privatizations, divestitures, asset sales, deals whose target and acquirer belong to the same parent company, and deals whose status is defined as "incomplete" by the SDC. We obtain the data of venture-capital-backed firms during our sample period from the Thomson One VentureXpert database. We construct the samples of IPOs, acquired firms, and venture-capital-backed firms by matching the original data to the Census databases using a combination of name-and-address matching algorithms (as commonly used by Census data researchers) and manual checking. The matching rates are very high: over $97 \%$ of the IPOs, over $84 \%$ of the private-target acquisitions from the SDC, and over $80 \%$ of the venture-backed firms in the VentureXpert database can be matched to the LBD. Finally, we obtain the data of analyst coverage from the Institutional Brokers’ Estimate System (IBES) database.

\subsection{Variable Definitions and Summary Statistics}

Since our study focuses on the disappearing IPO phenomenon and the greater tendency to exit through acquisitions rather than IPOs in the post-2000 period, we construct a dummy variable, Post2000, which equals one if the year of an observation is 2001 and onwards, and zero otherwise. To test the smaller net financial benefits hypothesis, we also construct a dummy variable, PostReg,

15 Given that a random sample of smaller establishments is continuously present in our sample, our data is not substantially skewed towards large firms. As a result, small firms are well represented in the data. The rotating sample of smaller establishments is sampled by the Census Bureau each year in the non-census years in order to minimize such a bias in the data. Since the coverage of smaller establishments in our data varies over years, we also repeat our analysis by confining only to establishments with more than 250 employees and found similar results. 
which equals one if the year of an observation is in the three years from 2004 and 2006, and zero if the year of the observation is from 2001 and 2003.

For our analyses involving the ASM/CMF sample, we follow Chemmanur, He, He, and Nandy (2018) and construct a broad set of variables at the firm, industry, and state levels that are associated with entrepreneurial firms' exit choices (i.e., going public, getting acquired, or remaining private). First, we calculate each firm's total factor productivity (TFP) as the weighted average of plant-level TFP, using sales (value of shipments) as the weight. To construct plant-level TFP, we follow the previous literature to estimate a log-linear Cobb-Douglas production function for each six-digit NAICS industry-year, where the dependent variable is the natural logarithm of sales (total value of shipments) and the independent variables are the natural logarithms of capital stock and labor costs. Appendix A provides a detailed description of the construction of TFP, which follows the existing literature (e.g., Chemmanur, He, and Nandy (2009), Chemmanur, Krishnan, and Nandy (2011), and Chemmanur and He (2011)).

We also construct other variables used in our multivariate analysis as follows. LnSales is the natural logarithm of the total value of shipments in thousands of 1997 dollars at the firm level. SalesGrowth is calculated as the average annual percentage change in sales (total value of shipments) in the past three years. LnAge is the natural logarithm of the age (in years) of the oldest plant of a firm. CapInt (capital intensity) is capital stock scaled by total employment. Capex (capital expenditure) is defined as capital expenditure over capital stock. MktShr is the market share in terms of sales at the three-digit NAICS level. WhiteProp is defined as the average proportion of total wages that is for white-collar workers in the past three years. $V C$ is a dummy variable that equals one if a firm is backed by venture capital, and zero otherwise. We calculate LnNumSeg as the natural logarithm of the number of industries (at the six-digit NAICS level) of a firm's establishments to examine the difference in exit choices between conglomerate and singlesegment firms. To measure product market competition, we calculate the plant-level Herfindahl Index $(H H I)$ in terms of sales at the three-digit NAICS level. Plant-level TFP, CapInt, Capex, MktShr, WhiteProp, and HHI are aggregated to the firm level using sales (total value of shipments) as the weight.

To proxy for alternative financing opportunities from venture capital at the industry or state level, we calculate VCFracSt (VCFracInd) as the fraction of venture-capital-backed firms at the state (three-digit NAICS) level for a year. To gauge the heterogeneity in exit choices between high- 
tech and other companies, we construct a dummy variable, HighTech, that equals one if a firm belongs to the tech industry. ${ }^{16}$ To proxy for a private firm's degree of information asymmetry, we calculate the firm's industry-level analyst coverage (LnNumAna) as the natural logarithm of one plus the average number of analysts following the public firms in the firm's three-digit NAICS industry. All continuous variables above are winsorized at their $1^{\text {st }}$ and $99^{\text {th }}$ percentiles to control for outliers. The detailed definitions of these variables are contained in Appendix B.

Table 1 provides the summary statistics of these variables for the ASM/CMF sample, i.e., private firms in the manufacturing sector. This sample contains about 999,000 non-public manufacturing firm-years during 1990-2014, among which around 500 go public via IPOs and around 950 exit through acquisitions. ${ }^{17}$ IPO is a dummy variable which equals one if a private firm goes public in a year, and zero otherwise. $A C Q$ is a dummy variable which equals one if a private firm is acquired in the year, and zero otherwise. In Table 1, the means of IPO and $A C Q$ are $0.052 \%$ and $0.095 \%$, respectively. $55.5 \%$ of the firm-year observations in our baseline regression sample are after year 2000. The means of TFP, LnSales, LnAge, CapInt, Capex, LnNumSeg, LnNumAna, and HHI are -0.050, 8.185, 2.605, 0.073, 0.082, 0.200, 1.160, and 0.013, respectively. The mean of MktShr is $0.011 \%$. On average, $38.5 \%$ of a firm's wages are paid to white-collar employees. Moreover, $2.9 \%$ of the firm-years are backed by venture capital, and $1.1 \%$ of the firmyears operate in the high-tech industries. On average, 3.6\% (3.5\%) of the firms per state (industry) are backed by venture capital.

[Insert Table 1 about here]

\section{UNIVARIATE ANALYSES}

In this section, we conduct univariate analyses to revisit the phenomena of disappearing IPOs in the U.S. as well as the growing propensity to exit through acquisitions instead of IPOs. We also examine the characteristics of IPO and acquired firms over time for a preliminary evaluation of the different hypotheses.

\footnotetext{
16 Tech industries includes the following six-digit NAICS codes: $333295,333315,334111,334112,334113,334119$, 334210, 334220, 334413, 334511, 421430, 421690, 423430, 423690, 443120, 511140, 511210, 514210, 518210, $519130,541330,541511,541512,541513,541519,541710,541711$, and 541712. This definition of high-tech industries follows that specified by the U.S. Census Bureau, which is listed on the following website: https://www.cencus.gov/censusexplorer/naics_codes_used.xls.

17 We round the sample size following the Census disclosure policy.
} 


\subsection{Revisiting the Phenomenon of Disappearing IPOs}

We first divide the universe of LBD firms in a given year into four categories: those going public in the year, exiting through acquisitions in the year, already being publicly traded (i.e., going public at least one year before), or remaining privately owned. We then plot in Panel A of Figure 1 the proportion of IPOs among all LBD firms in each year of our sample period, i.e., 1990-2014. As can be seen, the propensity of IPO drops dramatically from $0.005 \%$ in 1999 to $0.001 \%$ in 2001 , and remains at a low level afterwards. The overall IPO propensity in the pre-2000 period is also remarkably higher than that in the post-2000 period. Panels B and C of Figure 1 further show the proportion of publicly listed firms and the proportion of non-exiting private firms, respectively. There is an obvious downward trend for the proportion of public firms and an upward trend for the proportion of non-exiting private firms from the pre-2000 period to the post-2000 period. These results are consistent with the existing literature that documents the disappearing IPO puzzle and the delisting puzzle in the post-2000 era.

We further plot in Panel D of Figure 1 the proportion of acquired private firms among the LBD firms every year. Similar to IPO propensity, the propensity to exit through acquisitions also experienced a sharp decline around the burst of the tech bubble, from $0.017 \%$ in 2000 to $0.007 \%$ in 2002. However, the decline is reversed quickly after 2002, and the overall level of private-target acquisition propensity from middle 2000s is similar to that before 2000. The sharp contrast between the trends of IPOs and acquisitions is consistent with the general conception that more entrepreneurs choose to exit through acquisitions rather than IPOs in the post-2000 era.

[Insert Figure 1 about here]

\subsection{Disappearing IPOs in Subsamples: A Closer Look}

In this subsection, we examine the phenomenon of disappearing IPOs across various subsamples.

We first examine IPO propensity across different industries. For each year in our sample, we calculate IPO propensity as the proportion of IPOs among all LBD firms in that year and then average this ratio across years in the two sub-periods of 1990-2000 and 2001-2014. Panels A and B of Figure 2 presents the change in IPO propensity from the pre-2000 period to the post-2000 period for each two-digit NAICS industry. We present both the raw changes (Panel A) and 
percentage changes (Panel B) to assess the economic magnitudes from different angles. The top panel shows that while all industries exhibit negative changes in IPO propensity in terms of percentage points, the largest declines occur in the information industry (NAICS code 51) and the management of companies and enterprises industry (NAICS code 55). ${ }^{18}$ Moreover, the bottom panel shows that most industries experience an over 60-percent decline in IPO propensity. ${ }^{19}$ These results reveal that the phenomenon of disappearing IPOs is pervasive across industries.

Next, we plot the changes in IPO propensity across geographical regions (U.S. states) in Figure 2 Panels C and D. This panel is similar to Panels A and B except that we form subsamples based on states rather than industries. Panel $\mathrm{C}$ shows that while all states experience a decline in IPO propensity in terms of percentage points, California and Massachusetts experience the largest declines, possibly because these two states account for the majority of high-tech companies and have the most abundant venture capital financing, which is broadly consistent with the more abundant private equity financing hypothesis. Panel D shows that the majority of the U.S. states experience an over 50-percent decline in IPO propensity. Consistent with Panels A and B, these results show that the phenomenon of disappearing IPOs is a relevant issue for most of the U.S. economy.

In Figure 2 Panels E and F, we conduct subsample analyses across firm size. We follow Doidge, Karolyi, and Stulz (2017) and classify firms into nine size groups based on their employment: (1) fewer than 20 employees; (2) between 20 and 99 employees; (3) between 100 and 249 employees; (4) between 250 and 499 employees; (5) between 500 and 999 employees; (6) between 1,000 and 2,499 employees; (7) between 2,500 and 4,999 employees; (8) between 5,000 and 9,999 employees; and (9) over 10,000 employees. Interestingly, Panel E shows that larger firms experience a bigger decline in IPO propensity than smaller firms in terms of percentage points. Panel F presents the percentage-change in IPO propensity across firm size groups, in which the percentage drop in IPO propensity for small firms is only slightly larger than that for large firms. Therefore, these results using the proprietary private firm data contradict the common

\footnotetext{
18 The information industry comprises firms engaged in producing and distributing information and cultural products, providing the means to transmit or distribute these products as well as data or communications, and processing data. The management of companies and enterprises industry contains firms that administer, oversee, and manage establishments of the company or enterprise that normally undertake the strategic or organizational planning and decision making role of the company or enterprises (e.g., offices of holding companies).

${ }^{19}$ Note that we redact certain industries or states from our figures if the information pertaining to them does not pass the disclosure requirements of the Census.
} 
wisdom and an important assumption of some existing literature that the disappearing IPO phenomenon is mainly due to the decline in IPO propensity for small firms.

Overall, the results in Figure 2 show that the puzzle of disappearing IPOs is pervasive in the U.S. economy. Additionally, the subsample analyses reveal that, inconsistent with convention wisdom, the disappearing IPO is not just a small firm phenomenon.

[Insert Figure 2 about here]

\subsection{Is the Puzzle of Disappearing IPOs Due to a Weaker U.S. Economy?}

In this subsection, we conduct several analyses to test the weaker economy hypothesis. We first test Hypotheses $1 a$ and $1 b$ in Section 2.1 by examining whether the number of "eligible" private firms or the average quality of private firms decreases post 2000. Panel A of Figure 3 plots the total number of U.S. firms in the LBD during our sample period of 1990-2014. As can be seen, there is an upward trend in the number of firms from 1990 to 2007, and this number declines dramatically from 2008 to 2011 (possibly due to the financial crisis) before bouncing back afterwards. Overall, the total number of firms post-2000 is higher than that in the pre-2000 period. We also plot the fraction of large firms in the economy, i.e., those with at least 200 employees, in Panel B of Figure 3. There is a clear upward trend in the fraction of large firms throughout the sample period. These results provide visual evidence against the weaker economy hypothesis.

Despite the evidence in Figure 3, it is possible that the number of firms or larger firms (in terms of employment) may not accurately reflect the overall quality of U.S. firms. We therefore, in Figure 4, directly examine alternative measures of firm quality using the richer firm characteristics of the manufacturing sector (based on our ASM/CMF sample).

[Insert Figure 3 about here]

Panel A of Figure 4 presents the time series of average total factor productivity (TFP) of U.S. manufacturing firms as well as the fraction of manufacturing firms with TFP greater than 0.05 (which is approximately the $75^{\text {th }}$ percentile of this variable across our sample firms). The average TFP decreases from 1990 to 1994, followed by an increase till the end of our sample period. The proportion of high-TFP firms exhibits a similar pattern. These results again do not support the weaker economy hypothesis.

We further examine sales and sales growth as proxies for firm quality. Panel B of Figure 4 
presents the time trend in average sales of manufacturing firms as well as the proportion of firms with sales greater than $\$ 10$ million. We observe an upward trend in both average sales and highsales firms during our sample period. Panel $\mathrm{C}$ presents the time trends in average sales growth and the fraction of firms with sales growth greater than $15 \%$ (similar to the above figures, this cutoff is chosen based on the approximate $75^{\text {th }}$ percentile of the distribution). Although the trends in average sales growth and the fraction of high-growth firms are less clear than the trends based on the first two measures, there is no clear downward trend in sales growth or the fraction of highgrowth firms in the 2000s. Overall the results in Figures 3 and 4 do not support HIa and HIb under the weaker economy hypothesis.

[Insert Figure 4 about here]

\subsection{Quality of IPO Firms Relative to Acquired Firms and Private Firms.}

In this subsection, we test Hypotheses $2 a$ and $2 b$ under the greater sensitivity to product market competition hypothesis and Hypotheses $3 b$ and $3 c$ under the more abundant private equity financing hypothesis by examining the characteristics of IPO firms relative to acquired firms and remaining-private firms. Both hypotheses suggest that the quality threshold of going public significantly increases while the threshold of exiting through acquisitions does not necessarily change in the post-2000 era.

We first examine the average number of employees for IPO firms, acquired firms, and private firms using the comprehensive LBD sample. Figure 5 plots the annual average number of employees for these three categories of firms during our sample period of 1990-2014. Panel A shows that IPO firms generally have larger numbers of employees in the post-2000 period than in the pre-2000 period. In the meantime, this pattern exists for acquired firms and remaining-private firms as well in Panels B and C. Therefore, the results in Panel A support Hypothesis $2 a$ but not Hypothesis $2 b$. The result in Panel $\mathrm{C}$ shows that the increase in the number of employees occurs for all subgroups of firms, which suggests that we need to interpret Figure 5 with caution because the results can be driven by a general uptrend of firm size for all private firms.

[Insert Figure 5 about here]

Next, we turn to examining TFP, sales, and sales growth using the sample of manufacturing firms. We calculate the annual averages of TFP, sales, and sales growth in each year for IPO firms, 
acquired firms, and remaining-private firms. To facilitate comparison, we plot the differences among these three groups in Figure 6, with a focus on the difference between IPO firms and acquired firms and that between IPO firms and remaining-private firms.

Panel A of Figure 6 presents the results on TFP. The difference between IPO firms and acquired firms and that between IPO firms and private firms are positive in all years of the sample period. Additionally, both differences increase from the pre-2000 period to the post-2000 period. These results support Hypotheses $2 a$ and $3 b$. Additionally, the difference between acquired firms and private firms remains stable over time, which supports Hypotheses $2 b$ and $3 c$.

Panels B and C of Figure 6 present the corresponding results for sales and sales growth. Panel B shows that the trend in sales is consistent with that in TFP, providing further support for the increased quality threshold of going public. In Panel C, the trend in sales growth is much less clear than that for TFP or sales, but the differences between IPOs and acquired firms and that between IPOs and private firms are generally higher in the post-2000 than in the pre-2000 period. Overall, these results also support Hypotheses $2 a, 2 b, 3 b$, and $3 c$.

[Insert Figure 6 about here]

In Figure 7, we calculate the raw and percentage changes in TFP (Panel A1 \& A2), sales (Panel B1 \& B2), and sales growth (Panel C1 \& C2) from the pre-2000 period to the post-2000 period for IPO firms, acquired firms, and private firms, respectively. Overall, the increases in these three quality measures for IPO firms are much more positive than those for acquired firms and private firms. These results are consistent with Figure 6 and support the Hypotheses $2 a$ and $2 b$ under the greater sensitivity to product market competition hypothesis and the Hypotheses $3 b$ and $3 c$ under the more abundant private equity financing hypothesis.

[Insert Figure 7 about here]

\section{MULTIVARIATE ANALYSES}

In this section, we conduct multivariate analyses using the rich firm characteristics of our sample of manufacturing firms. Compared to univariate analyses, the multivariate test design has two advantages. First, multivariate analyses control for the confounding changes in firm characteristics over time. Second, the multivariate test design allows us to directly examine the 
drivers of exit choices in a discrete dependent variable model and therefore test more hypotheses from Section 2.

\subsection{Determinants of Exit Choices: Multinomial Logit Regression Analyses}

We construct a model of the determinants of private firms' exit decisions and use it to formally examine the changes in IPO propensity and acquisition propensity over time. Specifically, we estimate the following multinomial logit regressions of exit choices on various firm, state, and industry characteristics:

$$
\begin{aligned}
& \text { EXIT }_{i, j, s, t}=\mathrm{F}\left(\alpha+\beta_{1} \text { TFP }_{i, t}+\beta_{2} \text { LnSales }_{i, t}+\beta_{3} \text { LnAge }_{i, t}+\beta_{4} \text { CapInt }_{i, t}+\beta_{5} \text { Capex }_{i, t}+\right. \\
& \beta_{6} \text { MktShr }_{i, t}+\beta_{7} \text { WhiteProp }_{i, t}+\beta_{8} \text { VC }_{i, t}+\beta_{9} \text { LnNumSeg }_{i, t}+\beta_{10} \text { VCFracSt }_{s, t}+ \\
& \left.\beta_{11} \text { VCFracInd }_{j, t}+\beta_{12} \text { HighTech }_{j}+\beta_{13} \text { LnNumAna }_{j, t}+\beta_{14} \text { HHI }_{j, t}+\text { Year }_{t}\right)+\varepsilon_{i, j, s, t},(1)
\end{aligned}
$$

where $i$ indexes firm, $j$ indexes industry, $s$ indexes state, and $t$ indexes year. The dependent variable, EXIT, is a categorical variable that equals zero for a firm-year if the firm remains private in the year (the base category), equals one if the firm is acquired in the year, and equals two if the firm goes public in the year. Hence, each multinomial logit model in our context contains two columns, one comparing going public vs. remaining private and the other comparing getting acquired vs. remaining private. We include year fixed effects in all the regressions and cluster the standard errors by three-digit NAICS industry.

Table 2 presents the results. Columns (1) to (4) include all independent variables except $H H I$, and Columns (5) to (8) include all independent variables except LnNumAna. ${ }^{20}$ Columns (1), (2), (5), and (6) report the multinomial logit model for the sample in the pre-2000 period (19902000). Columns (1) and (5) show that larger firms, younger firms, firms with more capital expenditures, firms with higher proportions of white-collar salary, VC-backed firms, firms in industries with more VC investments, and high-tech firms are more likely to go public than to remain private in the pre-2000 period. Columns (2) and (6) show that such firms are also more likely to get acquired than to remain private in the pre-2000 period. Moreover, firms that operate in more business segments and in states with more $\mathrm{VC}$ investments are more likely to get acquired than to remain private in the pre-2000 period. Columns (3), (4), (7), and (8) present the multinomial logit model for the post-2000 period (2001-2014). Compared to the results from the pre-2000

${ }^{20}$ We include $H H I$ and LnNumAna in separate regressions as these two industry-level variables are highly correlated and including both into the same model induces severe multi-collinearity problems. 
sample, $T F P$, industry-level analyst coverage, and product market concentration now significantly predict IPO propensity but capital expenditures or VC investments at the industry level no longer significantly predict IPO propensity. Additionally, capital intensity, capital expenditures, and VC investments at the state level do not significantly predict the exit by acquisition relative to remaining private.

These preliminary results, especially the ones about TFP and industry-level VC investments, have implications for our hypotheses. On the one hand, TFP does not positively predict IPO decision in the pre-2000 period but does in the post-2000 period. On the other hand, TFP does not predict acquisition in both pre-2000 and post-2000 periods. These results support $H 2 a$ and $H 2 b$ under the greater sensitivity to product market competition hypothesis and $H 3 b$ and $\mathrm{H3c}$ under the more abundant private equity financing hypothesis. Additionally, industry-level VC investments positively predict IPOs in pre-2000 but not in post-2000, which also supports the more abundant private equity financing hypothesis

Next, we use the multinomial logit model as analyzed in Columns (1) to (4) to construct the predicted (i.e., fitted) IPO and acquisition probabilities for the pre-2000 and post-2000 periods using characteristics of private firms in the pre-2000 sample. ${ }^{21}$ Specifically, for the pre-2000 period, we calculate the predicted IPO and acquisition probabilities by applying the estimated coefficients in Columns (1) and (2), respectively. For the post-2000 period, we calculate the predicted IPO and acquisition probabilities by applying the estimated coefficients in Columns (3) and (4), respectively. This approach virtually "fixes the pool" of the same set of entrepreneurial firms and compare their IPO and acquisition propensities based on the changing institutional features in the US economy from pre-2000 to post-2000.

Panel B of Table 2 reports the results of this analysis. In addition to the estimated probabilities, we also report the t-tests on the differences between the pre- 2000 probabilities and the post-2000 probabilities. The estimated IPO probability is $0.0092 \%$ in the pre- 2000 period but only $0.0004 \%$ in the post- 2000 period. The difference is about 96 percent of the starting level (i.e., $0.0092 \%$ ) and also statistically significant at the $1 \%$ level. In sharp contrast, the probability of exiting through acquisitions is $0.0100 \%$ in the pre- 2000 period and $0.0095 \%$ in the post-2000 period. Although the decline in acquisition probability is statistically significant, it is only about five percent of the starting level (i.e., $0.0099 \%$ ) and therefore economically small. These results

${ }^{21}$ Results using the multinomial logit model as analyzed in Columns (5) to (8) are very similar. 
together show that IPO probability in the post-2000 period is significantly lower than that of the pre-2000 period even when we consider an observably "identical" set of entrepreneurial firms preparing to exit in the two time periods.

[Insert Table 2 about here]

\subsection{Determinants of Exit Decisions: An Interaction Analysis that Compares the Pre-2000 and the Post-2000 Periods.}

In this subsection, we formally examine the changes in the determinants of exit decisions from the pre-2000 period to the post-2000 period using an interaction analysis based on the multinomial logit model. This exercise helps us test the predictions of various hypotheses.

Specifically, we estimate the following multinomial logit regressions of exit choices on the interactions of the Post2000 dummy with firm, industry, and state characteristics:

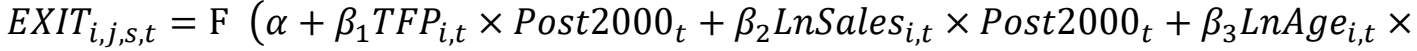

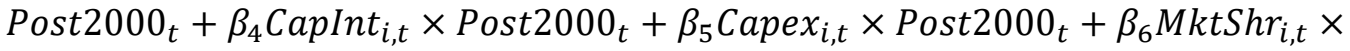

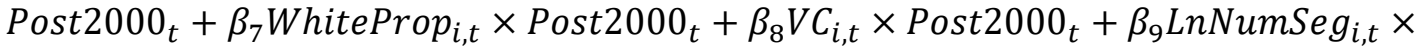

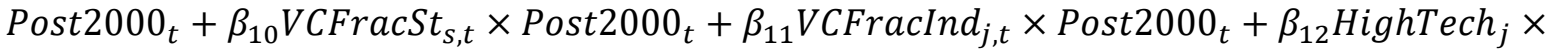

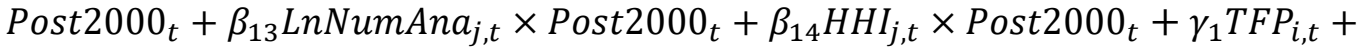

$$
\begin{aligned}
& \gamma_{2} \text { LnSales }_{i, t}+\gamma_{3} \text { LnAge }_{i, t}+\gamma_{4} \text { CapInt }_{i, t}+\gamma_{5} \text { Capex }_{i, t}+\gamma_{6} \text { MktShr }_{i, t}+\gamma_{7} \text { WhiteProp }_{i, t}+ \\
& \gamma_{8} \text { VC }_{i, t}+\gamma_{9} \text { LnNumSeg }_{i, t}+\gamma_{10} \text { VCFracSt }_{s, t}+\gamma_{11} \text { VCFracInd }_{j, t}+\gamma_{12} \text { HighTech }_{j}+ \\
& \left.\gamma_{13} L_{n N u m A n a}^{j, t}+\gamma_{14} H_{H I} I_{j, t}+\text { Year }_{t}\right)+\varepsilon_{i, j, s, t} \text {, }
\end{aligned}
$$

where the variables are similarly defined as in Equation (1). We include year fixed effects in all the regressions and cluster the standard errors by three-digit NAICS industry.

Table 3 reports the results. Similar to Panel A of Table 2, Columns (1) and (2) include all independent variables except $H H I$ and its interaction, and Columns (3) and (4) include all independent variables except LnNumAna and its interaction. In both IPO columns (Columns (1) and (3)), the interactions of TFP, VC, LnNumSeg, LnNumAna, and HHI are significantly positive, and that of Capex is significantly negative. Additionally, the interaction of VcFracInd is significantly negative in Column (1) and marginally significant in Column (3). In contrast, none of the independent variables are significant in the two columns regarding acquisition decisions (Columns (2) and (4)).

The results in Table 3 provide rich evidence for our hypotheses. First, when we compare the post-2000 period to the pre-2000 period, we find that the positive effect of TFP on going public 
relative to remaining private becomes significantly larger, while its effect on exiting through acquisitions does not significantly change. These findings support $H 2 a$ and $H 2 b$ under the greater sensitivity to product market competition hypothesis and $\mathrm{H} 3 \mathrm{~b}$ and $\mathrm{H3c}$ under the more abundant private equity financing hypothesis.

Second, firms in industries with less VC investment are more likely to go public during the post-2000 era, which is consistent with $H 3 a$ under the more abundant private equity financing hypothesis. ${ }^{22}$ Third, firms operating in more business segments (industries) and those in less competitive industries (i.e., with higher $H H I$ ) are more likely to go public in the post-2000 period than in the pre-2000 period, but the likelihood of these firms exiting through acquisitions does not significantly change between the two eras. These findings support $H 2 c$ under the greater sensitivity to product market competition hypothesis. Fourth, firms operating in industries with less analyst coverage are less likely to go public but not less likely to be acquired after 2000 than before 2000, which is consistent with $H 4 d$ under the smaller net financial benefits hypothesis. Finally, firms in high-tech industries are more likely to go public in the post-2000 period than in the pre-2000 period, but these firms' propensity to exit through acquisitions does not change much. This result does not support $H 5$ under the increased need for confidentiality hypothesis, although it could be explained by the possibility that high-tech firms might have higher unobservable quality and thus be able to meet the higher threshold quality of going public post-2000 (predicted by both the greater sensitivity to product market competition hypothesis and the more abundant private equity financing hypothesis).

[Insert Table 3 about here]

\subsection{Determinants of Exit Decisions: Before and After the Early-2000s Regulatory Changes}

Our analyses so far follow the existing literature and divide our sample period by the year 2000. To precisely test $H 4 a$ and $H 4 b$ under the smaller net financial benefits hypothesis, we separately estimate the multinomial logit regressions for two narrow windows, namely, three-year periods surrounding the year 2003.

\footnotetext{
22 Interestingly, VC-backed firms are more likely to go public post-2000, probably due to venture capital funds tend to invest in high-quality start-ups with higher IPO probability. In untabulated analyses, we find evidence consistent with this conjecture: VC-backed firms exhibit higher future TFP and sales growth than otherwise-similar firms.
} 
Panel A of Table 4 presents the multinomial logit regression of exit choices on various firm, state, and industry characteristics for the pre-regulation window (i.e., 2001-2003, in Columns (1), (2), (5), and (6)) and the post-regulation window (i.e., 2004-2006, in Columns (3), (4), (7), and (8)), respectively. The test design is similar to Table 2 except for the different time periods we examine. Panel B of Table 4 reports the predicted/fitted IPO and acquisition probabilities for the pre-regulation and post-regulation eras using characteristics of firms in the pre-regulation sample (i.e., the "base group") and regression coefficients from Columns (1) to (4). We find that the predicted post-regulation IPO probability is actually significantly higher than the predicted preregulation probability, even when we calculate these fitted probabilities using a common set of firm characteristics. Additionally, the post-regulation acquisition probability is also significantly higher than that pre-regulation. These results do not support $\mathrm{H} 4 \mathrm{a}$ and $\mathrm{H} 4 \mathrm{~b}$ under the smaller net financial benefits hypothesis.

\section{[Insert Table 4 about here]}

In Table 5, we test $H 4 c$ under the smaller net financial benefits hypothesis by estimating multinomial logit regressions that include the interactions of the exiting determinants with the post-regulation dummy, which equals one for 2004-2006, and zero for 2001-2003. The regression design is similar to that of Table 3 except for the different time periods that we examine. The smaller net financial benefits hypothesis $(\mathrm{H} 4 \mathrm{c})$ predicts the interaction between post-regulation dummy and TFP in the IPO columns to be significantly positive. However, the TFP interaction is only marginally significant in Column (1) and becomes insignificant in Column (3). We also examine the sales interaction as an alternative measure of IPO quality, and the coefficient is insignificant in either of the models. These results do not support $\mathrm{H} 4 \mathrm{c}$ under the smaller net financial benefits hypothesis.

\section{[Insert Table 5 about here]}

\subsection{Difference-in-Differences (DiD) Analysis on Predicted Exiting Probabilities}

In this subsection, we adopt an alternative test design, namely, the difference-in-differences (DiD) analysis of predicted exiting probabilities from multinomial logit models, to further analyze how economic and institutional environments (i.e., industry or geographical attributes) impact IPO and acquisition probabilities differently in the pre-2000 and post-2000 eras. Specifically, for each 
variable of interest (to test certain hypotheses), we sort the full regression sample into four subsamples based on whether the value of the variable is above or below the median and whether the year of the observation is before (including) or after 2000. We then estimate the multinomial logit regressions specified in Equation (1) for each of the four subsamples separately and obtain four sets of estimated coefficients. After that, we choose one of the two subsamples in the pre2000 era as the "base group" and calculate four predicted probabilities (each for IPOs and acquisitions) by applying the estimated regression coefficients to the characteristics of firms in this base group. By doing so, we "fix" the firm characteristics and explicitly test the impact of changing economic environments on firms' exiting probabilities. This DiD design is more flexible than our baseline multinomial logit regressions with interactions in that it allows the coefficients for all covariates in our model to be different in the four subgroups (i.e., not requiring that a given industry or state characteristic affects all the four subgroups of firms in an identical fashion).

Panel A of Table 6 presents the results using HHI (industry-level product market concentration) as the sorting variable. The top half presents the four predicted/fitted IPO probabilities, the differences between the post-2000 and the pre-2000 fitted probabilities (with tstatistics in parentheses), and the DiD estimators calculated as the differences between the two differences (with t-statistics in parentheses). We find that the IPO propensity for firms in industries with stronger product market competition (i.e., lower $H H I$ ) dropped more after 2000. This result, on the contrary, does not hold for the propensity of exiting through acquisitions. Panel B of Table 6 shows that the IPO propensity for single-segment firms dropped more after 2000. The findings in both Panel A and Panel B are consistent with the H2c under the greater sensitivity to product market competition hypothesis.

Panel C presents the results using VCFracst (the fraction of firms backed by venture capital investment in a state-year) as the sorting variable. The results show that the IPO propensity for firms in states with higher VC investments dropped more after 2000, which supports $H 3 a$ under the more abundant private equity financing hypothesis. The bottom half of Panel A further shows that firms in the states with higher VC investment also experience a greater decline in probabilities of getting acquired after 2000. Panel D reports the results on VCFracInd (the fraction of firms in a three-digit NAICS industry that are backed by venture capital investment), which offer similar inferences as those in Panel C. 
Panel E shows that the IPO propensity for firms in industries with higher information asymmetry (i.e., lower analyst coverage) and thus lower stock liquidity dropped more in the post2000 era, which is consistent with H4d under the smaller net financial benefits hypothesis.

Finally, the results in Panel F show that the IPO propensity for high-tech firms dropped more after 2000, which is consistent with H5 under the increased need for confidentiality hypothesis. Since we find mixed results regarding firms operating in high-tech industries (i.e., in Table 3 and Table 6), we acknowledge that either our evidence does not offer consistent support for the increased need for confidentiality hypothesis or that our industry-measure for the need of confidentiality is imprecise (or correlated with other firm attributes).

[Insert Table 6 about here]

\subsection{Further Analyses of the Greater Sensitivity to Product Market Competition Hypothesis and the More Abundant Private Equity Financing Hypothesis}

Our results so far provide the strongest support for the greater sensitivity to product market competition hypothesis and the more abundant private equity financing hypothesis. In this subsection, we adopt two new test designs to further examine these two hypotheses.

\subsubsection{OLS Analysis of TFP before and after 2000}

Our first analysis focuses on TFP because it is a key metric to test the unique prediction on exiting quality threshold from the above two hypotheses. Table 7 reports the following ordinary least squares (OLS) regressions:

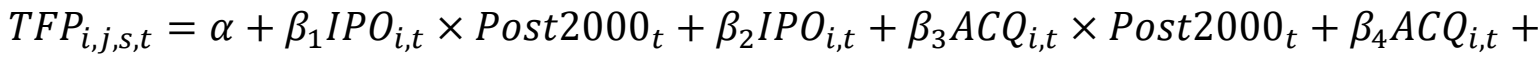

$$
\begin{aligned}
& \beta_{5} \text { LnSales }_{i, t}+\beta_{6} \text { LnAge }_{i, t}+\beta_{7} \text { CapInt }_{i, t}+\beta_{8} \text { Capex }_{i, t}+\beta_{9} \text { MktShr }_{i, t}+ \\
& \beta_{10} \text { WhiteProp }_{i, t}+\beta_{11} \text { VC }_{i, t}+\beta_{12} \text { LnNumSeg }_{i, t}+\beta_{13} \text { VCFracSt }_{s, t}+\beta_{14} \text { VCFracInd }_{j, t}+ \\
& \beta_{15} \text { HighTech }_{j}+\beta_{16} \text { LnNumAna }_{j, t}+\beta_{17} H_{H I} I_{j, t}+\text { Year }_{t}+\operatorname{Ind}_{j}+\varepsilon_{i, j, s, t} \text {, }
\end{aligned}
$$

where we examine the association between TFP and a private firm's exit choices in a given year. $I P O_{i, t}\left(A C Q_{i, t}\right)$ is a dummy variable that equals one if firm $i$ goes public (gets acquired) in year $t$ ). Post 2000 is a dummy variable that equals one if the year of observation is after 2000 . We include the same set of control variables at the firm, industry, and state levels as in Table 2 . We include year fixed effects in all models, and industry or industry $\times$ year fixed effects in some models. Standard errors are clustered by three-digit NAICS industry. 
Columns (1) and (2) present the baseline OLS regressions including year fixed effects. Similar to our multinomial logit analysis, we include $H H I$ and LnNumAna separately in these two models due to concerns for multi-collinearity. We find that the interaction between IPO and Post2000 is significantly associated with TFP in all specifications, indicating that the IPO firms in the post2000 era have significantly higher TFP compared to the remaining-private firms. The interaction between $A C Q$ and Post2000, however, is significantly associated with TFP only in Column (1) with no fixed effects. Moreover, we report the F-tests and the corresponding p-values for the differences between the coefficients of IPO $\times$ Post 2000 and $A C Q \times$ Post 2000 . We find that the differences are statistically significant in all specifications. Hence, the IPO firms in the post-2000 era have significantly higher TFP than private firms exiting through acquisitions.

For robustness, we include both year fixed effects and industry fixed effects in Columns (3) and (4), and industry $\times$ year fixed effects in Column (5). ${ }^{23}$ In all these robustness tests, the IPO interactions remain significant and the ACQ interactions remain insignificant, and the differences between the two are significant. These results confirm our previous findings that private firms with higher TFP are more likely to go public in post-2000 period relative to pre-2000 period, but they are not more likely to be acquired. Thus, the results are consistent with both the greater sensitivity to product market competition hypothesis ( $\mathrm{H} 2 \mathrm{a}$ and $\mathrm{H} 2 \mathrm{~b}$ ) and the more abundant private equity financing hypothesis ( $H 3 b$ and $H 3 c$ ).

[Insert Table 7 about here]

\subsubsection{Post-exit Long-term TFP for IPO and Matched Remaining-private Firms}

Our second analysis specifically tests $H 3 d$ under the more abundant private equity financing hypothesis by comparing the post-exit long-term TFP for IPO and matched remainingprivate firms pre- and post-2000. For each firm that goes public in a given year during our sample period, we first find remaining-private firms that operate in the same state and the same industry (at the three-digit NAICS level), as well as have the same VC-backing status as the IPO firm in that year. Further, we require the size (in terms of sales) of the matched firms to be within 0.5 and 2 times of the size of the IPO firm. Finally, among the above set of matched firms, we choose the

\footnotetext{
${ }^{23}$ This is actually one advantage of using OLS models because discrete-choice models like the multinomial logit do not allow us to include many layers of fixed effects to control for unobservable time-varying characteristics such as industry conditions.
} 
one with the closest TFP to the IPO firm. We calculate the two-year and three-year average TFP for both the IPO firms and the matched remaining-private firms from the year after the IPO, and then regress the post-IPO TFP on the IPO dummy and the interaction between the IPO dummy and the post-2000 dummy.

Table 8 reports the following OLS regressions:

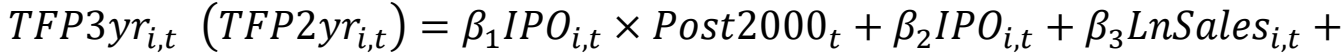

$$
\begin{aligned}
& \beta_{4} \text { LnAge }_{i, t}+\beta_{5} \text { CapInt }_{i, t}+\beta_{6} \text { Capex }_{i, t}+\beta_{7} \text { MktShr }_{i, t}+\beta_{8} \text { WhiteProp }_{i, t}+ \\
& \beta_{9} \text { LnNumSeg }_{i, t}++ \text { Year }_{t}+\text { MatchPair }_{i}+\varepsilon_{i, t} \text {, }
\end{aligned}
$$

where we examine the relation between three-year (two-year) average post-exit TFP and the IPO decisions for VC-backed firms (Columns (1) and (3)) and non-VC-backed firms (Columns (2) and (4)) separately. We include year fixed effects and the fixed effects for each matched pair of firms, so this analysis effectively compares an IPO firm's post-exit TFP with that of the matched remaining-private firm over two or three years after the IPO. Standard errors are clustered by threedigit NAICS industry.

We find that the coefficient estimate of the interaction term is significantly negative for the VC-backed sample but insignificant for the non-VC-backed sample. This result suggests that the gap in post-exit TFP between an IPO firm and an ex-ante similar remaining-private firm is significantly lower in the post-2000 era than the pre-2000 era only for VC-backed firms (i.e., those with available private equity financing). In contrast, for non-VC-backed firms, the post-exit TFP gap between an IPO firm and the matched private firm is not significantly different in both the pre2000 and the post-2000 eras. Taken together, these results suggest that the marginal benefit of going public (and raising capital from the public market) relative to staying private (and raising capital from PE financing) is lower in the post-2000 era, which is consistent with $H 3 d$ under the more abundant private equity financing hypothesis.

\section{[Insert Table 8 about here]}

\section{CONCLUSION}

The U.S. equity markets have experienced a remarkable decline in IPOs since 2000, both in terms of IPO volume and entrepreneurial firms' relative tendency to exit through acquisitions. Existing literature has provided several explanations, but many of these analyses to date focus on firms that have already gone public. Differing from previous studies, we use proprietary U.S. 
Census data to conduct a comprehensive analysis of the above two notable trends from the perspective of private firms' exiting choices between IPOs or acquisitions, and thus provide new evidence on the disappearing-IPO puzzle. Specifically, we test five different hypotheses motivated by the theoretical literature or common beliefs, namely, the weaker economy hypothesis, the greater sensitivity to product market competition hypothesis, the more abundant private equity financing hypothesis, the smaller net financial benefits from being a standalone public firm hypothesis, and the increased need for confidentiality hypothesis, using micro-level private firm data during 1990-2014.

We first revisit the phenomenon of disappearing IPOs. Consistent with the existing literature, we observe a significant decrease in IPO propensity after the year 2000, even after controlling for the changing characteristics of private firm in the U.S. economy. Interestingly, we find that small firms do not experience a larger decline in IPO propensity than large firms. Thus, the evidence using private firms contradicts the conventional wisdom that the puzzle of disappearing IPOs is mainly attributable to the decline in IPO propensity among small firms.

Next, we conduct both univariate and multivariate analyses to test the above five hypotheses. We find that the number of private firms, the fraction of high-quality (i.e., "eligible to exit") private firms, and the average quality (in terms of TFP, sales, or employment) of private firms increase from the pre-2000 period the post-2000 period. These results do not support the weaker economy hypothesis.

Our results strongly support the greater sensitivity to product market competition hypothesis. Specifically, we find that the differences in quality (in terms of TFP and sales) between IPO firms and acquired private firms and those between IPO firms and remaining-private firms have increased after the year 2000. Additionally, several multivariate analyses based on different test designs show that firms with higher TFP are more likely to go public relative to remaining private in the post-2000 period than in the pre-2000 period, but they are not more likely to get acquired after the year 2000. These results suggest that the quality threshold of going public (but not being acquired) has been raised in the post-2000 era, which is consistent with the heightened product market threat for standalone public firms. Furthermore, firms in more competitive industries and those with fewer business segments are less likely to go public after the year 2000 .

We also find evidence in support of the more abundant private equity financing hypothesis. Other than the TFP analysis discussed above, which is consistent with this hypothesis, we also find 
that firms in states or industries with higher venture capital investments experienced a larger decline in IPO propensity than their peers. Moreover, the IPO firms backed by venture capital have significantly lower post-exit long-term TFP than matched (i.e. similar) private firms that are also VC-backed in the post-2000 era relative to the pre-2000 era, while this pattern is absent among IPO and matched private firms without VC backing. This evidence suggests that the marginal benefit of going public (and raising capital from the public market) relative to staying private (and raising capital from private equity financing) is lower in the post-2000 era.

We find mixed evidence for the other two hypotheses. Regarding the smaller net financial benefits hypothesis, we find that firms in industries with lower analyst coverage (and thus smaller financial benefits of becoming liquidly traded public firms) are less likely to go public after the year 2000, which is consistent with this hypothesis. However, there does not seem to be a significant change in IPO propensity around early-2000s' regulatory changes that substantially increase the financial costs of standalone public firms, which runs against this hypothesis. Finally, by examining the exit choices of high-tech industry firms, which might be more concerned about confidentiality, we fail to find consistent evidence for the increased need for confidentiality hypothesis.

Our findings shed new light on the puzzle of disappearing IPOs as well as the growing propensity of entrepreneurial firms to exit through acquisitions. Using proprietary micro-level data on private firms, we provide a comprehensive picture of the disappearing IPOs in the post-2000 period, and show that this puzzle is a complicated phenomenon driven by factors in multiple dimensions, especially the evolving product market dynamics and the increased supply of private equity financing. As long as these economic factors continue to be in force, we probably would not see a rebound of the IPO volume to its pre-2000 level even after several recent legislative moves in the U.S. aiming to revive the IPO market such as the Jumpstart Our Business Startups Act (JOBS Act) in 2012. 


\section{REFERENCES}

Aggarwal, V.A. and Hsu, D.H., 2014. Entrepreneurial exits and innovation. Management Science, 60(4), pp.867-887.

Ball, E., Chiu, H.H. and Smith, R., 2011. Can VCs time the market? An analysis of exit choice for venture-backed firms. The Review of Financial Studies, 24(9), pp.3105-3138.

Bayar, O. and Chemmanur, T.J., 2011. IPOs versus acquisitions and the valuation premium puzzle: a theory of exit choice by entrepreneurs and venture capitalists. Journal of Financial and Quantitative Analysis, 46(6), pp.1755-1793.

Bayar, O. and Chemmanur, T.J., 2012. What drives the valuation premium in IPOs versus acquisitions? An empirical analysis. Journal of Corporate Finance, 18(3), pp.451-475.

Bebchuk, Lucian A., K.J. Martijn Cremers, and Urs C. Peyer, 2011, The CEO pay slice, Journal of Financial Economics 102, pp.199-221.

Bhattacharya, S. and Ritter, J.R., 1983. Innovation and communication: Signaling with partial disclosure. The Review of Economic Studies, 50(2), pp.331-346.

Bowen, D., Frésard, L. and Hoberg, G., 2019. Technological disruptive potential and the evolution of IPOs and sell-Outs. Working Paper.

Brau, J.C., Francis, B. and Kohers, N., 2003. The choice of IPO versus takeover: Empirical evidence. The Journal of Business, 76(4), pp.583-612.

Chaplinsky, S., Hanley, K.W. and Moon, S.K., 2017. The JOBS Act and the costs of going public. Journal of Accounting Research, 55(4), pp.795-836.

Chemmanur, T.J. and Fulghieri, P., 1999. A theory of the going-public decision. The Review of Financial Studies, 12(2), pp.249-279.

Chemmanur, T.J. and He, J., 2011. IPO waves, product market competition, and the going public decision: Theory and evidence. Journal of Financial Economics, 101(2), pp.382-412.

Chemmanur, T.J., He, J., He, S. and Nandy, D., 2018. Product market characteristics and the choice between IPOs and acquisitions. Journal of Financial and Quantitative Analysis, 53(2), pp.681-721.

Chemmanur, T.J., He, S. and Nandy, D.K., 2009. The going-public decision and the product market. The Review of Financial Studies, 23(5), pp.1855-1908. 
Chemmanur, T.J., Krishnan, K. and Nandy, D.K., 2011. How does venture capital financing improve efficiency in private firms? A look beneath the surface. The Review of Financial Studies, 24(12), pp.4037-4090.

Clementi, G.L., 2002. IPOs and the growth of firms. Working paper.

Cumming, D., 2008. Contracts and exits in venture capital finance. The Review of Financial Studies, 21(5), pp.1947-1982.

de Fontenay, E., 2017. The deregulation of private capital and the decline of the public company, Hastings Law Journal, 68, pp. 445-502.

Dambra, M., Field, L.C. and Gustafson, M.T., 2015. The JOBS Act and IPO volume: Evidence that disclosure costs affect the IPO decision. Journal of Financial Economics, 116(1), pp.121-143.

Doidge, C., Kahle, K.M., Karolyi, G.A. and Stulz, R.M., 2018. Eclipse of the public corporation or eclipse of the public markets?. Journal of Applied Corporate Finance, 30(1), pp.8-16.

Doidge, C., Karolyi, G.A. and Stulz, R.M., 2013. The US left behind? Financial globalization and the rise of IPOs outside the US. Journal of Financial Economics, 110(3), pp.546-573.

Doidge, C., Karolyi, G.A. and Stulz, R.M., 2017. The US listing gap. Journal of Financial Economics, 123(3), pp.464-487.

Ewens, M. and Farre-Mensa, J., 2020. The deregulation of the private equity markets and the decline in IPOs. Working Paper.

Gao, X., Ritter, J.R. and Zhu, Z., 2013. Where have all the IPOs gone? Journal of Financial and Quantitative Analysis, 48(6), pp.1663-1692.

Jarmin, R.S. and Miranda, J., 2002. The longitudinal business database. Available at SSRN 2128793.

Lattanzio, G., Megginson, W.L. and Sanati, A., 2019. Listing Gaps, Merger Waves, and the Privatization of American Equity Finance. Working Paper.

Loveland, R., Mulherin, J.H., and Okoeguale, K., 2018. Deregulation, Listing and Delisting. Working Paper.

Maksimovic, V. and Pichler, P., 2001. Technological innovation and initial public offerings. The Review of Financial Studies, 14(2), pp.459-494. 
Poulsen, A.B. and Stegemoller, M., 2008. Moving from private to public ownership: selling out to public firms versus initial public offerings. Financial Management, 37(1), pp.81-101.

Weild, D., 2011. How to revive small-cap IPOs. Wall Street Journal.

Zweig, J., 2010. The demise of the IPO market-and ideas on how to revive it. Wall Street Journal. 


\section{Appendix A: Measurement of Total Factor Productivity (TFP)}

Following the existing literature, we construct plant-level total factor productivity (TFP) by first estimating the following log-linear Cobb-Douglas production function for each six-digit NAICS industry and year:

$$
\ln \left(Y_{i j t}\right)=\alpha_{j t}+\beta_{j t} \ln K_{i j t}+\gamma_{j t} \ln L_{i j t}+\varepsilon_{i j t}
$$

where $Y_{i j t}, K_{i j t}$, and $L_{i j t}$ are sales (total value of shipments), capital stock, and labor cost, respectively, for firm $j$ in industry $i$ and year $t .^{24}$ Then we calculate the plant-level TFP as the residual from the above regression. Finally, we compute the weighted-average TFP at the firm level using sales as the weight.

The input variables of the Cobb-Douglas function are obtained from the ASM and CMF databases. Labor cost is defined as production worker equivalent man hours, which is the product of production worker man-hours and the ratio of total wages and salaries to production worker wages. Capital stock is estimated using the perpetual inventory method. For each plant in the ASM and CMF databases, we first identify the years for which the plant has a non-missing book value of capital. We then write forward annually the last available book value of capital with nominal capital expenditures (deflated at the industry level using information from the NBER-CES Manufacturing Industry Database) and depreciate it by the depreciation rate at the industry level obtained from the Bureau of Economic Analysis. The resulting series are then added together to yield our capital stock measure.

${ }^{24}$ Our results are robust to including material costs and/or energy costs as independent variables and using an index method to estimate the Cobb-Douglas function. 


\section{Appendix B: Definition of Variables}

\begin{tabular}{|c|c|}
\hline Variables & Definition \\
\hline$I P O$ & $\begin{array}{l}\text { A dummy variable that equals one if a private firm goes public in year } t \text {, and zero } \\
\text { otherwise. }\end{array}$ \\
\hline$A C Q$ & $\begin{array}{l}\text { A dummy variable that equals one if a private firm gets acquired in year } t \text {, and } \\
\text { zero otherwise. }\end{array}$ \\
\hline Post2000 & $\begin{array}{l}\text { A dummy variable that equals one if the year of an observation is later than } 2000 \text {, } \\
\text { and zero otherwise. }\end{array}$ \\
\hline PostReg & $\begin{array}{l}\text { A dummy variable that equals one if the year of an observation is between } 2001 \\
\text { and } 2003 \text {, and equals zero if it is between } 2004 \text { and } 2006 \text {. }\end{array}$ \\
\hline TFP & $\begin{array}{l}\text { The weighted-average of plant-level total factor productivity, which is calculated } \\
\text { using the method described in Appendix A. }\end{array}$ \\
\hline Sales & Total value of shipments in $\$ 1,000$ in terms of 1997 dollars. \\
\hline SalesGrowth & $\begin{array}{l}\text { Average annual percentage change in sales (total value of shipments) in the past } \\
\text { three years. }\end{array}$ \\
\hline LnSales & $\begin{array}{l}\text { The natural logarithm of sales (total value of shipments in } \$ 1,000 \text { ) in terms of } \\
1997 \text { dollars. }\end{array}$ \\
\hline LnAge & 1 logarithm of the age (in years) of the oldest plant of a firm. \\
\hline CapInt & $\begin{array}{l}\text { Capital intensity, defined as capital stock over total employment, where capital } \\
\text { stock is calculated using perpetual inventory method as described in Appendix } \\
\text { B. }\end{array}$ \\
\hline Capex & Capital expenditure ratio, defined as capital expenditures over capital stock. \\
\hline MktShr & $\begin{array}{l}\text { The weighted-average of plant-level market share in terms of sales at the three- } \\
\text { digit NAICS level. }\end{array}$ \\
\hline WhiteProp & $\begin{array}{l}\text { The average proportion of total wages that is for white-collar workers in the past } \\
\text { three years. }\end{array}$ \\
\hline$V C$ & $\begin{array}{l}\text { A dummy variable that equals one if a firm is backed by venture capital, and zero } \\
\text { otherwise. }\end{array}$ \\
\hline LnNumSeg & $\begin{array}{l}\text { The natural logarithm of the number of industries (at the six-digit NAICS level) } \\
\text { that a firm operates in. }\end{array}$ \\
\hline VCFracSt & The fraction of firms in a given state-year that are backed by venture capital. \\
\hline VCFracInd & $\begin{array}{l}\text { The fraction of firms in a given industry-year (at the three-digit NAICS level) } \\
\text { that are backed by venture capital. }\end{array}$ \\
\hline HighTech & $\begin{array}{l}\text { A dummy variable that equals one if a firm operates in one of the following six- } \\
\text { digit NAICS industries (following the definition given by the U.S. Bureau of } \\
\text { Census): } 333295,333315,334111,334112,334113,334119,334210,334220 \text {, } \\
334413,334511,421430,421690,423430,423690,443120,511140,511210 \text {, } \\
514210,518210,519130,541330,541511,541512,541513,541519,541710 \text {, } \\
541711,541712 \text {, and zero otherwise. }\end{array}$ \\
\hline LnNumAna & $\begin{array}{l}\text { The natural logarithm of one plus the average number of analysts following a } \\
\text { public firm over a given industry-year (at the three-digit NAICS level). }\end{array}$ \\
\hline HHI & $\begin{array}{l}\text { The weighted-average of plant-level Herfindahl Index in terms of sales at the } \\
\text { three-digit NAICS level. }\end{array}$ \\
\hline
\end{tabular}


Table 1: Summary Statistics for the Sample of Regression Analyses

This table reports the summary statistics of the variables used in the regression analyses. The sample for regression analyses contains private manufacturing firms from the ASM/CMF databases between 1990 and 2014, including a total of about 999,000 firm-years (rounded to thousand following Census disclosure requirement). The definitions of all variables are provided in Appendix B.

\begin{tabular}{lccc}
\hline & Mean & Std & $\mathrm{N}$ \\
\cline { 2 - 4 } Variables & $(1)$ & $(2)$ & $(3)$ \\
\hline IPO (in \%) & 0.052 & 2.285 & 999,000 \\
ACQ (in \%) & 0.095 & 3.080 & 999,000 \\
Post2000 & 0.555 & 0.497 & 999,000 \\
TFP & -0.050 & 0.469 & 999,000 \\
LnSales & 8.185 & 1.762 & 999,000 \\
LnAge & 2.605 & 0.868 & 999,000 \\
CapInt & 0.073 & 0.094 & 999,000 \\
Capex & 0.082 & 0.139 & 999,000 \\
MktShr (in \%) & 0.011 & 0.033 & 999,000 \\
WhiteProp & 0.385 & 0.189 & 999,000 \\
VC & 0.029 & 0.168 & 999,000 \\
LnNumSeg & 0.200 & 0.493 & 999,000 \\
VCFracSt & 0.036 & 0.024 & 999,000 \\
VCFracInd & 0.035 & 0.039 & 999,000 \\
HighTech & 0.011 & 0.102 & 999,000 \\
LnNumAna & 1.160 & 0.270 & 999,000 \\
HHI & 0.013 & 0.018 & 999,000 \\
\hline
\end{tabular}




\section{Table 2: Determinants of Exit Decisions through IPOs vs. Acquisitions: Multinomial Logit Regressions}

This table presents the analyses on the determinants of private firms' exit decisions through IPOs or acquisitions (ACQ). Panel A presents the multinomial logit regressions of exit choices on firm, industry, and state characteristics. The dependent variable is a categorical variable that equals zero if a firm remains private in year $t$ (the base category), equals one if a firm gets acquired in year $t$, and equals two if a firm goes public in year $t$. Each set of regressions consists of two columns, one that compares the exit decision of IPO to remaining private, and the other that compares the exit decision of getting acquired to remaining private. Columns (1), (2), (5), and (6) use the pre-2000 period of 1990-2000, and Columns (3), (4), (7), and (8) use the post-2000 period of 2001-2014. All the independent variables are defined in Appendix B. All regressions include year fixed effects. Robust z-statistics, clustered by three-digit NAICS industry, are reported in parentheses. $*, * *$, and $* * *$ represent statistical significance from the omitted category (remaining private) at the $10 \%, 5 \%$, and $1 \%$ levels, respectively. Panel B reports the predicted IPO and ACQ probabilities for the pre-2000 and post-2000 periods using the characteristics of firms from the pre-2000 sample and the regression coefficients from Columns (1) to (4). The reported probabilities are multiplied by $10^{4}$ to ease reading.

Panel A: Multinomial Logit Regressions

\begin{tabular}{|c|c|c|c|c|c|c|c|c|}
\hline \multirow[t]{2}{*}{ Sample } & \multicolumn{2}{|c|}{ Pre-2000 } & \multicolumn{2}{|c|}{ Post-2000 } & \multicolumn{2}{|c|}{ Pre-2000 } & \multicolumn{2}{|c|}{ Post-2000 } \\
\hline & $I P O$ & $A C Q$ & $I P O$ & $A C Q$ & $I P O$ & $A C Q$ & $I P O$ & $A C Q$ \\
\hline & (1) & (2) & (3) & (4) & (5) & (6) & (7) & (8) \\
\hline \multirow[t]{2}{*}{$T F P$} & -0.161 & -0.183 & 0.266 & -0.118 & -0.165 & -0.179 & $0.302 *$ & -0.115 \\
\hline & $(-0.861)$ & $(-1.374)$ & (1.477) & $(-1.020)$ & $(-0.875)$ & $(-1.348)$ & (1.724) & $(-0.961)$ \\
\hline \multirow[t]{2}{*}{ LnSales } & $0.867 * * *$ & $0.456 * * *$ & $0.765^{* * *}$ & $0.404 * * *$ & $0.861 * * *$ & $0.453 * * *$ & $0.770 * * *$ & $0.402 * * *$ \\
\hline & $(7.515)$ & $(8.417)$ & $(6.004)$ & (8.064) & $(7.425)$ & $(7.671)$ & $(6.141)$ & $(8.140)$ \\
\hline \multirow[t]{2}{*}{ LnAge } & $-0.413^{* * *}$ & $-0.229 * *$ & $-0.598 * * *$ & $-0.288^{* * *}$ & $-0.411 * * *$ & $-0.228 * *$ & $-0.594 * * *$ & $-0.285^{* * *}$ \\
\hline & $(-3.742)$ & $(-2.357)$ & $(-4.506)$ & $(-7.136)$ & $(-3.729)$ & $(-2.324)$ & $(-4.450)$ & $(-7.173)$ \\
\hline \multirow[t]{2}{*}{ CapInt } & -0.434 & -1.198 & 0.414 & -0.463 & -0.589 & $-1.256^{*}$ & 0.404 & -0.466 \\
\hline & $(-0.484)$ & $(-1.596)$ & $(0.884)$ & $(-1.624)$ & $(-0.670)$ & $(-1.716)$ & $(0.875)$ & $(-1.609)$ \\
\hline \multirow[t]{2}{*}{ Capex } & $2.315^{* * *}$ & $0.671 * * *$ & 0.511 & 0.417 & $2.301 * * *$ & $0.671^{* * *}$ & 0.480 & 0.416 \\
\hline & $(11.900)$ & $(2.755)$ & (1.368) & $(1.291)$ & (11.89) & $(2.767)$ & (1.308) & $(1.287)$ \\
\hline \multirow[t]{2}{*}{ MktShr } & -0.119 & -0.026 & -0.176 & -0.034 & -0.094 & -0.022 & -0.223 & -0.033 \\
\hline & $(-0.862)$ & $(-0.397)$ & $(-1.192)$ & $(-0.414)$ & $(-0.679)$ & $(-0.331)$ & $(-1.476)$ & $(-0.395)$ \\
\hline \multirow[t]{2}{*}{ WhiteProp } & $1.554 * * *$ & $0.635^{* * *}$ & $1.281 *$ & $1.018 * * *$ & $1.567 * * *$ & $0.639 * * *$ & $1.391 *$ & $1.006^{* * *}$ \\
\hline & $(3.267)$ & (3.383) & (1.763) & (4.563) & $(3.296)$ & (3.396) & (1.921) & $(4.743)$ \\
\hline \multirow[t]{2}{*}{$V C$} & $1.937 * * *$ & $1.479 * * *$ & $2.775^{* * *}$ & $1.639^{* * *}$ & $1.944 * * *$ & $1.482 * * *$ & $2.778^{* * *}$ & $1.642 * * *$ \\
\hline & (11.690) & $(10.720)$ & $(8.429)$ & $(13.760)$ & (11.550) & $(10.650)$ & $(8.391)$ & (13.710) \\
\hline \multirow[t]{2}{*}{ LnNumSeg } & -0.102 & $0.549^{* * *}$ & 0.299 & $0.620 * * *$ & -0.105 & $0.550 * * *$ & 0.298 & $0.619 * * *$ \\
\hline & $(-0.394)$ & $(3.782)$ & $(0.978)$ & (6.963) & $(-0.404)$ & (3.775) & $(0.966)$ & $(6.968)$ \\
\hline \multirow[t]{2}{*}{ VCFracSt } & 3.309 & $4.263^{* *}$ & 4.520 & 3.549 & 3.411 & $4.240 * *$ & 4.220 & 3.522 \\
\hline & (1.396) & $(2.098)$ & $(1.645)$ & $(1.455)$ & $(1.382)$ & $(2.095)$ & (1.599) & (1.439) \\
\hline \multirow[t]{2}{*}{ VCFracInd } & $6.113^{* * *}$ & $4.384 * * *$ & 2.652 & $2.967 * *$ & $6.394 * * *$ & $4.369 * * *$ & 3.135 & $2.833^{*}$ \\
\hline & $(5.188)$ & $(3.746)$ & (1.148) & (1.966) & $(6.068)$ & $(3.824)$ & (1.305) & $(1.842)$ \\
\hline \multirow[t]{2}{*}{ HighTech } & $0.502 * * *$ & $0.407 * *$ & $0.853 * * *$ & $0.338^{*}$ & $0.486^{* * *}$ & $0.413 * *$ & $0.971 * * *$ & $0.325^{* *}$ \\
\hline & (2.599) & $(2.533)$ & $(4.217)$ & (1.886) & $(2.579)$ & $(2.574)$ & $(3.728)$ & $(2.025)$ \\
\hline \multirow[t]{2}{*}{ LnNumAna } & -0.308 & -0.097 & $0.659 * *$ & -0.100 & & & & \\
\hline & $(-0.894)$ & $(-0.484)$ & (2.136) & $(-0.486)$ & & & & \\
\hline
\end{tabular}




\begin{tabular}{lcccccccc}
\hline Sample & \multicolumn{2}{c}{ Pre-2000 } & \multicolumn{2}{c}{ Post-2000 } & \multicolumn{2}{c}{ Pre-2000 } & \multicolumn{2}{c}{ Post-2000 } \\
\hline & \multicolumn{1}{c}{$I P O$} & $A C Q$ & $I P O$ & $A C Q$ & $I P O$ & $A C Q$ & $I P O$ & $A C Q$ \\
\cline { 2 - 8 } & $(1)$ & $(2)$ & $(3)$ & $(4)$ & $(5)$ & $(6)$ & $(7)$ & $(8)$ \\
\hline$H H I$ & & & & & -2.782 & 0.271 & $9.476^{* *}$ & 0.428 \\
& & & & & $(-1.054)$ & $(0.113)$ & $(2.054)$ & $(0.161)$ \\
Constant & $-17.200^{* * *}$ & $-12.620^{* * *}$ & $-18.920^{* * *}$ & $-11.070^{* * *}$ & $-17.480^{* * *}$ & $-12.700^{* * *}$ & $-18.320^{* * *}$ & $-11.160^{* * *}$ \\
& $(-16.600)$ & $(-20.330)$ & $(-12.530)$ & $(-18.330)$ & $(-16.730)$ & $(-22.790)$ & $(-12.040)$ & $(-18.930)$ \\
Year FE & Yes & Yes & Yes & Yes & Yes & Yes & Yes & Yes \\
Observations & 445,000 & 445,000 & 554,000 & 554,000 & 445,000 & 445,000 & 554,000 & 554,000 \\
\hline
\end{tabular}

Panel B: Predicted IPO and ACQ Probabilities for Pre-2000 and Post-2000 Eras

\begin{tabular}{lccc}
\hline & Pre-2000 Probability & Post-2000 Probability & T-test \\
\cline { 2 - 4 } IPO & 9.243 & 0.373 & -100.500 \\
ACQ & 9.963 & 9.504 & -19.850 \\
\hline
\end{tabular}




\section{Table 3: The Changing Impact of Exit Decision Determinants from Pre- to Post-2000}

This table presents the multinomial logit regressions of exit choices on the interactions of firm, industry, and state characteristics with Post2000, a dummy variable that equals one if the year of an observation is 2001 or later. The dependent variable is a categorical variable that equals zero if a firm remains private in year $t$, equals one if a firm gets acquired in year $t$, and equals two if a firm goes public in year $t$. Columns (1) and (3) compare the exit decision of IPO to remaining private, and Columns (2) and (4) compare the exit decision of getting acquired (ACQ) to remaining private. All the independent variables are defined in Appendix B. All regressions include year fixed effects. Robust z-statistics, clustered by three-digit NAICS industry, are reported in parentheses. $*, * *$, and $* * *$ represent statistical significance from the omitted category (remaining private) at the $10 \%, 5 \%$, and $1 \%$ levels, respectively.

\begin{tabular}{|c|c|c|c|c|}
\hline & $I P O$ & $A C Q$ & $I P O$ & $A C Q$ \\
\hline & $(1)$ & $(2)$ & (3) & (4) \\
\hline \multirow[t]{2}{*}{ TFP $\times$ Post 2000} & $0.432 * *$ & 0.069 & $0.473 * * *$ & 0.069 \\
\hline & $(2.517)$ & $(0.439)$ & $(2.717)$ & $(0.430)$ \\
\hline \multirow[t]{2}{*}{ LnSales $\times$ Post 2000} & -0.100 & -0.051 & -0.092 & -0.050 \\
\hline & $(-0.846)$ & $(-0.804)$ & $(-0.735)$ & $(-0.756)$ \\
\hline \multirow[t]{2}{*}{ LnAge $\times$ Post 2000} & -0.187 & -0.059 & -0.182 & -0.059 \\
\hline & $(-1.170)$ & $(-0.649)$ & $(-1.151)$ & $(-0.638)$ \\
\hline \multirow[t]{2}{*}{ CapInt $\times$ Post 2000} & 0.856 & 0.744 & 0.974 & 0.796 \\
\hline & $(1.071)$ & $(0.904)$ & $(1.202)$ & $(0.991)$ \\
\hline \multirow[t]{2}{*}{ Capex $\times$ Post 2000} & $-1.805^{* * *}$ & -0.254 & $-1.827 * * *$ & -0.256 \\
\hline & $(-3.807)$ & $(-0.746)$ & $(-3.882)$ & $(-0.755)$ \\
\hline \multirow[t]{2}{*}{ MktShr $\times$ Post 2000} & -0.057 & -0.008 & -0.125 & -0.012 \\
\hline & $(-0.502)$ & $(-0.080)$ & $(-1.159)$ & $(-0.115)$ \\
\hline \multirow[t]{2}{*}{ WhiteProp $\times$ Post 2000} & -0.240 & 0.419 & -0.155 & 0.405 \\
\hline & $(-0.413)$ & $(1.349)$ & $(-0.277)$ & $(1.350)$ \\
\hline \multirow[t]{2}{*}{$V C \times$ Post 2000} & $0.839 * *$ & 0.161 & $0.833 * *$ & 0.160 \\
\hline & $(1.998)$ & $(0.819)$ & $(1.968)$ & $(0.816)$ \\
\hline \multirow[t]{2}{*}{ LnNumSeg $\times$ Post 2000} & $0.399 * *$ & 0.069 & $0.403 * *$ & 0.068 \\
\hline & $(2.168)$ & $(0.498)$ & $(2.130)$ & $(0.486)$ \\
\hline \multirow[t]{2}{*}{ VCFracSt $\times$ Post 2000} & 2.897 & 0.491 & 3.422 & 0.426 \\
\hline & $(0.499)$ & $(0.112)$ & $(0.590)$ & $(0.097)$ \\
\hline \multirow[t]{2}{*}{ VCFracInd $\times$ Post 2000} & $-4.219 *$ & -1.990 & -3.768 & -2.163 \\
\hline & $(-1.719)$ & $(-1.295)$ & $(-1.606)$ & $(-1.359)$ \\
\hline \multirow[t]{2}{*}{ HighTech $\times$ Post2000 } & $0.386^{* *}$ & -0.017 & $0.506^{* *}$ & -0.035 \\
\hline & $(2.099)$ & $(-0.123)$ & $(2.436)$ & $(-0.265)$ \\
\hline \multirow[t]{2}{*}{ LnNumAna $\times$ Post 2000} & $0.954 * *$ & -0.015 & & \\
\hline & $(2.171)$ & $(-0.050)$ & & \\
\hline \multirow[t]{2}{*}{$H H I \times$ Post 2000} & & & $12.720 * * *$ & 0.299 \\
\hline & & & $(3.368)$ & $(0.078)$ \\
\hline \multirow[t]{2}{*}{$T F P$} & -0.165 & -0.187 & -0.169 & -0.184 \\
\hline & $(-0.884)$ & $(-1.419)$ & $(-0.903)$ & $(-1.396)$ \\
\hline LnSales & $0.864 * * *$ & $0.454 * * *$ & $0.858 * * *$ & $0.450 * * *$ \\
\hline
\end{tabular}




\begin{tabular}{|c|c|c|c|c|}
\hline & $I P O$ & $A C Q$ & $I P O$ & $A C Q$ \\
\hline & (1) & (2) & (3) & (4) \\
\hline & $(7.531)$ & $(8.431)$ & $(7.441)$ & $(7.712)$ \\
\hline \multirow[t]{2}{*}{ LnAge } & $-0.410 * * *$ & $-0.227 * *$ & $-0.408 * * *$ & $-0.226^{* *}$ \\
\hline & $(-3.680)$ & $(-2.353)$ & $(-3.672)$ & $(-2.320)$ \\
\hline \multirow[t]{2}{*}{ CapInt } & -0.456 & -1.217 & -0.602 & $-1.272 *$ \\
\hline & $(-0.502)$ & $(-1.629)$ & $(-0.671)$ & $(-1.742)$ \\
\hline \multirow[t]{2}{*}{ Capex } & $2.307 * * *$ & $0.664 * * *$ & $2.293 * * *$ & $0.664 * * *$ \\
\hline & $(11.870)$ & $(2.703)$ & (11.860) & $(2.715)$ \\
\hline \multirow[t]{2}{*}{$M k t S h r$} & -0.118 & -0.023 & -0.092 & -0.020 \\
\hline & $(-0.859)$ & $(-0.363)$ & $(-0.672)$ & $(-0.302)$ \\
\hline \multirow[t]{2}{*}{ WhiteProp } & $1.507 * * *$ & $0.593 * * *$ & $1.518 * * *$ & $0.596 * * *$ \\
\hline & $(3.207)$ & $(3.218)$ & $(3.236)$ & $(3.226)$ \\
\hline \multirow[t]{2}{*}{$V C$} & $1.927 * * *$ & $1.471 * * *$ & $1.934 * * *$ & $1.474 * * *$ \\
\hline & (11.800) & $(10.560)$ & (11.660) & (10.490) \\
\hline \multirow[t]{2}{*}{ LnNumSeg } & -0.100 & $0.551 * * *$ & -0.104 & $0.552 * * *$ \\
\hline & $(-0.386)$ & $(3.809)$ & $(-0.398)$ & $(3.802)$ \\
\hline \multirow[t]{2}{*}{ VCFracSt } & 5.886 & $6.784 * *$ & 5.766 & $6.828 * *$ \\
\hline & $(1.273)$ & $(2.086)$ & $(1.252)$ & $(2.110)$ \\
\hline \multirow[t]{2}{*}{ VCFracInd } & $6.994 * * *$ & $5.125 * * *$ & $7.347 * * *$ & $5.109 * * *$ \\
\hline & $(4.804)$ & $(3.873)$ & $(5.713)$ & $(3.979)$ \\
\hline \multirow[t]{2}{*}{ HighTech } & $0.478 * *$ & $0.368 * *$ & $0.459 * *$ & $0.374 * *$ \\
\hline & $(2.410)$ & $(2.218)$ & $(2.370)$ & $(2.255)$ \\
\hline \multirow[t]{2}{*}{ LnNumAna } & -0.291 & -0.091 & & \\
\hline & $(-0.838)$ & $(-0.459)$ & & \\
\hline \multirow[t]{2}{*}{$H H I$} & & & -2.913 & 0.269 \\
\hline & & & $(-1.098)$ & $(0.114)$ \\
\hline \multirow[t]{2}{*}{ Constant } & $-17.290 * * *$ & $-12.720 * * *$ & $-17.540 * * *$ & $-12.800 * * *$ \\
\hline & $(-18.550)$ & $(-21.050)$ & $(-18.740)$ & $(-23.670)$ \\
\hline Year FE & Yes & Yes & Yes & Yes \\
\hline Industry FE & No & No & No & No \\
\hline State FE & No & No & No & No \\
\hline Observations & 999,000 & 999,000 & 999,000 & 999,000 \\
\hline
\end{tabular}




\section{Table 4: Determinants of Exit Decisions through IPOs versus Acquisitions: Periods around the Early-2000s}

regulations

This table presents the analyses on the determinants of private firms' exit decisions through IPOs or acquisitions during the three-year windows before and after the series of regulations in early 2000s, including the Regulation Fair Disclosure, the Sarbanes Oxley Act, and the Global Settlement. Panel A presents the multinomial logit regressions of exit choices on firm, industry, and state characteristics. The dependent variable is a categorical variable that equals zero if a firm remains private in year $t$, equals one if a firm gets acquired in year $t$, and equals two if a firm goes public in year $t$. Each set of regressions consists of two columns, one that compares the exit decision of IPO to remaining private, and the other that compares the exit decision of getting acquired (ACQ) to remaining private. Columns (1), (2), (5), and (6) use the subperiod 2001-2003, and Columns (3), (4), (7), and (8) use the subperiod 2004-2006. All the independent variables are defined Appendix B. All regressions include year fixed effects. Robust z-statistics, clustered by three-digit NAICS industry, are reported in parentheses. ${ }^{*}, * *$, and $* * *$ represent statistical significance from the omitted category (remaining private) at the $10 \%, 5 \%$, and $1 \%$ levels, respectively. "N/A" denotes coefficients that cannot be reported due to the disclosure rules of the Census. Panel B reports the predicted IPO and ACQ probabilities for the pre-regulation (2001-2003) and post-regulation (2004-2006) eras using the characteristics of firms in the pre-regulation sample and the regression coefficients from Columns (1) to (4). The reported probabilities are multiplied by $10^{4}$ to ease reading.

\section{Panel A: Multinomial Logit Regressions}

\begin{tabular}{|c|c|c|c|c|c|c|c|c|}
\hline \multirow[t]{2}{*}{ Sample } & \multicolumn{2}{|c|}{ Pre-regulation } & \multicolumn{2}{|c|}{ Post-regulation } & \multicolumn{2}{|c|}{ Pre-regulation } & \multicolumn{2}{|c|}{ Post-regulation } \\
\hline & $I P O$ & $A C Q$ & $I P O$ & $A C Q$ & $I P O$ & $A C Q$ & $I P O$ & $A C Q$ \\
\hline & (1) & (2) & (3) & (4) & (5) & (6) & (7) & (8) \\
\hline \multirow[t]{2}{*}{$T F P$} & 0.160 & -0.134 & $0.897 *$ & $-0.334 * *$ & 0.160 & -0.156 & $0.925^{*}$ & $-0.326^{* *}$ \\
\hline & $(0.671)$ & $(-0.381)$ & $(1.846)$ & $(-2.053)$ & $(-0.383)$ & $(-0.377)$ & $(1.841)$ & $(-2.055)$ \\
\hline \multirow[t]{2}{*}{ LnSales } & $0.744^{*}$ & $0.303^{* *}$ & $0.611^{* * *}$ & $0.402 * * *$ & $0.725^{*}$ & $0.300^{* *}$ & $0.627 * * *$ & $0.381^{* * *}$ \\
\hline & (1.886) & (2.073) & $(3.750)$ & $(5.461)$ & $(1.860)$ & $(2.081)$ & (3.783) & (5.632) \\
\hline \multirow[t]{2}{*}{ LnAge } & $-1.041 * * *$ & $-0.475 * * *$ & -0.252 & -0.131 & $-1.044 * * *$ & $-0.470 * * *$ & -0.255 & -0.108 \\
\hline & $(-5.103)$ & $(-2.876)$ & $(-1.081)$ & $(-0.922)$ & $(-5.089)$ & $(-2.798)$ & $(-0.992)$ & $(-0.946)$ \\
\hline \multirow[t]{2}{*}{ CapInt } & $-2.481^{*}$ & $-1.516^{*}$ & 0.713 & -0.439 & $-2.552 *$ & $-1.524^{*}$ & 0.801 & -0.406 \\
\hline & $(-1.665)$ & $(-1.727)$ & $(0.704)$ & $(-0.526)$ & $-(1.660)$ & $(-1.717)$ & $(0.754)$ & $(-0.403)$ \\
\hline \multirow[t]{2}{*}{ Capex } & 0.212 & 0.514 & -1.260 & 0.767 & 0.213 & 0.515 & -1.253 & 0.770 \\
\hline & $(0.370)$ & $(0.814)$ & $(-1.255)$ & (1.388) & $(0.391)$ & $(0.803)$ & $(-1.291)$ & $(1.492)$ \\
\hline \multirow[t]{2}{*}{ MktShr } & 0.203 & -0.140 & -0.240 & -0.031 & 0.204 & -0.144 & -0.234 & -0.031 \\
\hline & $(0.398)$ & $(-0.607)$ & $(-1.023)$ & $(-0.255)$ & $(0.414)$ & $(-0.633)$ & $(-1.189)$ & $(-0.227)$ \\
\hline \multirow[t]{2}{*}{ WhiteProp } & $2.395^{* *}$ & $1.514 * * *$ & 0.599 & -0.030 & $2.403 * *$ & $1.525^{* * *}$ & 0.624 & -0.034 \\
\hline & (2.116) & (3.424) & $(0.663)$ & $(-0.063)$ & (2.099) & $(3.467)$ & $(0.650)$ & $(-0.071)$ \\
\hline \multirow[t]{2}{*}{$V C$} & $\mathrm{~N} / \mathrm{A}$ & $1.182 * * *$ & N/A & $1.679 * * *$ & N/A & $1.190 * * *$ & N/A & $1.692^{* * *}$ \\
\hline & N/A & (2.964) & N/A & $(6.960)$ & N/A & $(3.035)$ & N/A & $(7.025)$ \\
\hline \multirow[t]{2}{*}{ LnNumSeg } & 0.629 & $1.163 * * *$ & 0.082 & $0.442 * * *$ & 0.660 & $1.168^{* * *}$ & 0.075 & $0.446^{* * *}$ \\
\hline & $(0.833)$ & $(3.661)$ & $(0.235)$ & (5.597) & (1.003) & (3.992) & $(0.228)$ & $(5.600)$ \\
\hline \multirow[t]{2}{*}{ VCFracSt } & -2.607 & $6.900 * * *$ & -2.752 & $8.651^{* *}$ & -2.615 & $6.853 * * *$ & -2.797 & $8.726^{* *}$ \\
\hline & $(-0.551)$ & $(2.985)$ & $(-0.404)$ & $(2.303)$ & $(-0.497)$ & $(3.045)$ & $(-0.388)$ & (2.337) \\
\hline \multirow[t]{2}{*}{ VCFracInd } & -2.740 & $3.795^{* *}$ & 3.273 & $6.019^{* * *}$ & -2.755 & $3.989 * *$ & 3.152 & $6.028 * * *$ \\
\hline & $(-0.495)$ & $(2.242)$ & (1.128) & $(2.662)$ & $(-0.513)$ & $(2.201)$ & (1.209) & $(3.236)$ \\
\hline \multirow[t]{2}{*}{ HighTech } & $\mathrm{N} / \mathrm{A}$ & N/A & $\mathrm{N} / \mathrm{A}$ & N/A & N/A & N/A & N/A & N/A \\
\hline & N/A & N/A & N/A & N/A & N/A & N/A & N/A & N/A \\
\hline
\end{tabular}




\begin{tabular}{lcccccccc}
\hline Sample & \multicolumn{2}{c}{ Pre-regulation } & \multicolumn{2}{c}{ Post-regulation } & \multicolumn{2}{c}{ Pre-regulation } & \multicolumn{2}{c}{ Post-regulation } \\
\hline & $I P O$ & $A C Q$ & $I P O$ & $A C Q$ & $I P O$ & $A C Q$ & $I P O$ & $A C Q$ \\
\cline { 2 - 9 } & $(1)$ & $(2)$ & $(3)$ & $(4)$ & $(5)$ & $(6)$ & $(7)$ & $(8)$ \\
\hline LnNumAna & 0.708 & -0.573 & 0.401 & 0.035 & & & & \\
& $(0.922)$ & $(-1.639)$ & $(0.668)$ & $(0.092)$ & & & & \\
HHI & & & & & $16.580^{* *}$ & 1.890 & 7.926 & 1.244 \\
& & & & & $(2.144)$ & $(0.382)$ & $(0.996)$ & $(0.218)$ \\
Constant & $-17.500^{* * *}$ & $-10.750^{* * *}$ & $-14.420^{* * *}$ & $-11.880^{* * *}$ & $-17.500^{* * *}$ & $-10.770^{* * *}$ & $-14.580^{* * *}$ & $-12.040^{* * *}$ \\
& $(-4.646)$ & $(-7.601)$ & $(-7.800)$ & $(-18.640)$ & $(-4.625)$ & $(-7.600)$ & $(-7.413)$ & $(-18.550)$ \\
Year FE & Yes & Yes & Yes & Yes & Yes & Yes & Yes & Yes \\
Observations & 154,000 & 154,000 & 62,000 & 62,000 & 154,000 & 154,000 & 62,000 & 62,000 \\
\hline
\end{tabular}

Panel B: Predicted IPO and ACQ Probabilities for Pre- and Post-regulation Eras

\begin{tabular}{lccc}
\hline & Pre-regulation Probability & Post-regulation Probability & T-test \\
\cline { 2 - 4 } IPO & 1.367 & 3.509 & 42.82 \\
ACQ & 1.458 & 7.083 & 48.96 \\
\hline
\end{tabular}


Table 5: The Changing Impact of Exit Decision Determinants from Pre- to Post-regulation periods This table presents the multinomial logit regressions of exit choices on the interactions of firm, industry, and state characteristics with the PostReg, a dummy variable that equals one if the year of an observation is between 2004 and 2006, and equals zero if the year of the observation is between 2001 and 2003. The dependent variable is a categorical variable that equals zero if a firm remains private in year $t$, equals one if a firm gets acquired in year $t$, and equals two if a firm goes public in year $t$. Columns (1) and (3) compare the exit decision of IPO to remaining private, and Columns (2) and (4) compare the exit decision of getting acquired to remaining private. All the independent variables are defined in Appendix B. All columns include year fixed effects. Robust z-statistics, clustered by three-digit NAICS industry, are reported in parentheses. ${ }^{*}, * *$, and $* * *$ represent statistical significance from the omitted category (remaining private) at the $10 \%, 5 \%$, and $1 \%$ levels, respectively. "N/A" denotes coefficients that cannot be reported due to the disclosure rules of the Census.

\begin{tabular}{|c|c|c|c|c|}
\hline & $I P O$ & $A C Q$ & $I P O$ & $A C Q$ \\
\hline & $(1)$ & $(2)$ & (3) & (4) \\
\hline \multirow[t]{2}{*}{ TFP $\times$ PostReg } & $0.769^{*}$ & -0.191 & 0.791 & -0.196 \\
\hline & $(1.659)$ & $(-0.499)$ & $(1.645)$ & $(-0.511)$ \\
\hline \multirow[t]{2}{*}{ LnSales $\times$ PostReg } & -0.118 & 0.089 & -0.125 & 0.101 \\
\hline & $(-0.315)$ & $(0.508)$ & $(-0.334)$ & $(0.576)$ \\
\hline \multirow[t]{2}{*}{ LnAge $\times$ PostReg } & $0.777 * *$ & 0.355 & $0.793 * *$ & 0.346 \\
\hline & $(2.353)$ & $(1.362)$ & $(2.434)$ & $(1.334)$ \\
\hline \multirow[t]{2}{*}{ CapInt $\times$ PostReg } & 3.081 & 1.096 & 2.777 & 1.189 \\
\hline & $(1.487)$ & $(0.732)$ & $(1.474)$ & $(0.806)$ \\
\hline \multirow[t]{2}{*}{ Capex $\times$ PostReg } & -1.482 & 0.264 & -1.566 & 0.252 \\
\hline & $(-1.136)$ & $(0.362)$ & $(-1.298)$ & $(0.348)$ \\
\hline \multirow[t]{2}{*}{ MktShr $\times$ PostReg } & -0.504 & 0.115 & -0.426 & 0.092 \\
\hline & $(-1.492)$ & $(0.455)$ & $(-1.263)$ & $(0.348)$ \\
\hline \multirow[t]{2}{*}{ WhiteProp $\times$ PostReg } & $-1.956 * *$ & $-1.542 * *$ & $-1.901 * *$ & $-1.477 * *$ \\
\hline & $(-2.016)$ & $(-2.482)$ & $(-2.020)$ & $(-2.399)$ \\
\hline \multirow[t]{2}{*}{$V C \times P o s t R e g$} & N/A & 0.507 & N/A & 0.495 \\
\hline & N/A & $(1.308)$ & $\mathrm{N} / \mathrm{A}$ & $(1.281)$ \\
\hline \multirow[t]{2}{*}{ LnNumSeg $\times$ PostReg } & -0.449 & $-0.707 * *$ & -0.448 & $-0.707 * *$ \\
\hline & $(-0.886)$ & $(-2.134)$ & $(-0.867)$ & $(-2.145)$ \\
\hline \multirow[t]{2}{*}{ VCFracSt $\times$ PostReg } & -0.587 & 1.767 & -0.480 & 1.619 \\
\hline & $(-0.049)$ & $(0.497)$ & $(-0.044)$ & $(0.447)$ \\
\hline \multirow[t]{2}{*}{ VCFracInd $\times$ PostReg } & 6.915 & 2.194 & 6.500 & $3.668^{*}$ \\
\hline & $(1.263)$ & $(0.857)$ & $(1.069)$ & $(1.854)$ \\
\hline \multirow[t]{2}{*}{ HighTech $\times$ PostReg } & N/A & N/A & $\mathrm{N} / \mathrm{A}$ & N/A \\
\hline & N/A & N/A & $\mathrm{N} / \mathrm{A}$ & N/A \\
\hline \multirow[t]{2}{*}{ LnNumAna $\times$ PostReg } & -0.397 & 0.654 & & \\
\hline & $(-0.516)$ & $(1.141)$ & & \\
\hline \multirow[t]{2}{*}{$H H I$} & & & -7.084 & 1.821 \\
\hline & & & $(-0.977)$ & $(0.170)$ \\
\hline \multirow[t]{2}{*}{$T F P$} & 0.128 & -0.134 & 0.146 & -0.124 \\
\hline & $(0.573)$ & $(-0.381)$ & $(0.621)$ & $(-0.348)$ \\
\hline
\end{tabular}




\begin{tabular}{|c|c|c|c|c|}
\hline & $I P O$ & $A C Q$ & $I P O$ & $A C Q$ \\
\hline & (1) & (2) & (3) & (4) \\
\hline \multirow[t]{2}{*}{ LnSales } & $0.741^{*}$ & $0.303 * *$ & $0.744 *$ & $0.290 * *$ \\
\hline & (1.919) & $(2.074)$ & (1.906) & (1.987) \\
\hline \multirow[t]{2}{*}{ LnAge } & $-1.046 * * *$ & $-0.475 * * *$ & $-1.046 * * *$ & $-0.465 * * *$ \\
\hline & $(-4.786)$ & $(-2.878)$ & $(-4.982)$ & $(-2.826)$ \\
\hline \multirow[t]{2}{*}{ CapInt } & -2.345 & $-1.516^{*}$ & -2.033 & $-1.617^{*}$ \\
\hline & $(-1.564)$ & $(-1.727)$ & $(-1.460)$ & $(-1.832)$ \\
\hline \multirow{2}{*}{ Capex } & 0.210 & 0.514 & 0.283 & 0.522 \\
\hline & $(0.340)$ & $(0.842)$ & $(0.488)$ & $(0.857)$ \\
\hline \multirow[t]{2}{*}{ MktShr } & 0.290 & -0.140 & 0.193 & -0.123 \\
\hline & $(0.865)$ & $(-0.608)$ & $(0.576)$ & $(-0.534)$ \\
\hline \multirow[t]{2}{*}{ WhiteProp } & $2.462 *$ & $1.514 * * *$ & $2.513 * *$ & $1.459 * * *$ \\
\hline & (1.930) & $(3.425)$ & $(2.216)$ & $(3.195)$ \\
\hline \multirow[t]{2}{*}{$V C$} & $3.193 * * *$ & $1.182 * * *$ & $3.232 * * *$ & $1.193 * * *$ \\
\hline & $(6.378)$ & $(2.965)$ & $(6.376)$ & (2.984) \\
\hline \multirow[t]{2}{*}{ LnNumSeg } & 0.532 & $1.163 * * *$ & 0.531 & $1.164 * * *$ \\
\hline & $(0.929)$ & $(3.663)$ & $(0.900)$ & $(3.678)$ \\
\hline \multirow[t]{2}{*}{ VCFracSt } & -2.019 & $6.900 * * *$ & -2.417 & $7.009 * * *$ \\
\hline & $(-0.244)$ & $(2.987)$ & $(-0.322)$ & $(3.031)$ \\
\hline \multirow[t]{2}{*}{ VCFracInd } & -4.012 & $3.795 * *$ & -2.700 & 2.423 \\
\hline & $(-0.718)$ & $(2.243)$ & $(-0.461)$ & $(1.480)$ \\
\hline \multirow[t]{2}{*}{ HighTech } & N/A & N/A & N/A & N/A \\
\hline & N/A & N/A & N/A & N/A \\
\hline \multirow[t]{2}{*}{ LnNumAna } & 1.118 & -0.573 & & \\
\hline & (1.394) & $(-1.640)$ & & \\
\hline \multirow[t]{2}{*}{$H H I$} & & & $16.330^{* *}$ & -0.316 \\
\hline & & & $(2.247)$ & $(-0.039)$ \\
\hline \multirow[t]{2}{*}{ Constant } & $-17.470 * * *$ & $-10.750 * * *$ & $-16.930 * * *$ & $-11.130 * * *$ \\
\hline & $(-4.620)$ & $(-7.605)$ & $(-4.359)$ & $(-7.951)$ \\
\hline Year FE & Yes & Yes & Yes & Yes \\
\hline Industry FE & No & No & No & No \\
\hline State FE & No & No & No & No \\
\hline Observations & 216,000 & 216,000 & 216,000 & 216,000 \\
\hline
\end{tabular}


Table 6: Difference-in-differences Tests on the Predicted IPO and Acquisition Probabilities from Multinomial Logit Regressions

This table reports the difference-in-differences (DiD) tests on the predicted IPO and acquisition probabilities from multinomial logit regressions estimated on various subsamples and time periods (i.e., pre-2000 or post-2000 eras). The full sample period is 1990-2014. For each variable of interest, we sort the full regression sample into four subsamples based on whether the value of the variable is above or below the median and whether the year of the observation if before or after 2000 (1990-2000 vs. 2001-2014). After that, we estimate the multinomial logit regression specified by Equation (1) for each of the four subsamples separately and obtain four sets of regression coefficients. We then choose one of the two subsamples in the pre-2000 era as the "base group" and calculate four predicted probabilities (each for IPOs and acquisitions) by applying the four sets of estimated regression coefficients to the characteristics of firms in this base group. For Panels A to F, we use the firms in the industries with more competition (low $H H I$ ), single-segment firms, firms in the states with high VC coverage, firms in the industries with high VC coverage, firms in the industries with more information asymmetry (low analyst coverage), and high-tech firms as the base group, respectively. In each panel, we present the four calculated probabilities, the differences between the post-2000 and the pre-2000 probabilities (with t-statistics in parentheses), and the DiD estimators calculated as the differences between the two differences (with t-statistics in parentheses). All the numbers (except for t-statistics) are multiplied by $10^{4}$ to ease reading.

Panel A: Predicted IPO/ACQ Probabilities by Industry Concentration

\begin{tabular}{lcccc}
\hline \multicolumn{5}{c}{ IPO Probabilities } \\
\hline High $H H I$ & Pre-2000 & Post-2000 & Diff (Post-Pre) & DiD \\
Low $H H I$ & 4.180 & 0.166 & $-4.014(-109.000)$ & \multirow{2}{*}{$-0.475(-9.454)$} \\
\hline \multicolumn{5}{c}{ ACQ Probabilities } \\
\hline High $H H I$ & 4.489 & $<0.001$ & $-4.489(-69.830)$ & DiD \\
Low $H H I$ & Pre-2000 & Post-2000 & Diff (Post-Pre) & \multirow{2}{*}{$2.174(47.650)$} \\
\hline
\end{tabular}

Panel B: Predicted IPO/ACQ Probabilities by Number of Business Segments

IPO Probabilities

\begin{tabular}{lcccc}
\hline & Pre-2000 & Post-2000 & Diff (Post-Pre) & DiD \\
\hline Single-segment & 7.039 & 0.153 & $-6.886(-80.930)$ & \multirow{2}{*}{$2.538(31.000)$} \\
Multi-segment & 6.054 & 1.706 & $-4.438(-142.400)$ & \\
\hline \multicolumn{5}{c}{ ACQ Probabilities } \\
\hline Single-segment & 7.811 & 6.364 & $-1.447(-72.110)$ & \multirow{2}{*}{$0.477(15.200)$} \\
Multi-segment & 10.980 & 10.010 & $-0.970(-43.760)$ & \\
\hline
\end{tabular}

Panel C: Predicted IPO/ACQ Probabilities by State-level VC Investments IPO Probabilities

\begin{tabular}{lcccc}
\hline & Pre-2000 & Post-2000 & Diff (Post-Pre) & DiD \\
\hline High VCFracSt & 11.200 & 0.679 & $-10.521(-75.270)$ & \multirow{2}{*}{$2.030(25.950)$} \\
Low VCFracSt & 8.491 & $<0.001$ & $-8.491(-61.82)$ & \\
\hline
\end{tabular}


ACQ Probabilities

\begin{tabular}{lcccc}
\hline \multicolumn{5}{c}{ ACQ Probabilities } \\
\hline & Pre-2000 & Post-2000 & Diff (Post-Pre) & DiD \\
\hline High VCFracSt & 11.880 & 6.419 & $-5.461(-104.900)$ & $14.904(93.840)$ \\
Low VCFracSt & 8.977 & 18.420 & $9.443(76.490)$ & \\
\hline
\end{tabular}

Panel D: Predicted IPO/ACQ Probabilities by Industry-level VC Investments

\begin{tabular}{lcccc}
\hline \multicolumn{5}{c}{ IPO Probabilities } \\
\hline High VCFracInd & 12.680 & 0.546 & $-12.134(-89.940)$ & \multirow{2}{*}{$5.359(37.680)$} \\
Low VCFracInd & 6.775 & $<0.001$ & $-6.775(-57.770)$ & \\
\hline \multicolumn{5}{c}{ ACQ Probabilities } \\
\hline High VCFracInd & Pre-2000 & Post-2000 & Diff (Post-Pre) & DiD \\
Low VCFracInd & 12.570 & 10.730 & $-1.840(-56.290)$ & \multirow{2}{*}{$8.423(58.770)$} \\
\hline
\end{tabular}

Panel E: Predicted IPO/ACQ Probabilities by Industry-level Analyst Coverage

\begin{tabular}{|c|c|c|c|c|}
\hline \multicolumn{5}{|c|}{ IPO Probabilities } \\
\hline & Pre-2000 & Post-2000 & Diff (Post-Pre) & DiD \\
\hline High NumAna & 6.220 & $<0.001$ & $-6.220(-64.530)$ & \multirow{2}{*}{$-0.932(-12.480)$} \\
\hline Low NumAna & 7.720 & 0.568 & $-7.152(-51.860)$ & \\
\hline \multicolumn{5}{|c|}{ ACQ Probabilities } \\
\hline & Pre-2000 & Post-2000 & Diff (Post-Pre) & DiD \\
\hline High NumAna & 7.976 & 6.624 & $-1.352(-51.590)$ & \multirow{2}{*}{$1.934(36.380)$} \\
\hline Low NumAna & 8.538 & 9.120 & $0.582(9.739)$ & \\
\hline
\end{tabular}

Panel F: Predicted IPO/ACQ Probabilities by Whether Industry is High Tech IPO Probabilities

\begin{tabular}{lcccc}
\hline & Pre-2000 & Post-2000 & Diff (Post-Pre) & DiD \\
\hline HighTech & 123.800 & $<0.001$ & $-123.800(-29.080)$ & \multirow{2}{*}{$42.288(12.940)$} \\
Non-HighTech & 85.190 & 3.678 & $-81.512(-23.790)$ & \\
\hline \multicolumn{5}{c}{ ACQ Probabilities } \\
\hline HighTech & Pre-2000 & Post-2000 & Diff (Post-Pre) & DiD \\
Non-HighTech & 65.330 & $<0.001$ & $-65.330(-40.880)$ & \multirow{2}{*}{$65.160(37.720)$} \\
\hline
\end{tabular}


Table 7: TFP of IPO, Acquired, and Private Firms: Multivariate Analyses

This table presents the OLS regressions of TFP on a private firm's exit choices in a given year (i.e., goes public, gets acquired, or remains private), the interactions between exit choices and the Post2000 dummy variable, and control variables at the firm, industry, and state levels. The dependent variable, TFP, is a firm's total factor productivity in year $t$. IPO $(A C Q)$ is a dummy variable that equals one if the firm goes public (gets acquired) in year $t$. Post 2000 is a dummy variable that equals one if the year of an observation is equal to or later than 2000, and zero otherwise. All other variables are defined in Appendix B. Columns (1) and (2) include year fixed effects; Columns (3) and (4) include year fixed effects and industry fixed effects; Column (5) includes industry $\times$ year fixed effects. We report the F-tests and the corresponding pvalues for the differences between the coefficients of IPO $\times$ Post 2000 and ACQ $\times$ Post 2000 in each regression. Robust t-statistics, clustered by three-digit NAICS industry, are reported in parentheses. *, **, and $* * *$ represent statistical significance at the $10 \%, 5 \%$, and $1 \%$ levels, respectively.

\begin{tabular}{|c|c|c|c|c|c|}
\hline & \multicolumn{5}{|c|}{ Dependent Variable: TFP } \\
\hline & $(1)$ & $(2)$ & (3) & $(4)$ & $(5)$ \\
\hline \multirow[t]{2}{*}{$I P O \times$ Post 2000} & $0.122 * * *$ & $0.117 * *$ & $0.125 * * *$ & $0.121 * * *$ & $0.128 * * *$ \\
\hline & $(2.693)$ & $(2.668)$ & $(2.841)$ & $(2.724)$ & $(3.011)$ \\
\hline \multirow[t]{2}{*}{$I P O$} & -0.025 & -0.023 & -0.041 & -0.038 & -0.041 \\
\hline & $(-0.636)$ & $(-0.557)$ & $(-1.049)$ & $(-0.961)$ & $(-1.145)$ \\
\hline \multirow[t]{2}{*}{$A C Q \times$ Post 2000} & 0.037 & 0.034 & 0.037 & 0.035 & 0.035 \\
\hline & $(1.196)$ & $(1.081)$ & $(1.184)$ & $(1.123)$ & $(1.191)$ \\
\hline \multirow[t]{2}{*}{$A C Q$} & -0.038 & -0.037 & $-0.044 *$ & $-0.043 *$ & $-0.043 * *$ \\
\hline & $(-1.624)$ & $(-1.532)$ & $(-1.935)$ & $(-1.857)$ & $(-2.029)$ \\
\hline \multirow[t]{2}{*}{ LnSales } & $0.100 * * *$ & $0.100 * * *$ & $0.109 * * *$ & $0.109 * * *$ & $0.111 * * *$ \\
\hline & $(13.040)$ & $(12.380)$ & $(13.960)$ & $(13.860)$ & $(15.240)$ \\
\hline \multirow[t]{2}{*}{ LnAge } & $-0.072 * * *$ & $-0.072 * * *$ & $-0.075^{* * *}$ & $-0.075^{* * *}$ & $-0.076 * * *$ \\
\hline & $(-39.440)$ & $(-35.850)$ & $(-36.710)$ & $(-37.130)$ & $(-35.420)$ \\
\hline \multirow[t]{2}{*}{ CapInt } & $-0.339 * * *$ & $-0.330 * * *$ & $-0.280 * * *$ & $-0.278 * * *$ & $-0.287 * * *$ \\
\hline & $(-6.119)$ & $(-5.919)$ & $(-4.982)$ & $(-4.968)$ & $(-5.097)$ \\
\hline \multirow[t]{2}{*}{ Capex } & $0.462 * * *$ & $0.463 * * *$ & $0.455^{* * *}$ & $0.456 * * *$ & $0.459 * * *$ \\
\hline & (19.130) & (19.140) & $(19.470)$ & $(19.400)$ & (19.400) \\
\hline \multirow[t]{2}{*}{ MktShr } & $0.037 * *$ & $0.044 * *$ & $0.031^{*}$ & $0.032 *$ & $0.029 *$ \\
\hline & $(2.116)$ & $(2.479)$ & (1.738) & (1.744) & $(1.737)$ \\
\hline \multirow[t]{2}{*}{ WhiteProp } & $-0.225 * * *$ & $-0.223 * * *$ & $-0.245^{* * *}$ & $-0.244 * * *$ & $-0.248 * * *$ \\
\hline & $(-13.560)$ & $(-14.220)$ & $(-16.870)$ & $(-16.860)$ & $(-17.890)$ \\
\hline \multirow[t]{2}{*}{$V C$} & $-0.027 * * *$ & $-0.027 * * *$ & $-0.035^{* * *}$ & $-0.035^{* * *}$ & $-0.036 * * *$ \\
\hline & $(-3.281)$ & $(-3.165)$ & $(-4.028)$ & $(-4.015)$ & $(-4.436)$ \\
\hline \multirow[t]{2}{*}{ LnNumSeg } & $-0.013 *$ & $-0.013 * *$ & -0.010 & -0.010 & $-0.012 *$ \\
\hline & $(-1.963)$ & $(-2.045)$ & $(-1.465)$ & $(-1.461)$ & $(-1.760)$ \\
\hline \multirow[t]{2}{*}{ VCFracSt } & $0.474 * * *$ & $0.472 * * *$ & $0.430 * * *$ & $0.428 * * *$ & $0.438 * * *$ \\
\hline & $(3.002)$ & $(3.138)$ & $(3.468)$ & $(3.481)$ & $(3.827)$ \\
\hline \multirow[t]{2}{*}{ VCFracInd } & $-0.612 *$ & $-0.618 *$ & -0.073 & -0.049 & \\
\hline & $(-1.778)$ & $(-2.005)$ & $(-0.369)$ & $(-0.235)$ & \\
\hline HighTech & 0.061 & 0.056 & & & \\
\hline
\end{tabular}




\begin{tabular}{lccccc}
\hline & \multicolumn{5}{c}{ Dependent Variable: TFP } \\
\cline { 2 - 5 } & $(1)$ & $(2)$ & $(3)$ & $(4)$ & $(5)$ \\
\hline \multirow{4}{*}{ LnNumAna } & $(1.578)$ & $(1.574)$ & & \\
& -0.059 & & $-0.035^{* *}$ & & \\
HHI & $(-1.315)$ & & $(-2.310)$ & & \\
& & $-0.913^{* * *}$ & & 0.083 & \\
Constant & & $(-3.064)$ & & $(0.312)$ & \\
& $-0.539 * * *$ & $-0.592^{* * *}$ & $-0.638^{* * *}$ & $-0.681 * * *$ & $-0.698^{* * *}$ \\
& $(-6.194)$ & $(-9.462)$ & $(-8.991)$ & $(-11.090)$ & $(-12.030)$ \\
F-test & & & & \\
P-value & 5.060 & 5.409 & 6.328 & 6.067 & 7.072 \\
Year FE & 0.029 & 0.024 & 0.015 & 0.017 & 0.010 \\
Industry FE & Yes & Yes & Yes & Yes & No \\
Industry $\times$ Year FE & No & No & Yes & Yes & No \\
Observations & No & No & No & No & Yes \\
R-squared & 999,000 & 999,000 & 999,000 & 999,000 & 999,000 \\
\hline
\end{tabular}




\section{Table 8: Post-exit Long-term TFP for IPO and Matched Private Firms}

This table presents the OLS regressions of firms' post-exit long-term total factor productivity (TFP) on $I P O$, the interaction between IPO and the Post2000 dummy variable, and other control variables. The sample includes IPO firms and matched private firms with non-missing TFP data within three years after the IPO. For each firm that goes public in a given year during our sample period, we first find remainingprivate firms that operate in the same state and the same industry (at the three-digit NAICS level), as well as have the same VC-backing status as the IPO firm in that year. Further, we require the size (in terms of sales) of the matched firms to be within 0.5 and 2 times of the size of the IPO firm. Finally, among the above set of matched firms, we choose the one with the closest TFP to the IPO firm. We run the regressions separately for VC-backed firms and non-VC-backed firms. The dependent variable of Columns (1) and (2) is the three-year average TFP after the IPO. The dependent variable of Columns (3) and (4) is the two-year average TFP after the IPO. IPO is a dummy variable that equals one if the firm goes public in year $t$, and zero if the firm remains private. Post 2000 is a dummy variable that equals one if the year of an observation is later than 2000. All other variables are defined in Appendix B. All regressions include year fixed effects and matched-pair fixed effects. Robust t-statistics, clustered by three-digit NAICS industry, are reported in parentheses. $* * *$, and $* * *$ represent statistical significance at the $10 \%, 5 \%$, and $1 \%$ levels, respectively.

\begin{tabular}{|c|c|c|c|c|}
\hline \multirow[b]{2}{*}{ Subsamples } & \multicolumn{2}{|c|}{ Dep. Var.: TFP3yr } & \multicolumn{2}{|c|}{ Dep. Var.: TFP2yr } \\
\hline & $V C$ & Non-VC & $V C$ & Non-VC \\
\hline & (1) & $(2)$ & (3) & (4) \\
\hline \multirow[t]{2}{*}{$I P O \times$ Post 2000} & $-0.184 * *$ & -0.059 & $-0.244 * *$ & -0.069 \\
\hline & $(-2.188)$ & $(-0.522)$ & $(-2.836)$ & $(-0.580)$ \\
\hline \multirow[t]{2}{*}{$I P O$} & $0.140 * * *$ & -0.003 & $0.165 * * *$ & 0.006 \\
\hline & $(3.069)$ & $(-0.046)$ & $(3.295)$ & $(0.104)$ \\
\hline \multirow[t]{2}{*}{ LnSales } & 0.086 & 0.039 & 0.094 & 0.045 \\
\hline & (1.339) & $(0.591)$ & $(1.652)$ & $(0.637)$ \\
\hline \multirow[t]{2}{*}{ LnAge } & $-0.119 * * *$ & $-0.099 * * *$ & $-0.115^{* * *}$ & $-0.096 * * *$ \\
\hline & $(-8.643)$ & $(-3.165)$ & $(-6.804)$ & $(-2.898)$ \\
\hline \multirow[t]{2}{*}{ CapInt } & -0.091 & 0.281 & -0.149 & 0.273 \\
\hline & $(-0.339)$ & $(1.455)$ & $(-0.463)$ & $(1.125)$ \\
\hline \multirow[t]{2}{*}{ Capex } & 0.049 & $-0.389 * *$ & 0.020 & $-0.432 * * *$ \\
\hline & $(0.204)$ & $(-2.837)$ & $(0.079)$ & $(-3.243)$ \\
\hline \multirow[t]{2}{*}{ MktShr } & 0.132 & -0.026 & 0.136 & -0.028 \\
\hline & $(1.631)$ & $(-0.560)$ & (1.587) & $(-0.653)$ \\
\hline \multirow[t]{2}{*}{ WhiteProp } & -0.250 & -0.092 & -0.215 & $-0.136^{* *}$ \\
\hline & $(-1.402)$ & $(-1.463)$ & $(-1.105)$ & $(-2.103)$ \\
\hline \multirow[t]{2}{*}{ LnNumSeg } & $0.071 * *$ & 0.015 & $0.063 * *$ & 0.019 \\
\hline & $(2.775)$ & $(0.514)$ & $(2.303)$ & $(0.629)$ \\
\hline \multirow[t]{2}{*}{ Constant } & -0.517 & 0.002 & -0.617 & -0.037 \\
\hline & $(-0.786)$ & $(0.003)$ & $(-0.997)$ & $(-0.049)$ \\
\hline Year FE & Yes & Yes & Yes & Yes \\
\hline Matched Pair FE & Yes & Yes & Yes & Yes \\
\hline Observations & 450 & 600 & 450 & 600 \\
\hline R-squared & 0.470 & 0.499 & 0.456 & 0.499 \\
\hline
\end{tabular}


Figure 1: Fraction of IPO/Acquired/Public/Private Firms by Year

This figure shows the fraction of IPO/acquired/public/private firms in the LBD sample from 1990 to 2014. IPO/acquired/public firms are identified by matching LBD data to SDC and Compustat data. The remaining firms are treated as private firms.

Panel A: Fraction of IPO Firms by Year

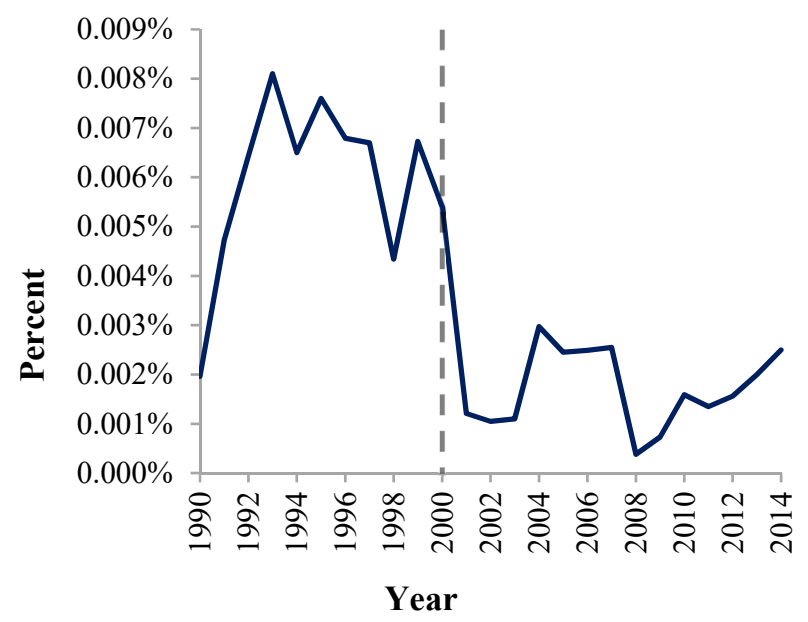

Panel C: Fraction of Private Firms by Year

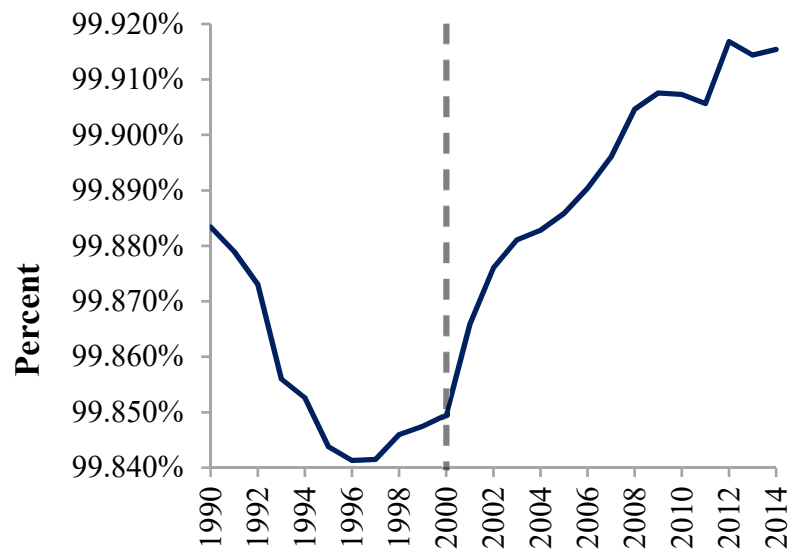

Year

\section{Panel B: Fraction of Public Firms by Year}

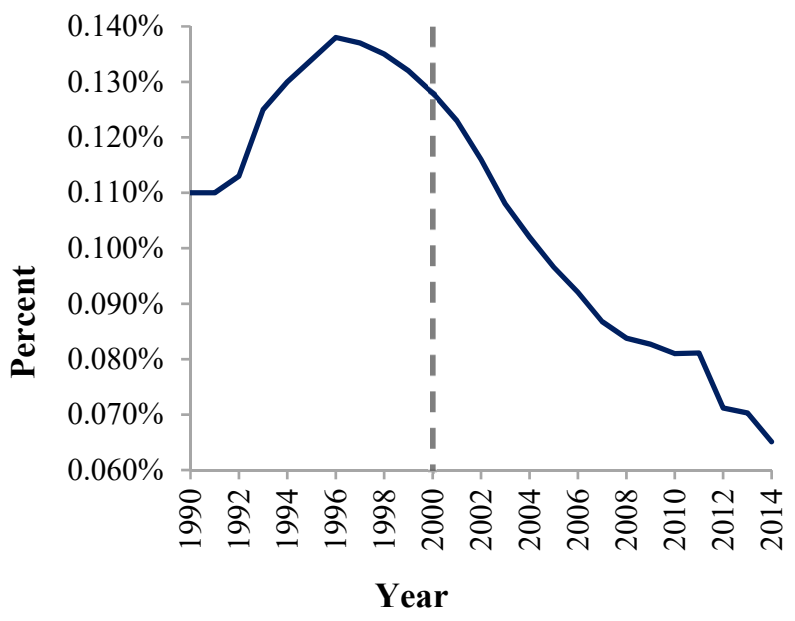

Panel D: Fraction of Acquired Firms by Year

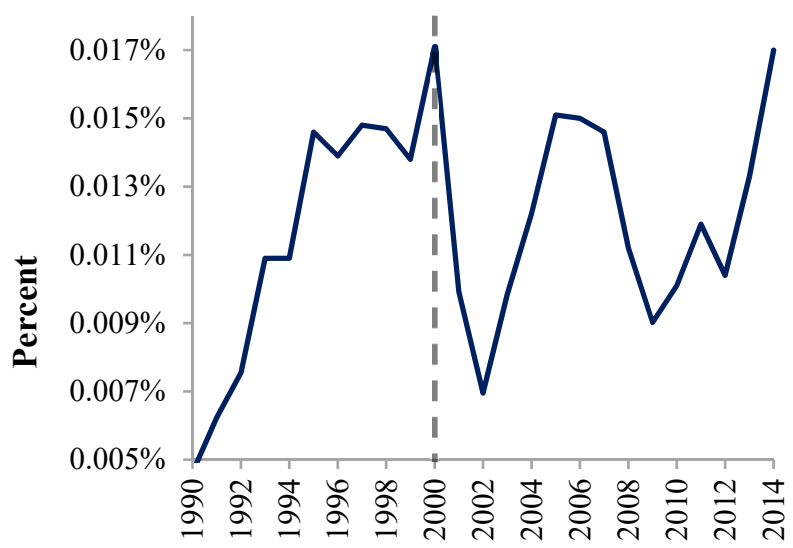

Year 
Figure 2: Raw and Percentage Changes in IPO Propensity from Pre-2000 to Post-2000 Era

This figure shows the raw and percentage changes in IPO propensity in the sample of LBD firms from pre2000 to post-2000 era by various groups of firms. Panels A and B show the raw and percentage changes in IPO propensity by industry (at the two-digit NAICS level). Panels C and D show the raw and percentage changes in IPO propensity by state. The statistics for certain industries and states from LBD data are omitted due to the disclosure requirements of the Census. Panels $\mathrm{E}$ and $\mathrm{F}$ show the raw and percentage changes in IPO propensity by firms with different size (number of employees).

Panel A: Change in IPO Propensity from Pre-2000 to Post-2000 Era by NAICS Industry

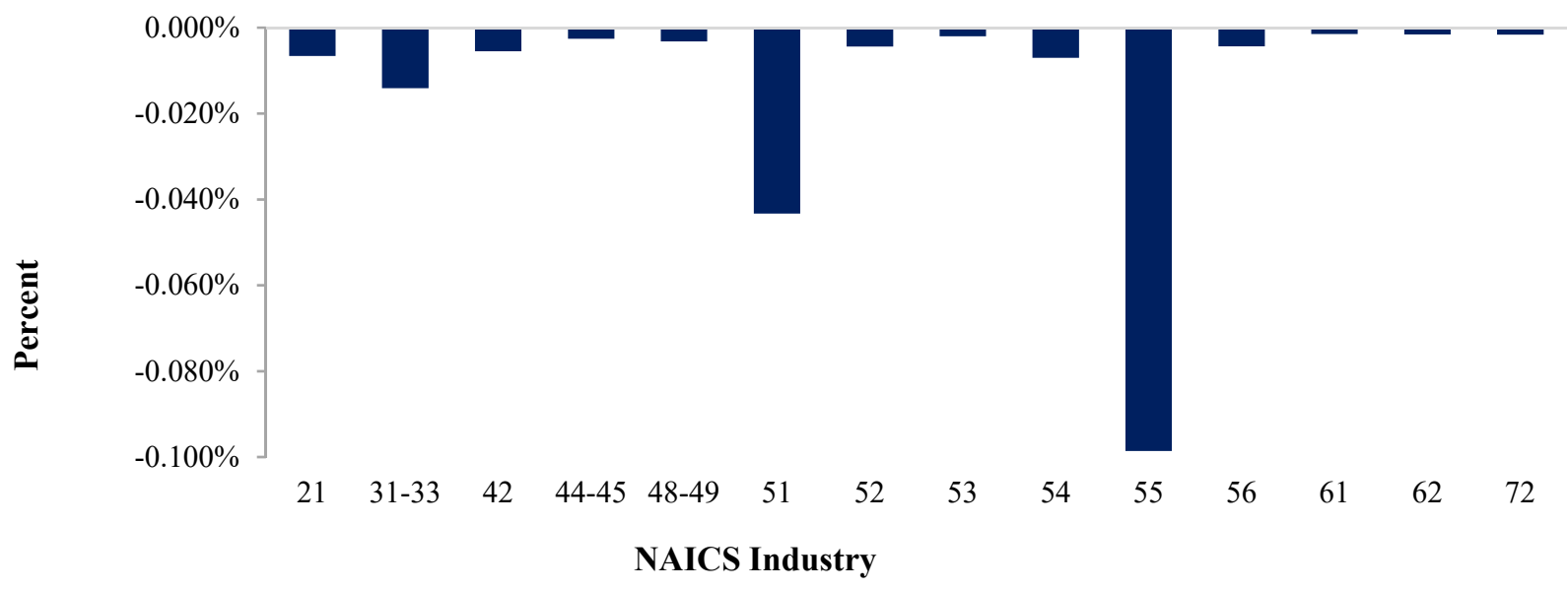

Panel B: Percentage Change in IPO Propensity from Pre-2000 to Post-2000 Era by NAICS Industry

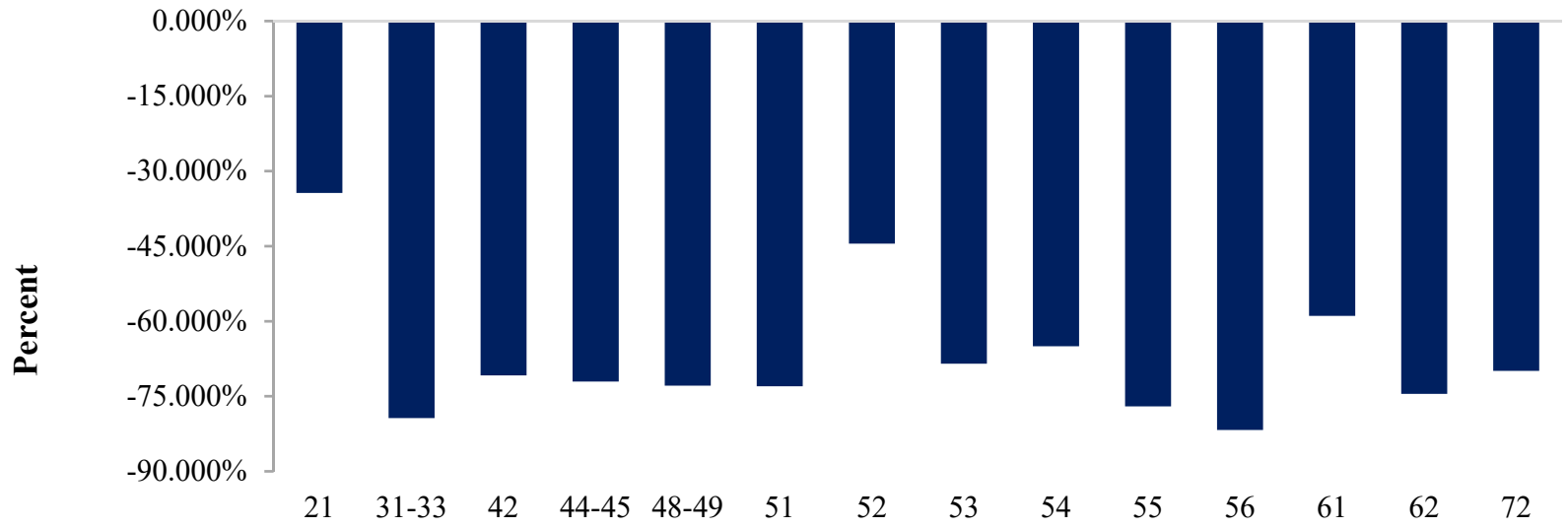

NAICS Industry 
Panel C: Change in IPO Propensity from Pre-2000 to Post-2000 Era by State

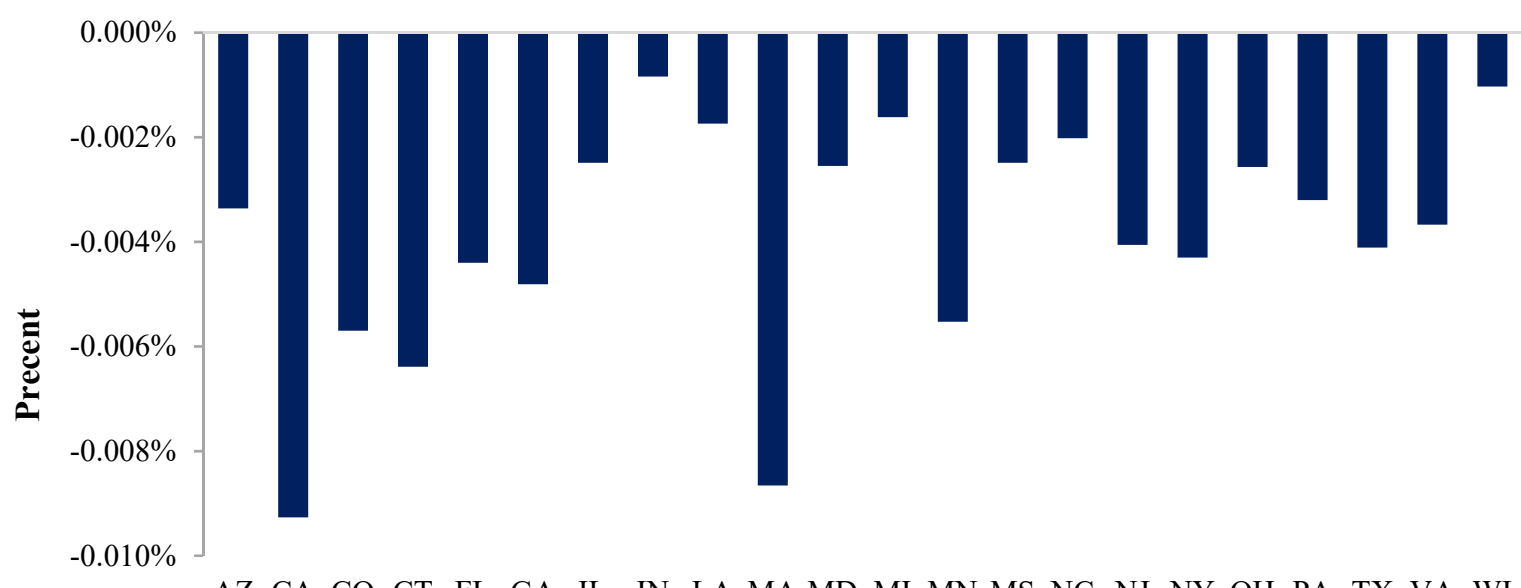

State

Panel D: Percentage Change in IPO Propensity from Pre-2000 to Post-2000 Era by State

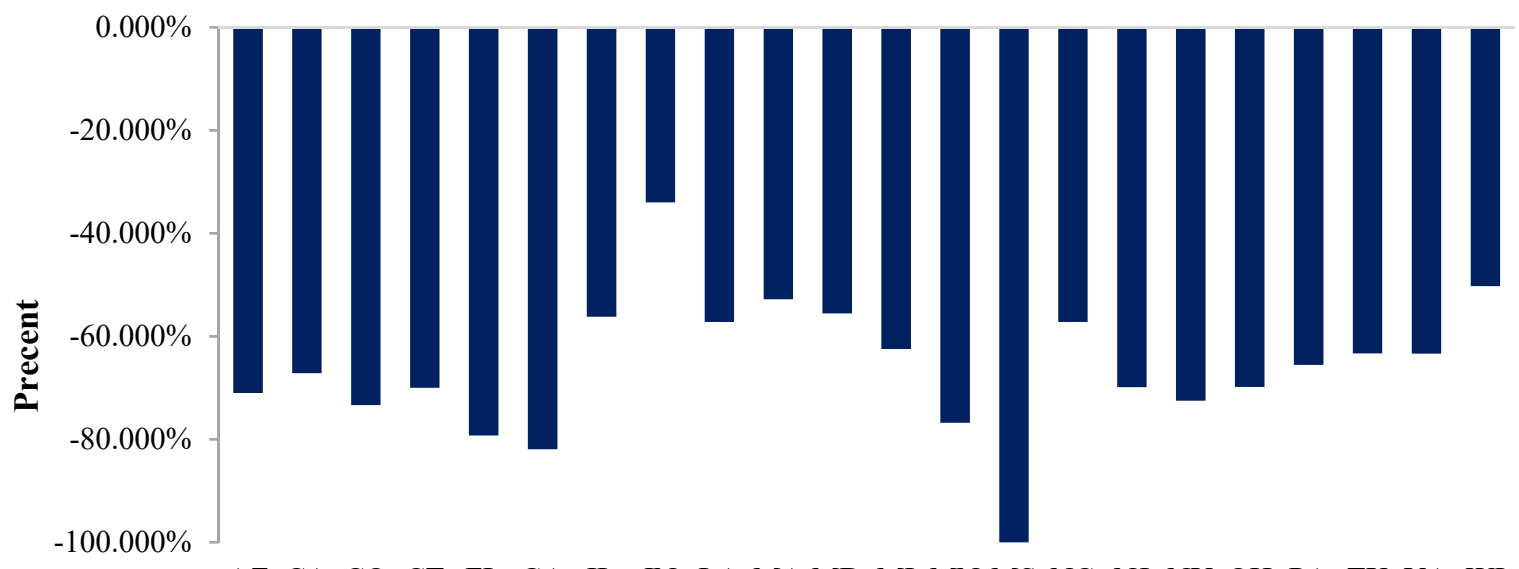

AZ CA CO CT FL GA IL IN LA MA MD MI MN MS NC NJ NY OH PA TX VA WI

State 
Panel E: Change in IPO Propensity from Pre-2000 to Post-2000 Era by Firm Size

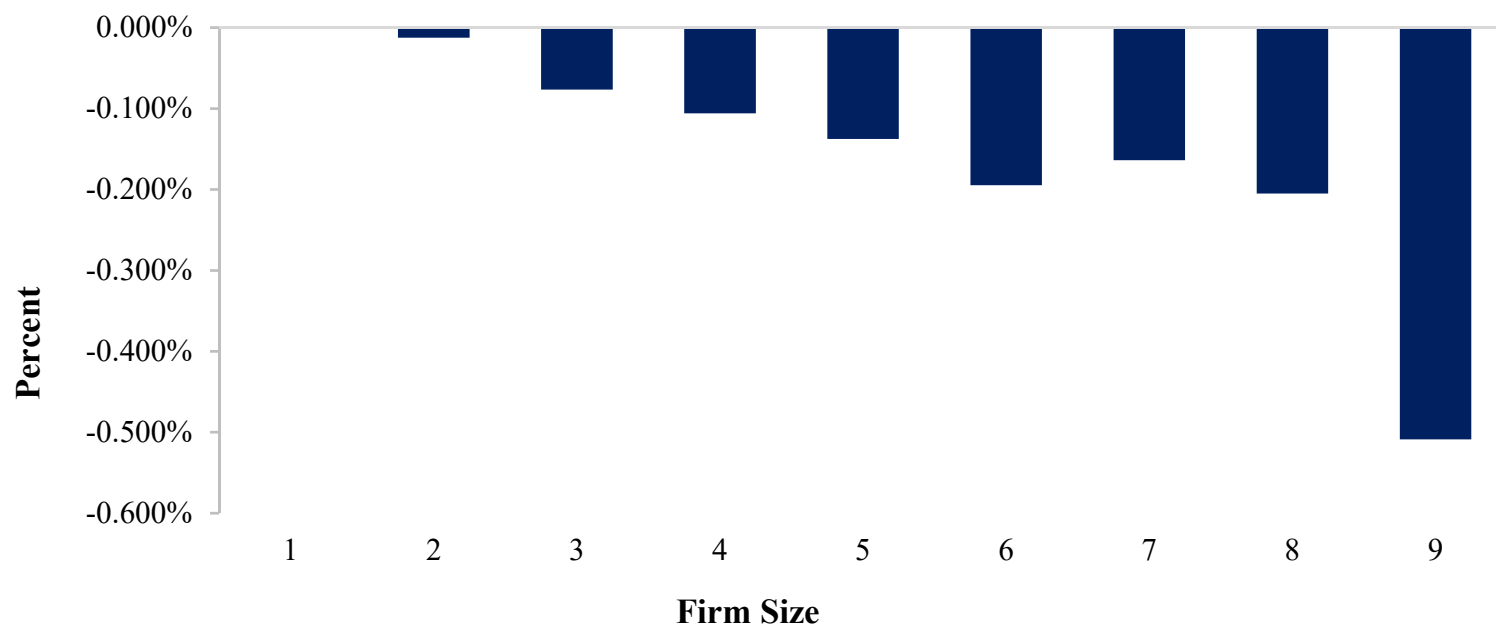

Panel F: Percentage Change in IPO Propensity from Pre-2000 to Post-2000 Era by Firm Size

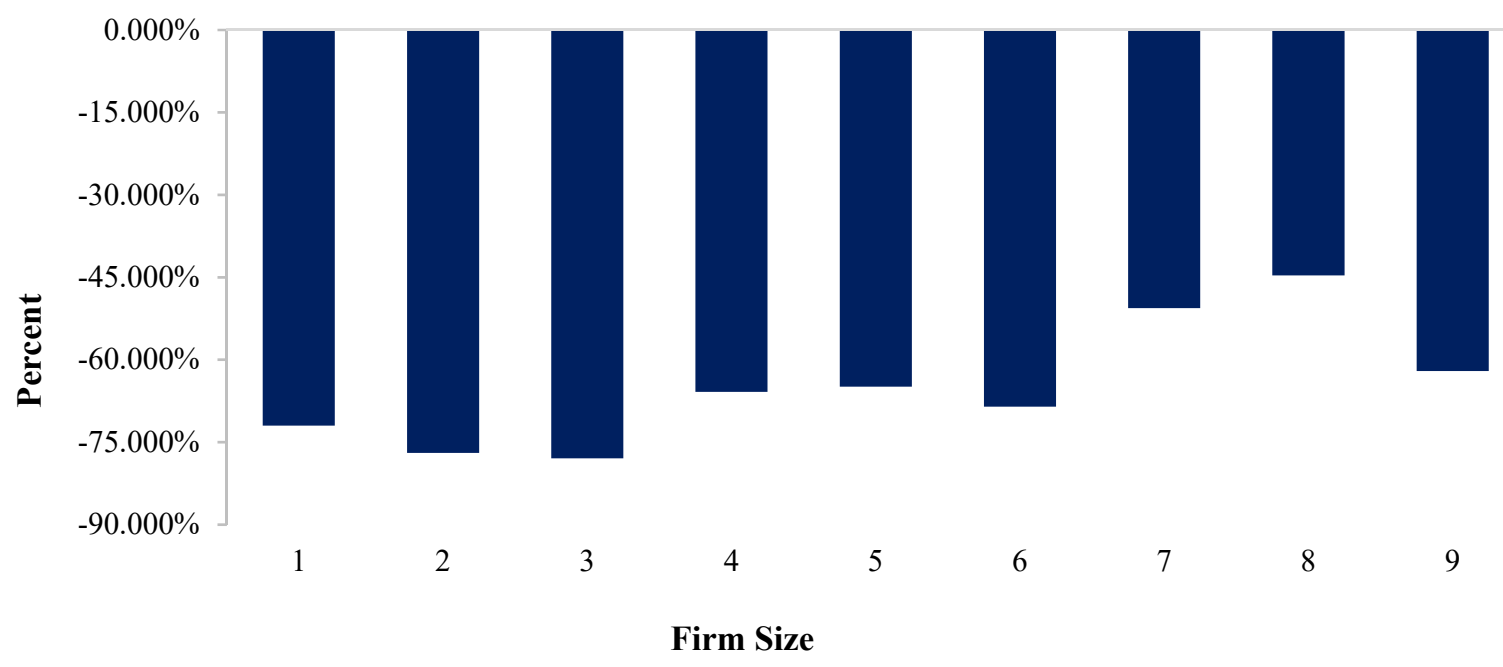


Figure 3: Number of Firms and Fraction of Firms with at Least 200 Employees in the LBD Sample by Year

This figure shows the number of firms and the fraction of firms with at least 200 employees in the LBD sample from 1990 to 2014.

\section{Panel A: Number of LBD Firms by Year}

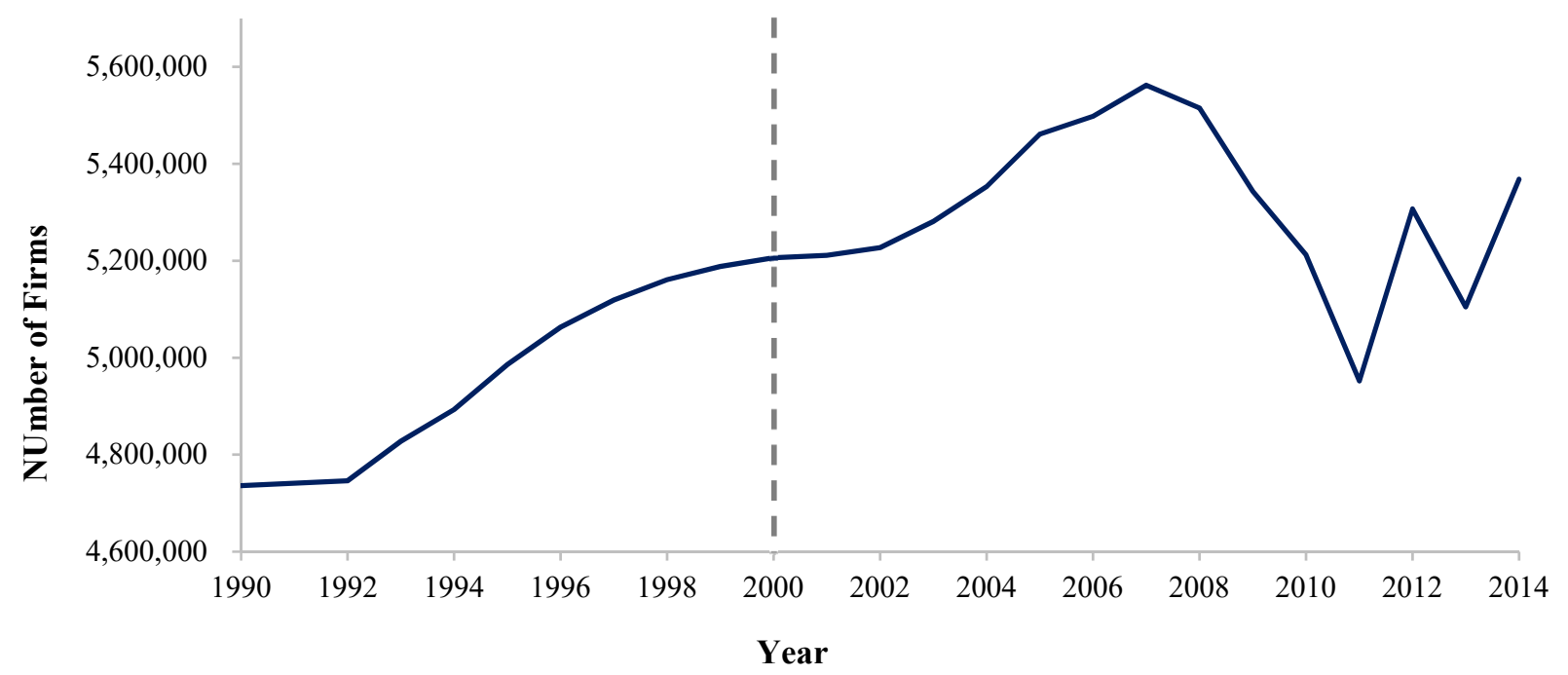

Panel B: Fraction of LBD Firms with at Least 200 Employees by Year

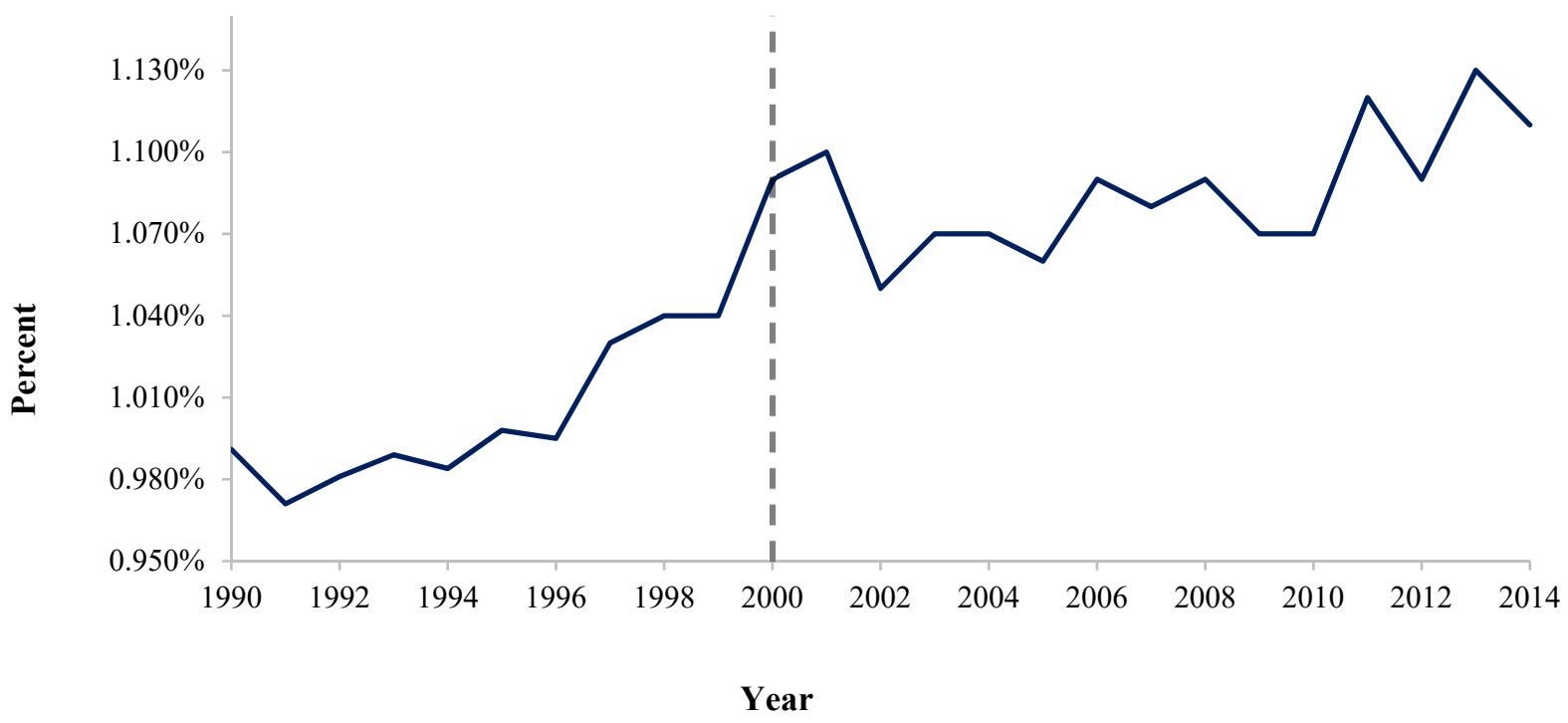


Figure 4: Average TFP/Sales/Sales Growth and Fraction of Manufacturing Firms with High TFP/Sales/Sales Growth by Year

This figure shows the five-year rolling average TFP/sales/sales growth by year (the left vertical axis) as well as the time trend in the fraction of manufacturing firms with TFP greater than 0.05 , sales greater than $\$ 10$ million, or sales growth greater than $15 \%$ (the right vertical axis). Definitions of annual TFP, sales, and sales growth are provided in Appendix A.

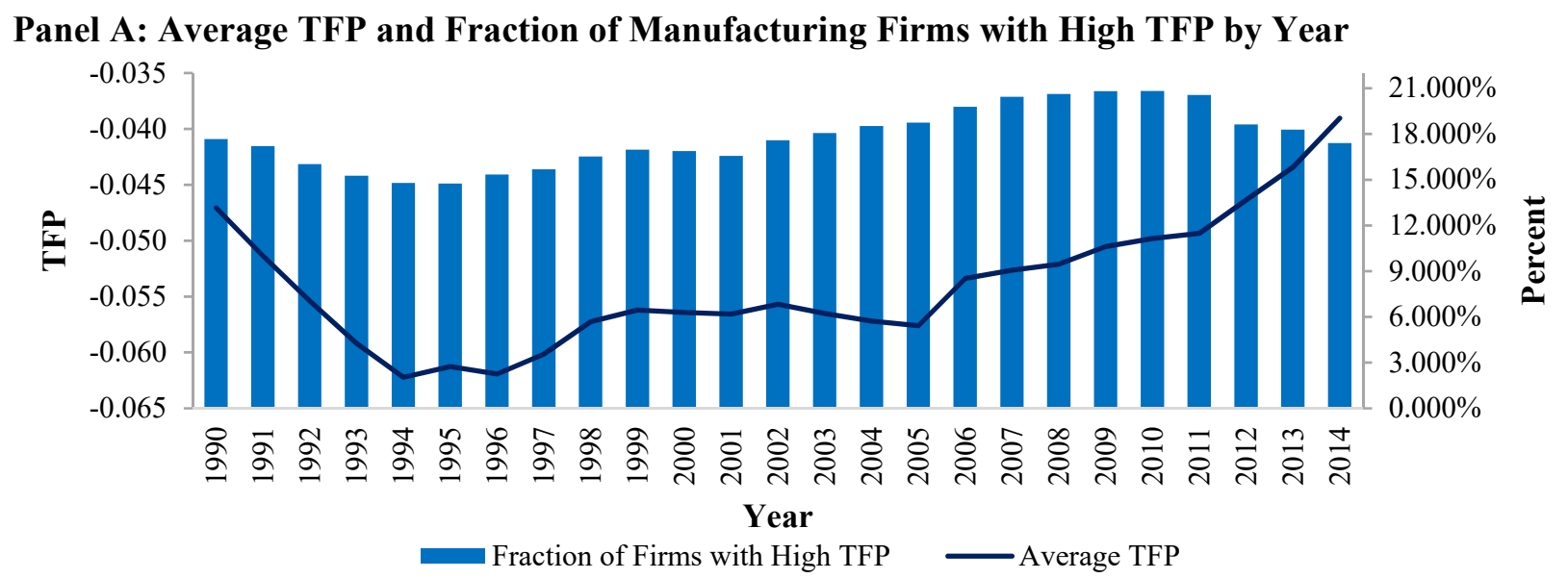

Panel B: Average Sales and Fraction of Manufacturing Firms with High Sales by Year

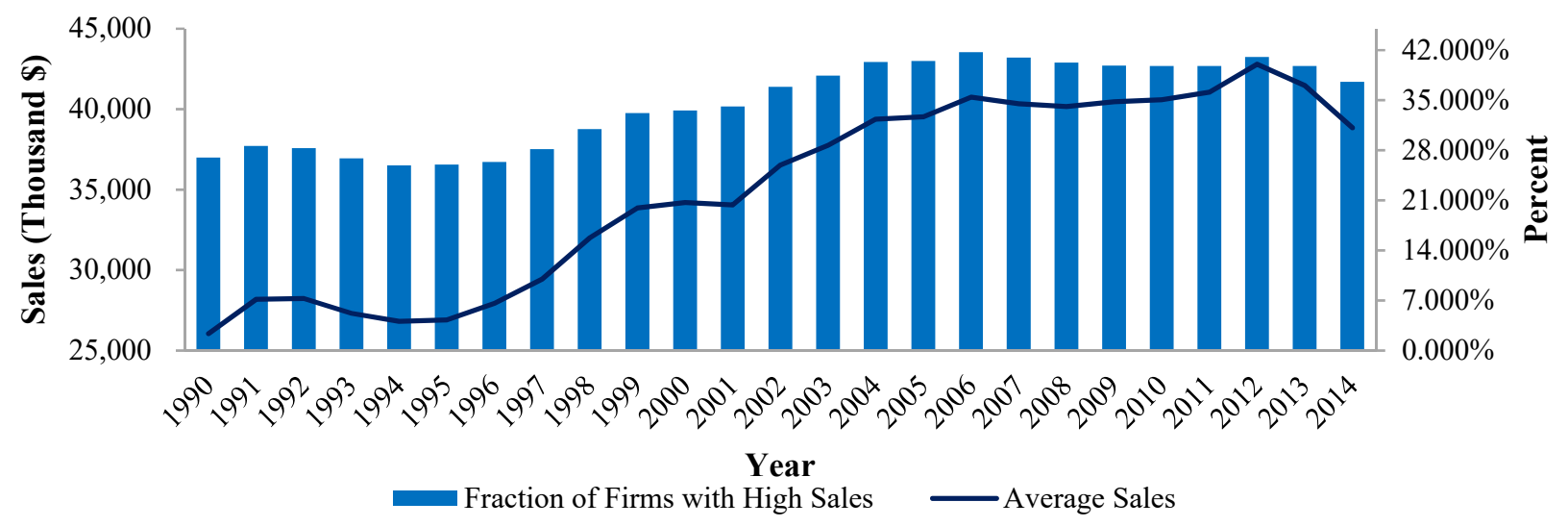

Panel C: Average Sales Growth and Fraction of Manufacturing Firms with High Sales Growth by Year

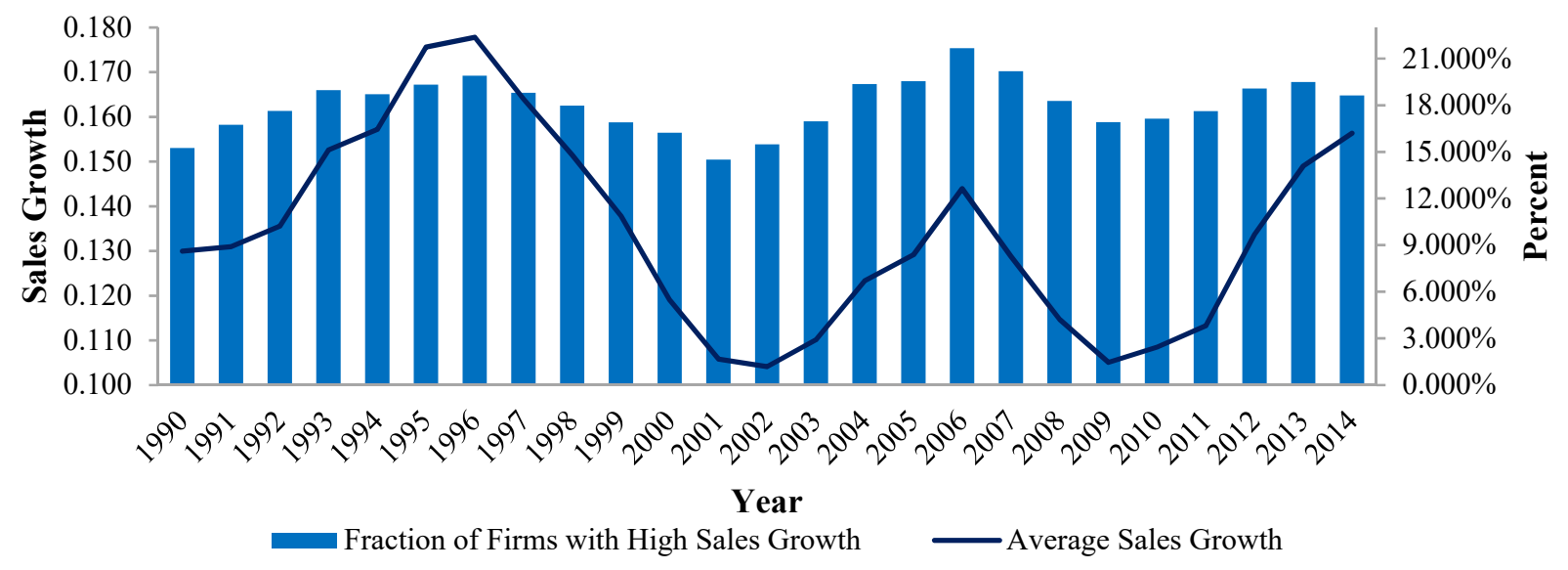


Figure 5: Average Number of Employees of IPO/Acquired/Public/Private Firms in the LBD Sample by Year

This figure shows the five-year rolling average number of employees of IPO/acquired/private firms in the LBD sample from 1990 to 2014. IPO/acquired firms are identified by matching LBD data to SDC and Compustat data. The remaining firms are treated as private firms.

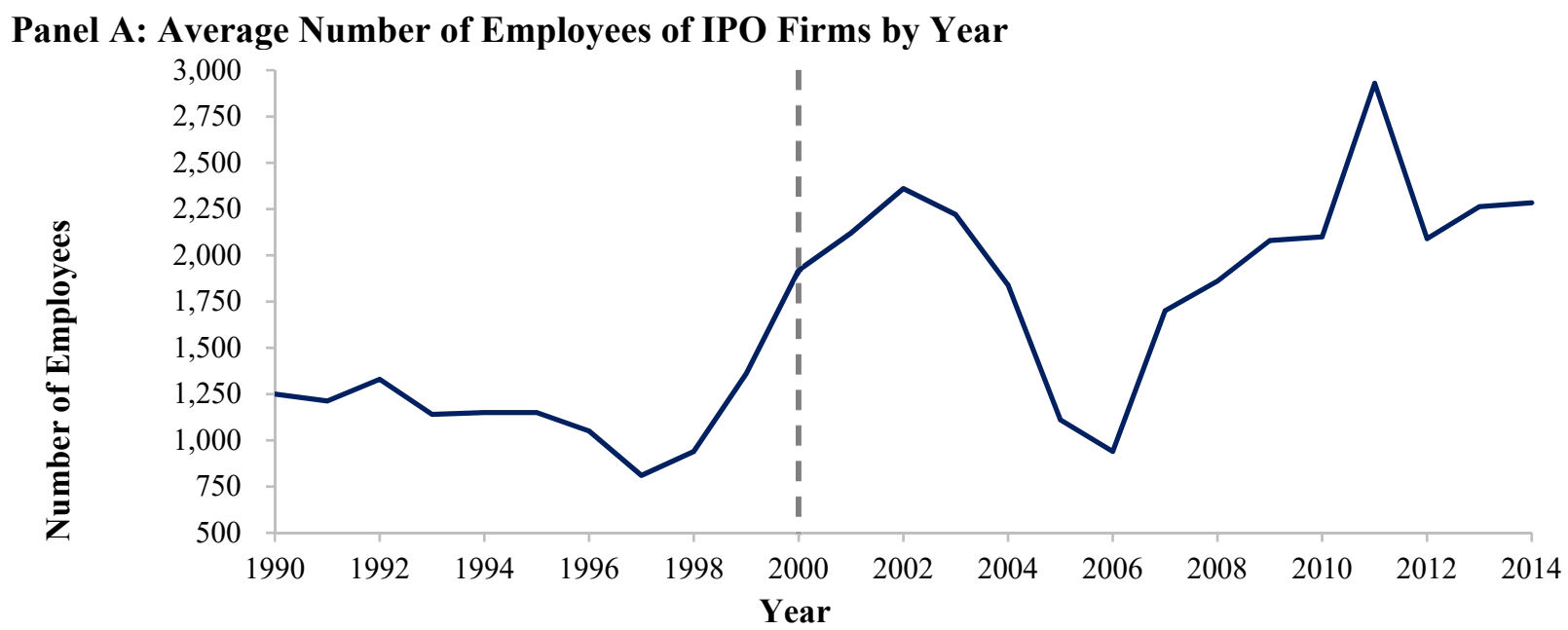

Panel B: Average Number of Employees of Acquired Firms by Year

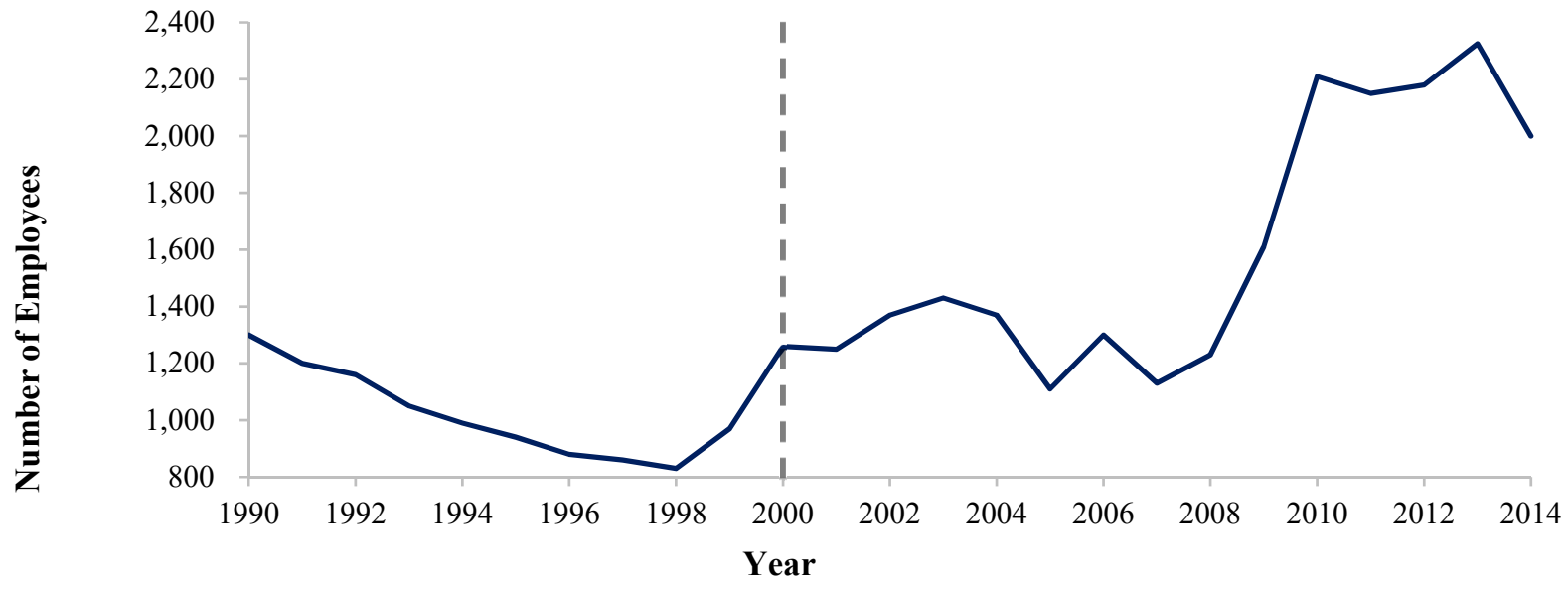

Panel C: Average Number of Employees of Private Firms by Year

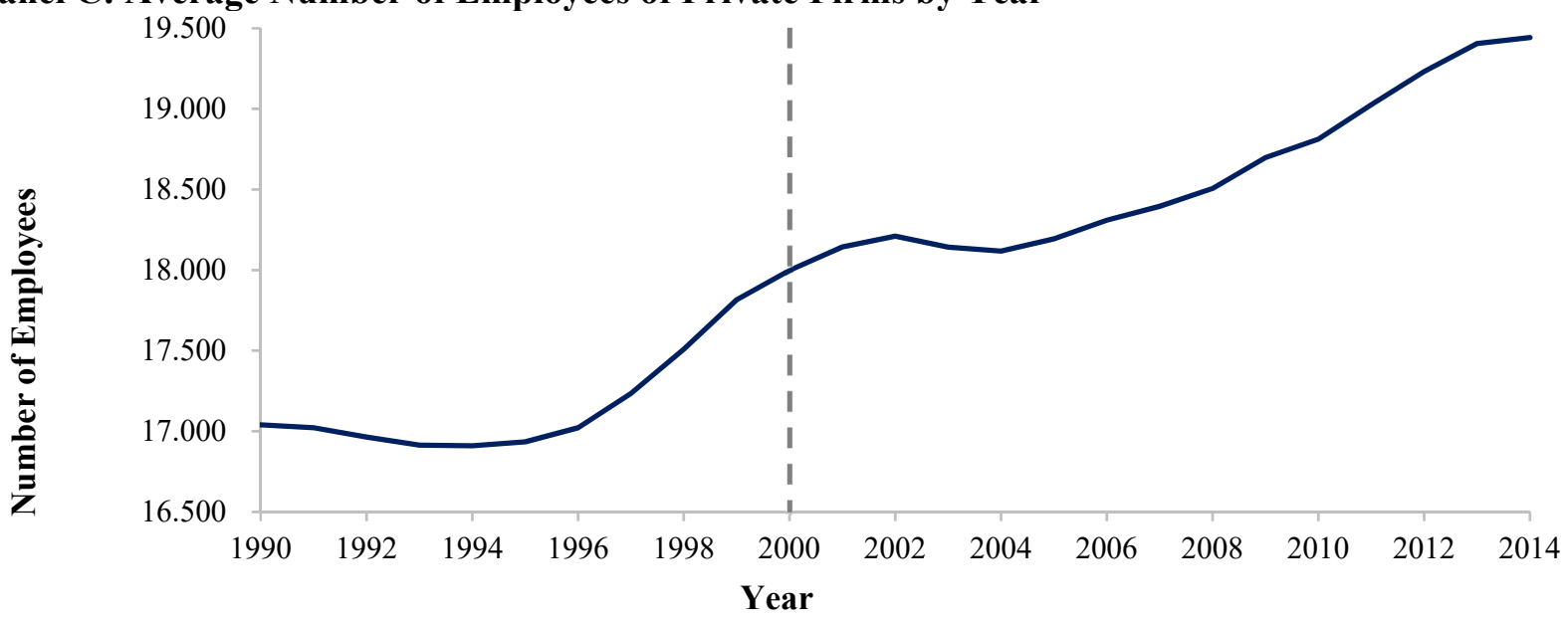


Figure 6: Difference in TFP/Sales/Sales Growth among IPO/Acquired/Private Manufacturing Firms by Year

This figure shows the difference in TFP/sales/sales growth among IPO/acquired/private manufacturing firms from 1990 to 2014. Definitions of annual TFP, sales, and sales growth are provided in Appendix A.

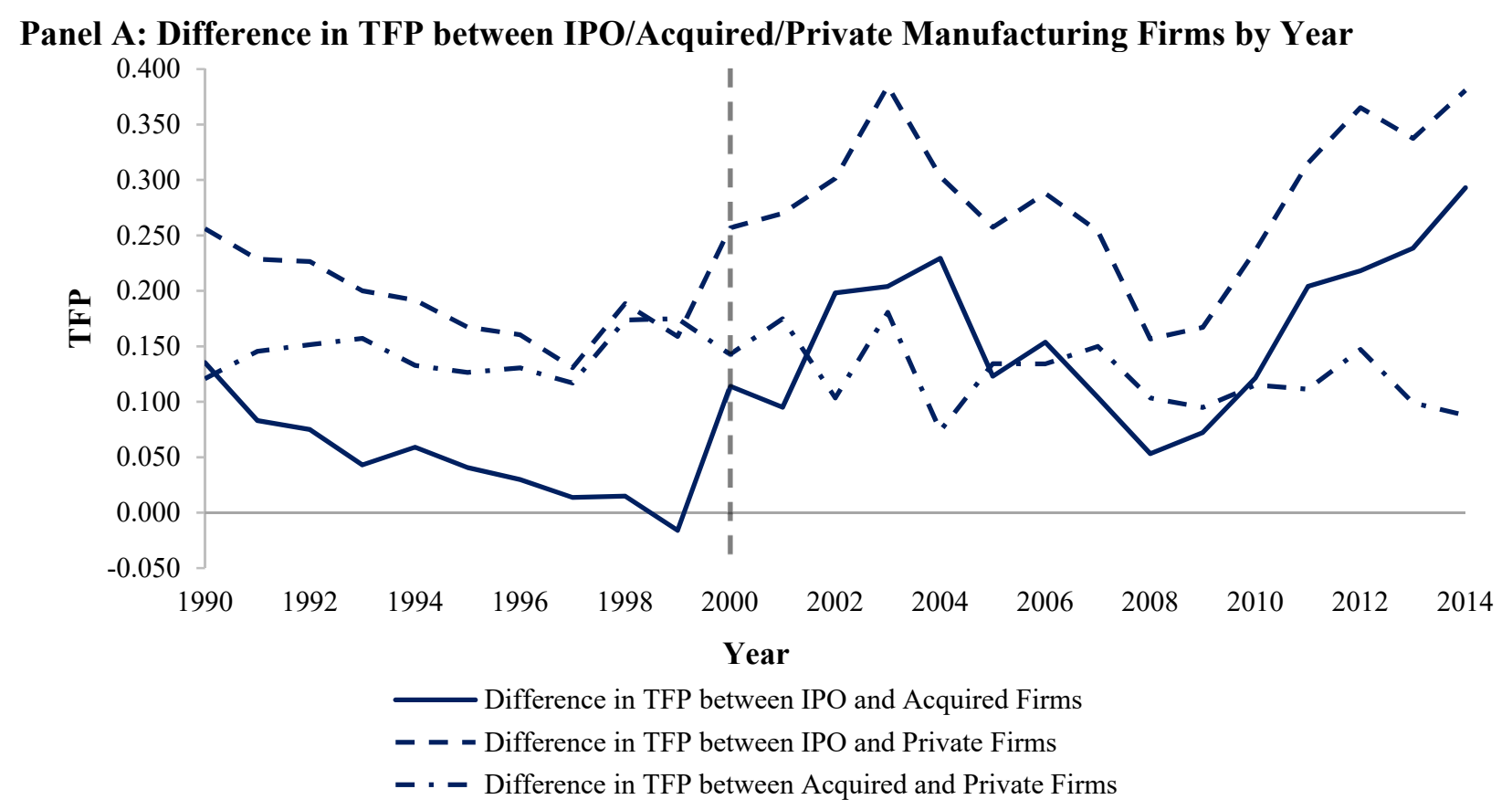

Panel B: Difference in Sales between IPO/Acquired/Private Manufacturing Firms by Year

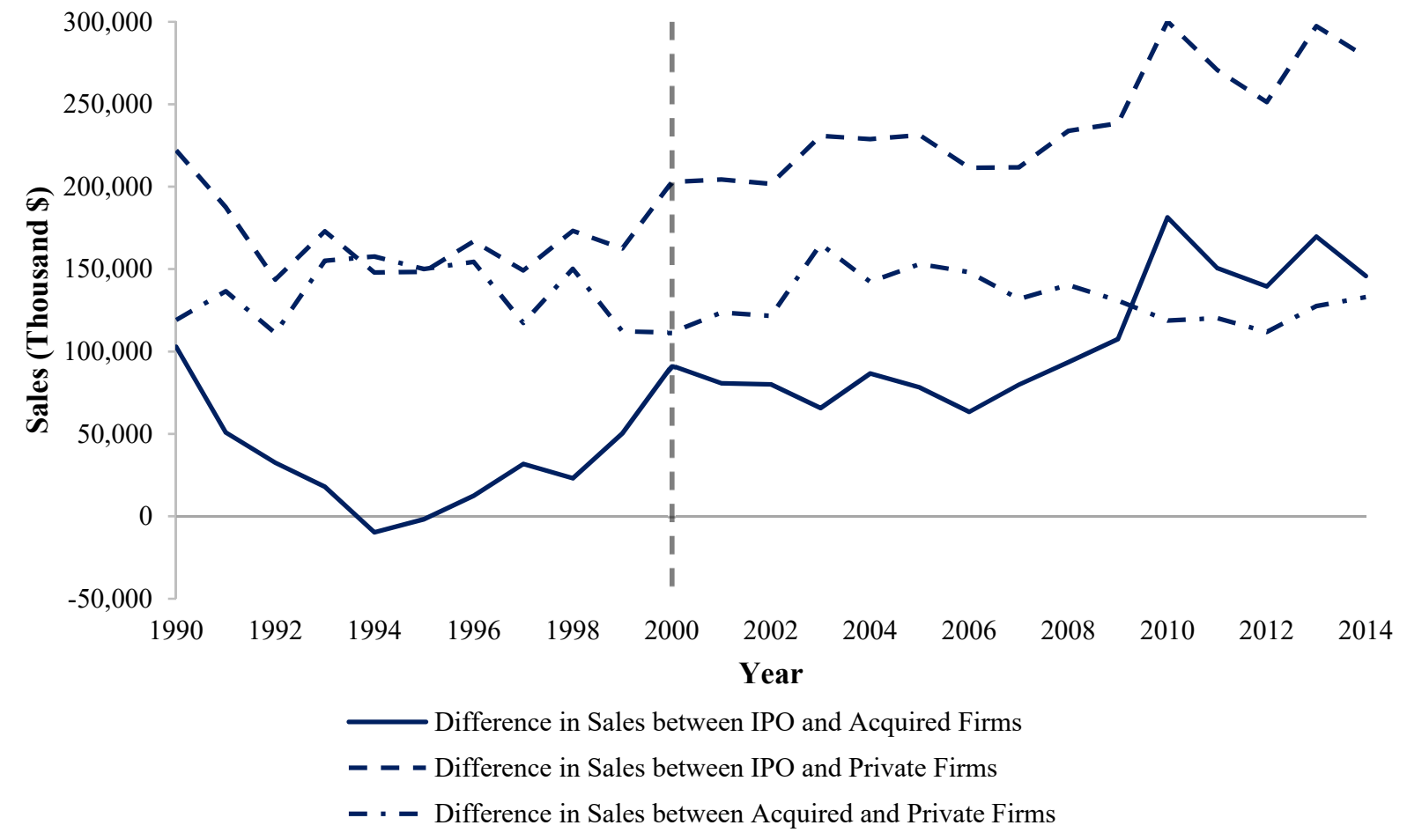




\section{Panel C: Difference in Sales Growth between IPO/Acquired/Private Manufacturing Firms by Year}

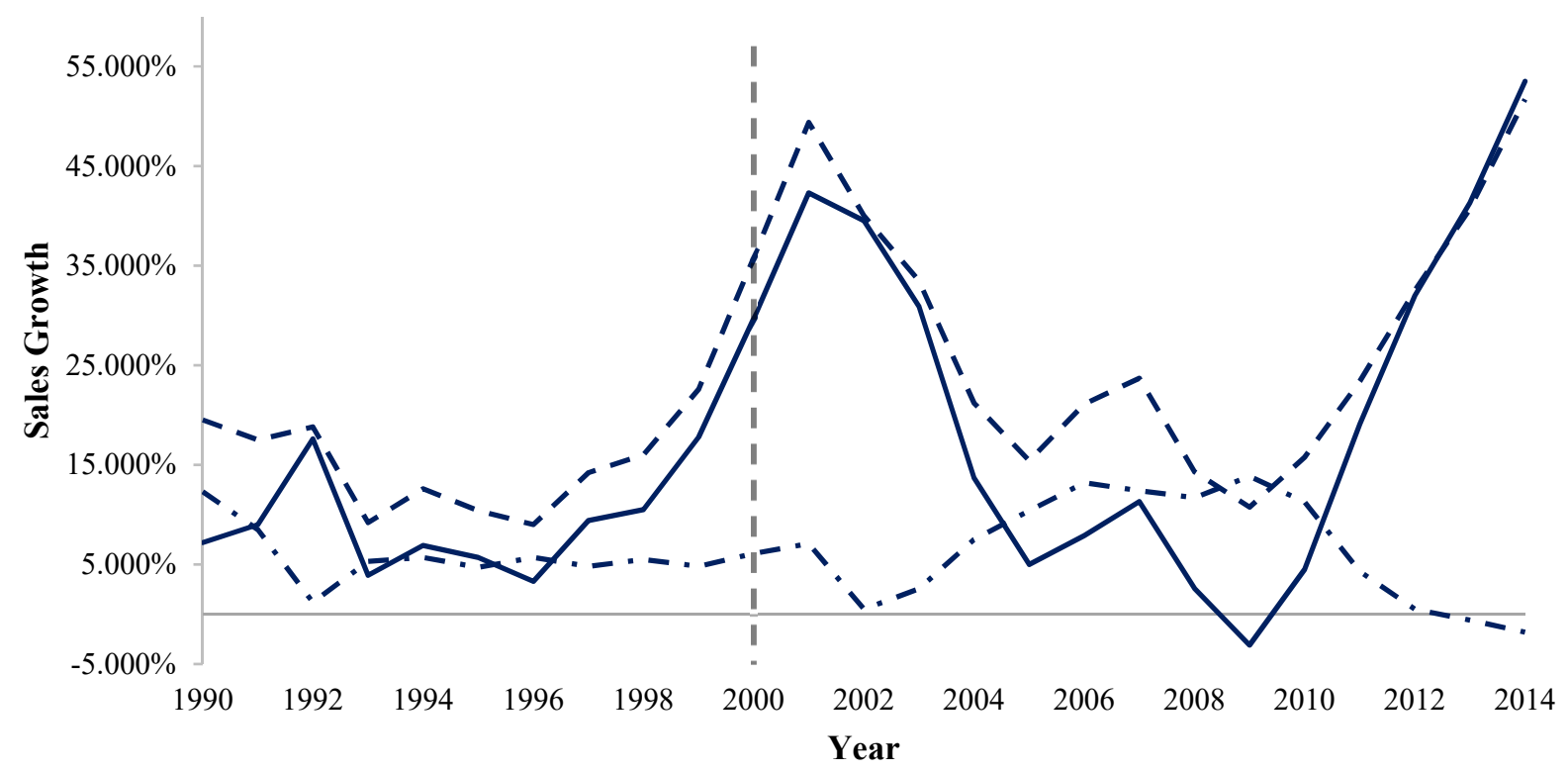

- Difference in Sales Growth between IPO and Acquired Firms

- - - Difference in Sales Growth between IPO and Private Firms

- - Difference in Sales Growth between Acquired and Private Firms 
Figure 7: Raw and Percentage Changes in TFP/Sales/Sales Growth from Pre-2000 to Post-2000 Era by Exit Choices

This figure shows the raw and percentage changes in TFP/sales/sales growth for IPO/acquired/private manufacturing firms from pre-2000 to post-2000 era. Definitions of annual TFP, sales, and sales growth are provided in Appendix A.

Panel A1: Change in TFP from Pre-2000 to Post-2000 Era by Exit Choice

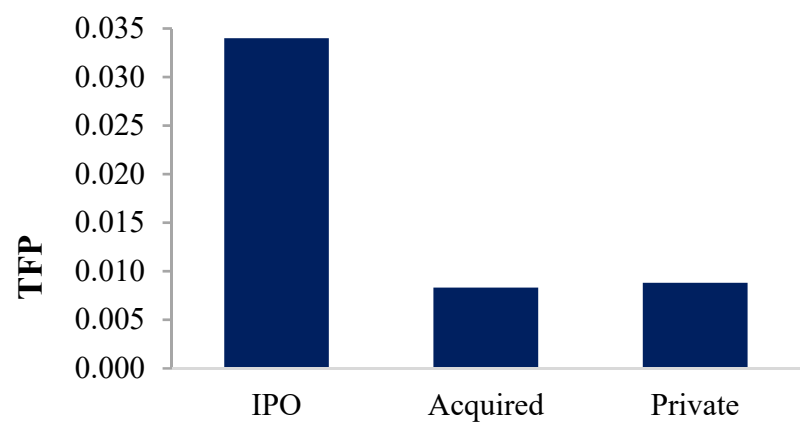

Exit Choice

Panel B1: Change in Sales from Pre-2000 to Post-2000 Era by Exit Choice

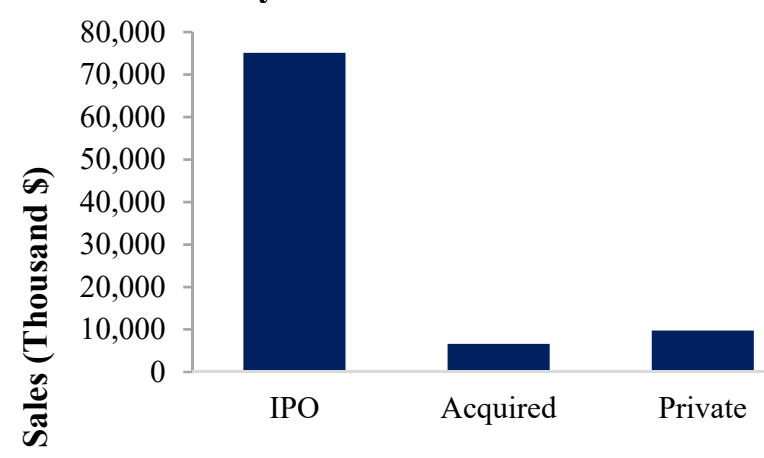

Exit Choice

Panel C1: Change in Sales Growth from Pre2000 to Post-2000 Era by Exit Choice

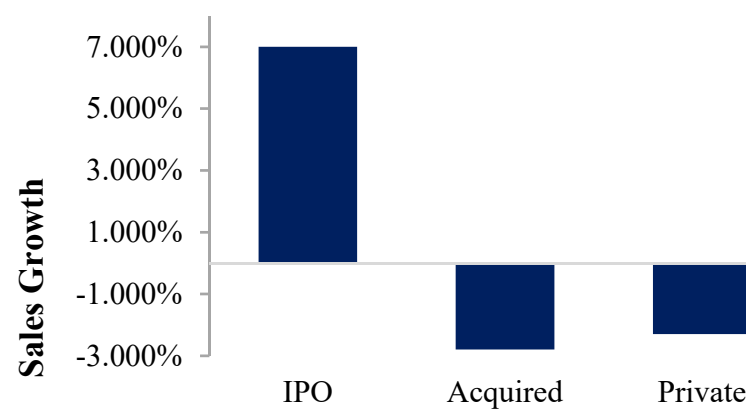

Exit Choice
Panel A2: Percentage Change in TFP from Pre-2000 to Post-2000 Era by Exit Choice

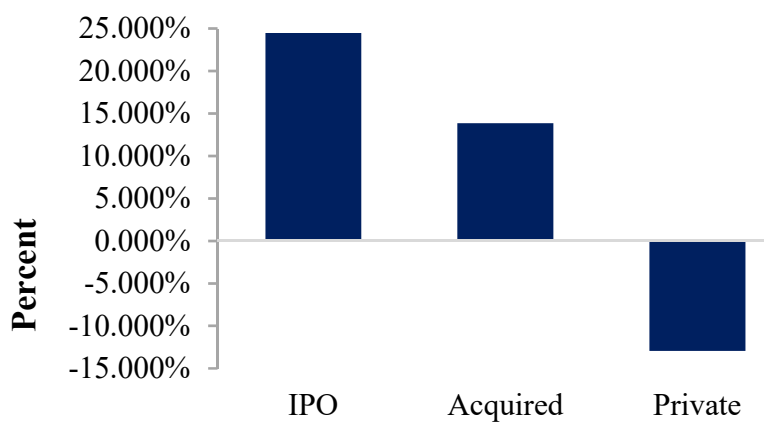

Exit Choice

Panel B2: Percentage Change in Sales from Pre-2000 to Post-2000 Era by Exit Choice

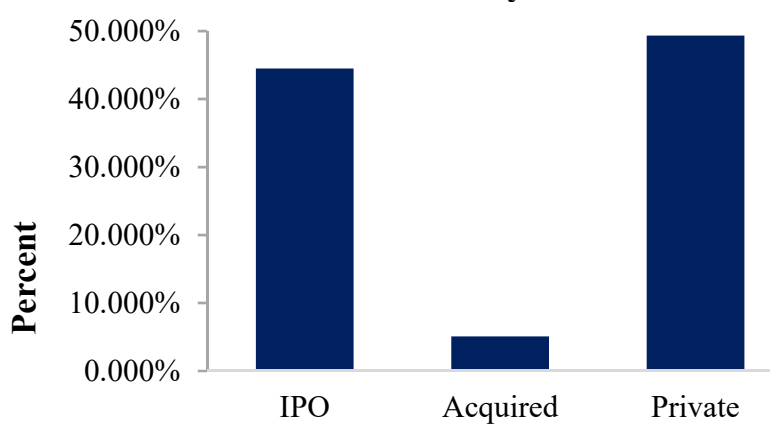

Exit Choice

Panel C2: Percentage Change in Sales Growth from Pre-2000 to Post-2000 Era by Exit Choice

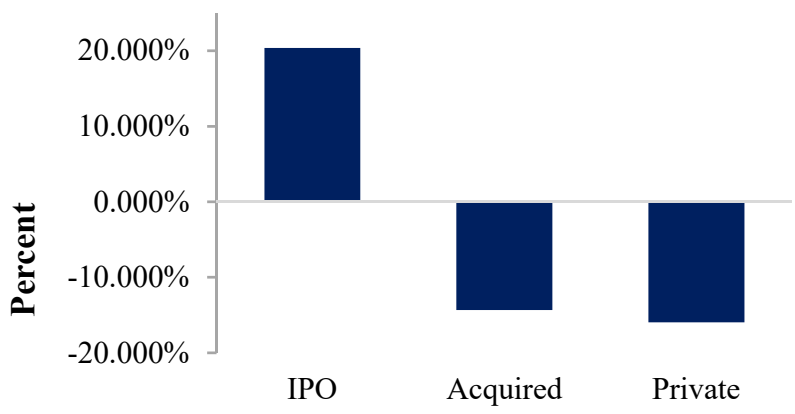

Exit Choice 